San Jose State University

SJSU ScholarWorks

Master's Theses

Master's Theses and Graduate Research

1994

\title{
Application of NOAA's CoastWatch Change Analysis Project for wetland and upland change detection in the Elkhorn Slough watershed
}

Raymond Lawrence Harris

San Jose State University

Follow this and additional works at: https://scholarworks.sjsu.edu/etd_theses

\section{Recommended Citation}

Harris, Raymond Lawrence, "Application of NOAA's CoastWatch Change Analysis Project for wetland and upland change detection in the Elkhorn Slough watershed" (1994). Master's Theses. 914.

DOI: https://doi.org/10.31979/etd.482t-y33p

https://scholarworks.sjsu.edu/etd_theses/914

This Thesis is brought to you for free and open access by the Master's Theses and Graduate Research at SJSU ScholarWorks. It has been accepted for inclusion in Master's Theses by an authorized administrator of SJSU ScholarWorks. For more information, please contact scholarworks@sjsu.edu. 


\section{INFORMATION TO USERS}

This manuscript has been reproduced from the microfilm master. UMI films the text directly from the original or copy submitted. Thus, some thesis and dissertation copies are in typewriter face, while others may be from any type of computer printer.

The quality of this reproduction is dependent upon the quality of the copy submitted. Broken or indistinct print, colored or poor quality illustrations and photographs, print bleedthrough, substandard margins, and improper alignment can adversely affect reproduction.

In the unlikely. event that the author did not send UMI a complete manuscript and there are missing pages, these will be noted. Also, if unauthorized copyright material had to be removed, a note will indicate the deletion.

Oversize materials (e.g., maps, drawings, charts) are reproduced by sectioning the original, beginning at the upper left-hand corner and contimuing from left to right in equal sections with small overlaps. Each original is also photographed in one exposure and is included in reduced form at the back of the book.

Photographs included in the original mamuscript have been reproduced xerographically in this copy. Higher quality $6^{\prime \prime} \times 9^{n}$ black and white photographic prints are available for any photographs or illustrations appearing in this copy for an additional charge. Contact UMI directly to order.

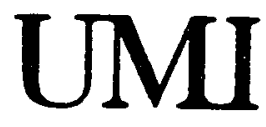

A Bell \& Howell information Company 



\title{
APPLICATION OF NOAA'S \\ COASTWATCH CHANGE ANALYSIS PROJECT \\ FOR WETLAND AND UPLAND CHANGE DETECTION \\ IN THE ELKHORN SLOUGH WATERSHED
}

\author{
A Thesis \\ Presented to \\ The Faculty of the Department of Geography \\ and Environmental Studies \\ San Jose State University \\ In Partial Fulfillment \\ of the Requirements for the Degree \\ Master of Science \\ by \\ Raymond Lawrence Harris, Jr. \\ December, 1994
}


UMI Number: 1361172

DMI Microform Edition 1361172

Copyright 1995, by UMI Company. All rights reserved.

This microform edition is protected against unauthorized copying under Title 17, United States Code.

\section{UMI}

300 North Zeeb Road

Ann Arbor, MI 48103 
(C) 1994

Raymond Lawrence Harris, Jr.

ALL RIGHTS RESERVED 
APPROVED FOR THE DEPARTMENT OF GEOGRAPHY AND ENVIRONMENTAL STUDIES

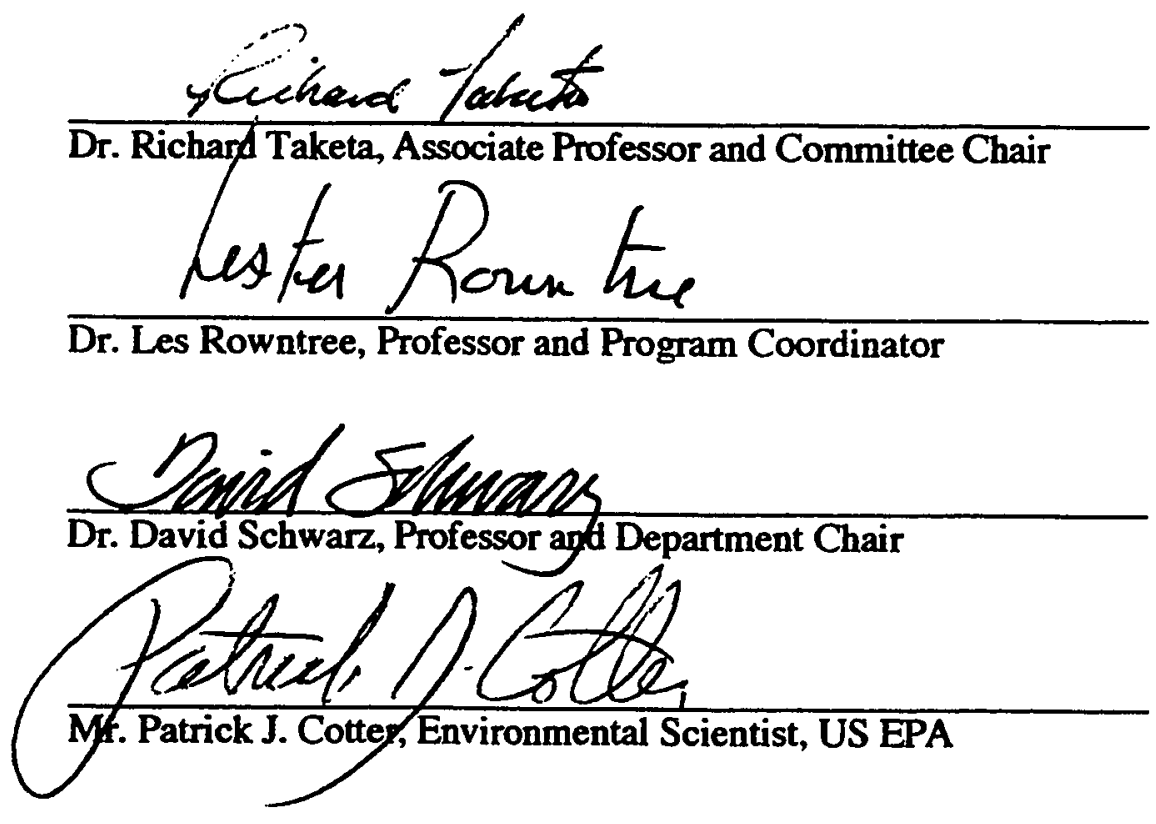

APPROVED FOR THE UNIVERSITY

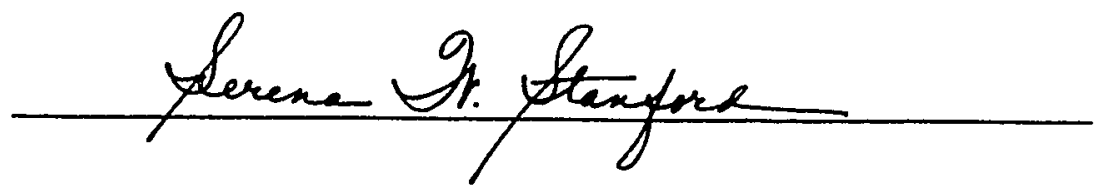




\section{ABSTRACT \\ APPLICATION OF NOAA'S \\ COASTWATCH CHANGE ANALYSIS PROJECT \\ FOR WETLAND AND UPLAND CHANGE DETECTION \\ IN THE ELKHORN SLOUGH WATERSHED}

by Raymond Lawrence Harris, Jr.

The National Oceanic and Atmospheric Administration's CoastWatch Change Analysis Project (C-CAP) guidelines for classification and change comparison of U.S. estuarine drainage areas were applied in the Elkhorn Slough watershed, California. The C-CAP classification scheme was used to interpret 1990 Landsat Thematic Mapper (TM) image data of the watershed into 12 required C-CAP classes. The overall accuracy of the C-CAP classification was $86.84 \%$, exceeding the $85 \%$ requirement. TM data were effective for the classification of large wetland and upland areas greater than 85.5 x 85.5 meters. Post-classification change comparison using the $1990 \mathrm{C}-\mathrm{CAP}$ data and 1972 U.S. Fish and Wildlife Service National Wetland Inventory in a GIS was an effective method for change detection in wetland areas. The C-CAP guidelines, with modifications for West Coast ecosystems, can guide inventory, documentation, and analysis of habitat change in Californian coastal drainage areas. 


\section{ACKNOWLEDGMENTS}

I gratefully acknowledge the support and assistance of several people. Foremost, my thanks to the committee members, Dr. Lester Rowntree, Dr. David Schwarz, Mr. Patrick Cotter, and especially Dr. Richard Taketa as chairperson who provided patient guidance and thoughtful insight. This study would not have been possible without the generous support of Mr. David Peterson and the staff of the NASA-Ames Research Center Ecosystems Science and Technology Branch. Special thanks to Ms. Susan Benjamin for her guidance and training, and to Dr. Leonard Gaydos of the USGS EROS Data Center at NASA-Ames Research Center. Grateful appreciation to Mr. Mike Fitzgerald and Mr. David Paton of the Aircraft Data Facility at NASA-Ames for aerial transparencies and digital data. Thanks to Dr. Rick Starr of the Sea Grant Extension Program for contributions of wetland data. My great appreciation to Dr. Rikk Kvitek of the Moss Landing Marine Labs for his contribution of GPS data for ground observations. Thanks to Mr. Les Strnad and Mr. Rick Hyman of the California Coastal Commission for documents and information on the Elkhorn Slough. Thanks also to Dr. Gary Sharp of CIRIOS for valuable network connections. Many others have contributed valuable time, assistance, and guidance to the project all of whom receive my thanks and appreciation. A final measure of gratitude to my friends and family, especially to my wife, Amy, for her endless support. 


\section{TABLE OF CONTENTS}

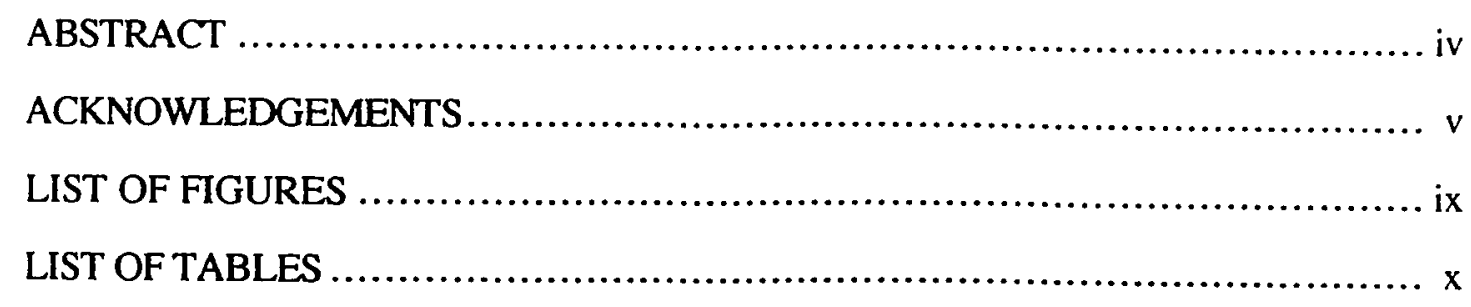

CHAPTER 1 INTRODUCTION AND RELATED RESEARCH .............. 1

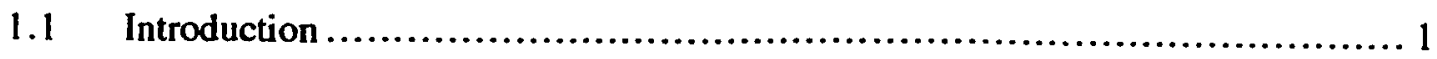

1.2 Cumulative Assessment of Environmental Impacts and Ecosystem Effects ............................................................. 2

1.3 Remote Sensing and GIS in Cumulative Impact Assessment...................6

1.4 Remote Sensing and GIS in Resource Management of Coastal Areas.............7

1.5 NOAA'S CoastWatch Change Analysis Project Develops a Standard Protocol................................................................ 12

1.6 Agency Efforts to Develop Cumulative Impact Assessment Tools in the Monterey Bay Region..................................................... 14

1.7 Will the C-CAP Protocol Work on California Coasts? .......................... 16

1.8 Elkhorn Slough Watershed Study Site.......................................... 18

1.9 Hypothesis ............................................................ 20

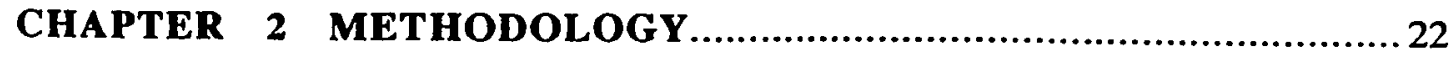

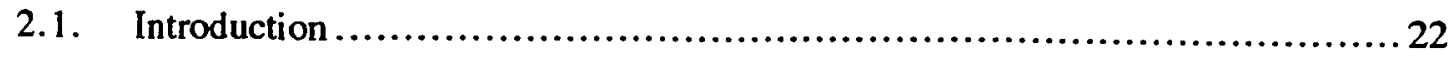

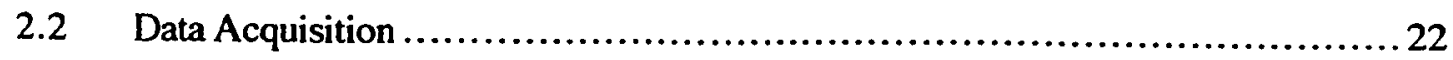

2.3 Data Processing.......................................................... 27 
2.4. Change Detection..................................................... 32

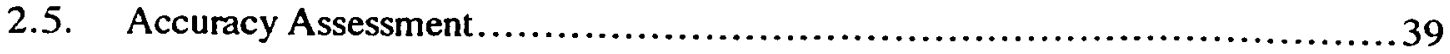

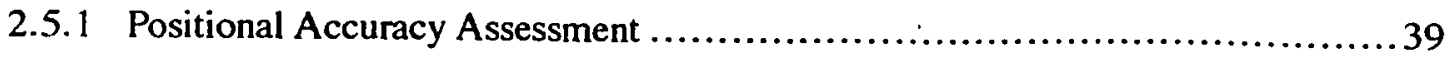

2.5.2 Classification Accuracy Assessment ....................................40

2.6. Wetland Gain and Loss Comparison Maps Using a Land Cover Change

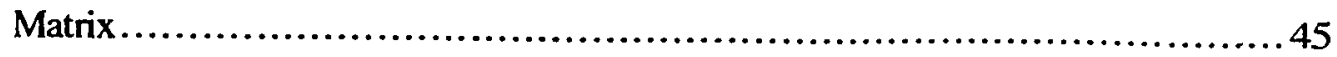

CHAPTER 3 RESULTS .................................................... 47

3.1 Introduction ............................................................ 47

3.2 Data Processing..................................................... 47

3.2.1 Vector to Raster Conversion of USFWS NWI Maps of Moss Landing and Prunedale Quadrangles ............................................ 50

3.2.2 Conversion, Class Translation, and Resampling of Dickert et al. Data .............57

3.3 Accuracy Assessment .................................................61

3.3.1 Positional Accuracy Assessment .........................................61

3.3.2 Classification Accuracy Assessment .........................................64

3.4 Change Detection..................................................... 71

3.5 Geographic Characteristics of Wetland Changes ............................... 78

3.5.1 Wetland Gain and Loss Comparison Between 1972 USFWS NWI Data

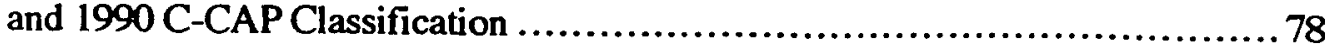

3.5.2 Wetland Gain and Loss Comparison Between 1980 Dickert et al. Data and $1990 \mathrm{C}$-CAP Classification ........................................ 84

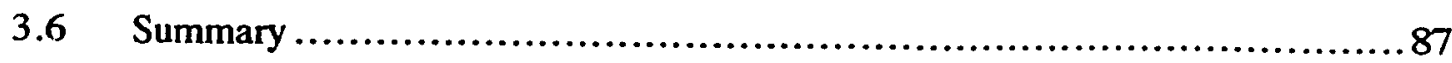

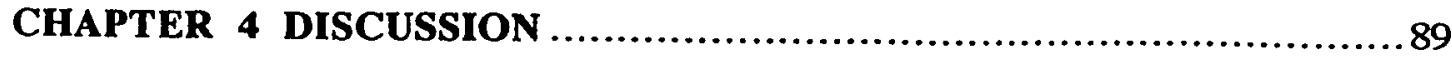

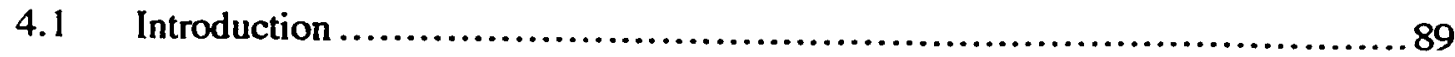

4.2 C-CAP Classification Accuracy and Detail Using TM Data........................89

4.3 The C-CAP Classification Scheme as a Universal Land Cover System ............ 93 vii 
4.4 Land Cover Change Comparison Benefits and Limitations ......................96

CHAPTER 5 CONCLUSION ........................................... 103

5.1 Findings Relevant to the Application of C-CAP in the MBNMS................ 103

5.2 Modifications of the C-CAP Protocol for Use in the MBNMS ................... 105

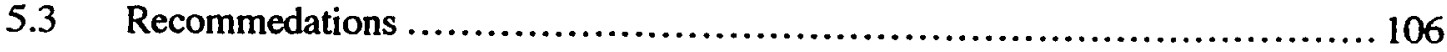

5.4 Application of C-CAP Land Cover Data to Cumulative Impact

Assessments in the Elkhorn Slough Watershed ........................... 108

5.5 The Role of C-CAP Methodology and Products in a Comprehensive Environmental Monitoring System for the MBNMS............................... 109

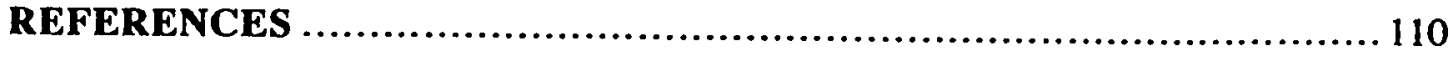

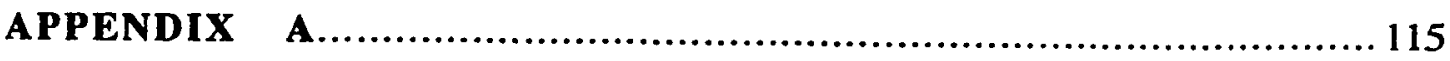

C-CAP Costal Land Cover Classification System

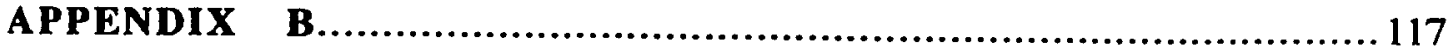

U.S. Fish and Wildlife Service Wetland and Deepwater Habitat

Classification Key

viii 
Figure

\section{LIST OF FIGURES}

1-1. Monterey Bay National Marine Sanctuary Boundary ......................... 2

1-2. Dickert et al. (1980) Elkhom Slough Watershed Siudy Area .................... 1

1-3. Elkhom Slough Watershed Study Area Showing Place Names and Major Roads ............................................................ 19

2-1. Diagram of the Major Components in the Change Detection

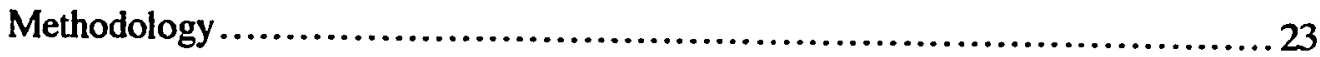

2-2. Graphic Representation of a Post-Classification Change Detection

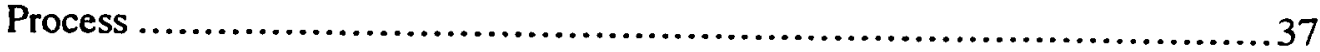

3-1. The TM Subregion Extracted for the Study ..................................49

3-2. C-CAP Classification Map of TM data .....................................52

3-3. USFWS NWI Overlays for Moss Landing and Prunedale Quadrangles ...........56 56

3-4. Dickert et al. (1980) Land Cover Data Translated to C-CAP Classes...............60

3-5. 1990 C-CAP Classification Masked to Match the Watershed and Resampled to $50 \mathrm{~m}$ per Pixel................................................77

3-6. Map of the Geographic Distribution of Wetland Gain and Loss Comparison in the Elkhom Slough Watershed between 1972 USFWS NWI Maps and the 1990 C-CAP Classification 80

3-7. Geographic Distribution of Wetland Gain and Loss Comparison in the Elkhom Slough Watershed between 1980 Dickert et al. Data and the 1990 C-CAP Classification Masked to Match the Watershed and Resampled to $50 \mathrm{~m}$ per Pixel..................................................86

4-1. Wetland Losses Colored According to Their 1990 C-CAP Class ................ 100 ix 


\section{LIST OF TABLES}

Table

2-1. Required C-CAP Classes.................................................. 27

2-2. Translation of USFWS NWI Wetland Classes to C-CAP............................. 31

2-3. Translation of Dickert et al. (1980) Classes to C-CAP Classes....................... 33

2-4. Example of Change Detection Matrix .......................................36

2-5. Hypothetical Error Matrix ............................................ 41

3-1. Number of Pixels and Land Area in the 1990 C-CAP Classification ..............53

3-2. Number of Pixels and Land Area of USFWS NWI Classes...................... 58

3-3. Dickert et al. (1980) Land Cover Classes .......................................62

3-4. Ground Control Point Coordinates Used in RMSE Calculation.................65

3-5. Overall Classification Accuracy Table .......................................66

3-6. Overall Wetland Classification Accuracy Table................................68

3-7. Coordinates and Class of Ground Observation Samples .......................69

3-8. Overall Wetland Classification Accuracy Table with Wetland Classes

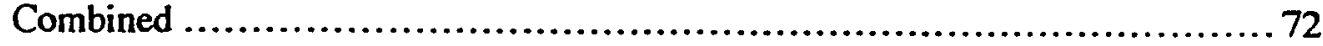

3-9. Change Comparison Matrix Between 1972 USFWS NWI Data and 1990 C-CAP Classification Data ............................................... 73

3-10. Change Comparison Matrix Between Dickert et al. (1980) Data and 1990 C-CAP Classification Data 


\section{CHAPTER 1}

\section{INTRODUCTION AND RELATED RESEARCH}

\subsection{Introduction}

In 1992 the National Oceanic and Atmospheric Administration (NOAA) designated the Monterey Bay National Marine Sanctuary (MBNMS). It is the second largest marine sanctuary in the world covering approximately 13,802 square kilometers $\left(\mathrm{km}^{2}\right)$ of ocean and coastal waters from the Marin County headlands to Cambria, Califomia (NOAA 1992) (see figure 1-1). The MBNMS contains significant submarine canyon, nearshore sublittoral, intertidal, kelp forest, and wetland habitats that foster an extensive list of unique and endangered flora and fauna. Approximately 18 endangered and 3 threatened species exist within the sanctuary boundaries (NOAA 1992).

Coastal drainage areas are the primary source of pollutants affecting habitat and water quality in wetland and marine environments of the MBNMS (NOAA 1992). Diversion of freshwater inputs, increases in urban and agricultural runoff, and destruction of natural habitat has a direct, quantitative effect on the areal extent of sensitive habitats and an indirect effect on habitat and water quality. Cumulative impacts, the incremental effects that result from the accumulation of human-induced perturbations upon an ecosystem over time and space, of these disturbances are not clearly understood.

Cumulative impacts of land use in the coastal zone are of increasing concern to scientists and resource managers because habitat loss over time negatively alters ecosystems. Cumulative impacts are also of concern because the inconspicuous and incremental nature of environmental impacts makes identifying, monitoring, and predicting their effects difficult. Methods to track, monitor, and predict cumulative impacts in the 


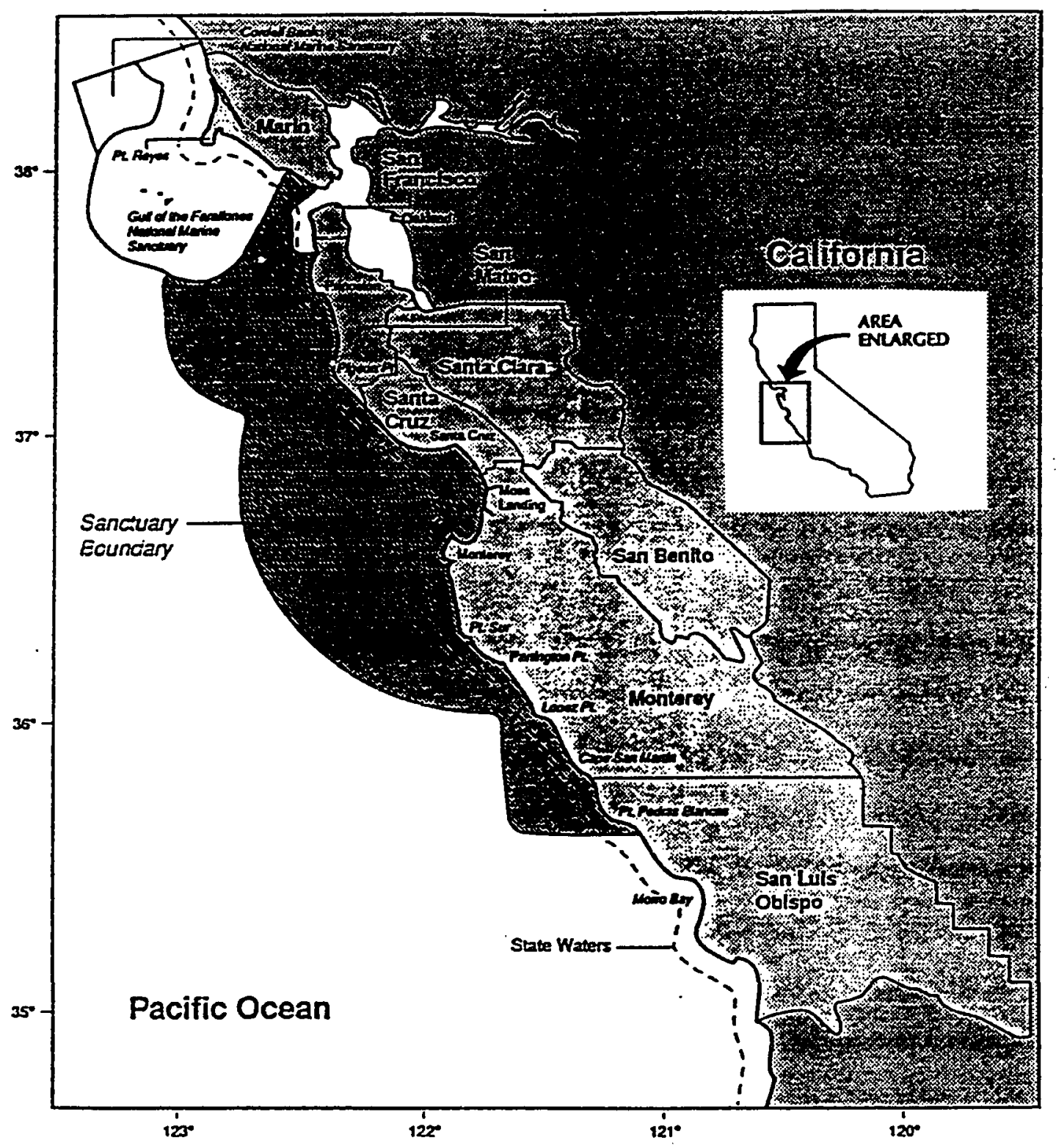

Figure 1-1. Monterey Bay National Marine Sanctuary Boundary (NOAA 1992). 
coastal watersheds of the MBNMS are needed to reduce non-point source pollution, protect sensitive habitats, and conserve species (NOAA 1992; AMBAG 1992; California Coastal Commission 1992).

This study describes and applies a method to classify land cover and compare land cover change over time in a coastal watershed of the MBNMS. Land cover change is a direct, quantitative measure of habitat gain or loss, and is fundamental information for a cumulative impact assessment. The method, derived from the NOAA Coastal Ocean Program's CoastWatch Change Analysis Project: Guidelines for Regional Implementation (Dobson et al. 1993), uses satellite imagery and a geographic information system (GIS) to identify habitat types and analyze change. The focus is on the use of Landsat Thematic Mapper (TM) satellite imagery for detecting and monitoring land cover change in the Elkhorn Slough watershed. The specific method tested is multi-date change detection using TM image data and ancillary digital data.

The goal of this study is to identify elements of the CoastWatch Change Analysis Project (C-CAP) guidelines valuable to the development of a comprehensive environmental information system for the sanctuary. The objectives of this study are: 1) determine if the C-CAP protocol applies to the inventory and monitoring of habitat gain or loss in a coastal watershed of the MBNMS, 2) identify the limitations and capabilities of using TM imagery and ancillary data to detect wetland and upland land cover changes, and 3) evaluate the utility of the protocol for cumulative impact assessment methodologies. An assumption is that land cover changes exhibit a change in spectral response.

\subsection{Cumulative Assessment of Environmental Impacts and Ecosystem Effects}

Conventional environmental impact assessment is generally limited to individual project sites and a reactive approach to resource management. However, ecological features are not limited to parcel or political boundaries. At a regional scale, more 
appropriate geographic units, such as watersheds, facilitate integrated ecosystem management. This holistic, ecosystem approach is needed to protect biodiversity, reduce species extinction, retain sensitive habitat, and maintain beneficial uses.

Regional geographic scales are important to environmental protection because of the ecological effects of habitat fragmentation (Soulé 1986, 1991). Habitat fragmentation typically occurs in and around human settlements when natural habitat is cleared or replaced, leaving only fragments of the original. Three primary effects are associated with habitat fragmentation (Soule 1986). Area effect is the term used to express that the rate of extinction is inversely proportional to habitat patch size. The smaller the habitat area, the higher the extinction rate. Edge effect is the term used to express the ratio of interior habitat to edge habitat. Edges are transitions between ecotypes where habitat meets a road or other element. The higher the ratio of perimeter (edge) to area (habitat), the greater the susceptibility to invasion, disease, and extinction. Distance effect is the term used to describe the relationship between an isolated habitat patch and other suitable habitats. Wildlife movement decreases as the distance between habitat patches increases. These effects illustrate a process: the probability of extinction increases as habitat becomes fragmented, isolated, and dispersed.

Habitat destruction is not the only type of impact. Pollution compounds fragmentation effects by decreasing the quality of the habitat, rendering species more susceptible to extinction. Typically, once the natural habitat is removed by human development, the developed area exports pollutants to the ecosystem. Human actions tend to denature habitat on a regional scale in 3 primary ways: agriculture, forestry, and urbanization. Each of these land use types contributes pollutants to wetland and marine habitats through the hydrologic cycle of a watershed in the coastal zone. Therefore, tracking and monitoring habitat changes and pollutant loading over the geographic area of 
the watershed is important for the assessment of cumulative impacts (Bedford and Preston 1988; Preston and Bedford 1988; Lee and Gosselink 1988).

The watershed approach to cumulative impacts assessments is based on several reasons (Bedford and Preston 1988; Lee and Gosselink 1988):

1. Cumulative effects on wetland functions usually occur at a watershed or basin scale.

2. The landscape scale can address impacts that are not tangible at sitespecific scales (e.g., habitat fragmentation).

3. Landscape variables such as climate, soils, geology, topography, vegetative cover, and land use effect wetland structure and functions.

4. Individual sites apparently are not as important as the pattern of sites within the landscape in terms of protecting ecosystem integrity.

Thus, the landscape perspective taken at a regional scale of coastal watersheds is an appropriate approach for cumulative impact assessment. However, methodological questions regarding the design and application of a cumulative impact assessment are unclear.

Cumulative impact assessment, as an environmental assessment tool, has been hampered by theoretical and methodological problems. Preston and Bedford (1988) list the following fundamental inhibitors frustrating scientists and resource managers:

1. Defining appropriate spatial and temporal boundaries of an ecosystem.

2. Identifying pathways of impact accumulation.

3. Determining tolerance thresholds within ecosystems.

4. Tracking episodes of disturbance.

5. Separating human-induced disturbance from natural change.

6. Overcoming technological limitations. 
Each of these problems has different solutions depending on the type of ecological unit under study. However, watersheds and associated wetlands, as an ecosystem, have received a predominance of cumulative impact research because of the urgency of wetland protection, and because a watershed is a readily determined spatial boundary. Furthermore, the pathways of accumulation within a watershed are associated with the hydrologic cycle.

\subsection{Remote Sensing and GIS in Cumulative Impact Assessment}

The assessment of cumulative impacts within a watershed generally involves a remote sensing data source and the development of a GIS for spatial analysis (Dickert and Tuttle 1985; Haddad and Hoffman 1987; Haddad and McGarry 1989; Johnston et al. 1990; McCreary et al. 1992). A GIS can integrate remote sensing and field data, in spatial and tabular form, for analysis of complex environmental information. A GIS can compile and process large amounts of data in digital form: It can also perform geographical analyses and display spatial relationships between ecosystem components.

Traditional survey and inventory methods used to monitor watersheds involve large amounts of data because drainage areas can be geographically extensive. Remote sensing, mainly in the form of aerial photography, has been a primary source for land cover and planimetric data. However, aerial photography and manual techniques of photointerpretation over large areas are expensive and time-consuming (Haddad and Harris 1985). When assessing large watersheds, satellite imagery is a cost-effective data source that can be used to establish a periodic baseline survey of the region (Haddad and Harris 1985; USGS FGDC 1992). The Federal Geographic Data Committee (FGDC), Wetland Subcommittee concluded that satellite image data "...facilitates the integration of multiple data sets in GIS applications" (USGS FGDC 1992). The FGDC also states that satellite imagery is of greatest value when combined with ancillary digital data that includes aerial 
photographs. Satellite image data also can be used to: detect disturbance in surrounding wetlands, identify where rapid changes occur, and identify inundated or saturated soils (USGS FGDC 1992). Satellite images, geometrically corrected and rectified to a coordinate system, can also provide an on-screen reference image for comparing vectorbased object locations (Westmoreland and Stow, 1992). Using this technique, errors in mapping conducted by various agencies can be revealed (Haddad 1993).

TM imagery has been used to detect wetland and marine habitats (Augenstein et al. 1991; Haddad and Harris 1985; Haddad and Ekberg, 1987; Haddad and McGarry 1989; Dobson and Bright 1992; Jensen et al. 1993). TM sensors can capture data in digital form over large areas with the advantage of frequent visits (every 16 days) and synoptic coverage of entire watersheds. TM's disadvantage is its relatively coarse 28.5 meters $(\mathrm{m})$ per pixel spatial resolution, which is inadequate for small areas and site-specific studies. However, Welch et al. (1985) found that TM data can meet National Map Accuracy Standards at a 1:24,000 scale, but the TM data were better suited to a 1:50,000 scale. Thus, the primary elements of temporal and spatial data are available for monitoring change and deriving map updates for a region using satellite TM data.

\subsection{Remote Sensing and GIS in Resource Management of Coastal Areas}

A marine and coastal GIS has been invaluable to marine resource managers in the Florida Keys National Marine Sanctuary (Friel and Haddad 1992). The Florida Marine Research Institute and the Florida Department of Natural Resources are pioneering an ecosystem approach to coastal and marine resource management for the Florida Keys National Marine Sanctuary through the Coastal and Marine Resource Assessment (CAMRA) project (Friel and Haddad 1992). The primary objective of CAMRA is "...to develop, analyze, and disseminate marine resource information..." for the purpose of creating an ecosystem approach to management decision-making. The key tool of the 
CAMRA is a Marine Resources Geographic Information System (MRGIS) developed in 1981 from a raster-based GIS using LANDSAT data. The MRGIS fills information gaps for coastal marine resources needed for management decisions. The CAMRA project will map coastal and submarine habitat, and analyze coastal marine resource impacts. One of the most important products of the CAMRA project are Resource Impact Maps (RIMs), which are coastal versions of USGS topographic quadrangles. RIMs help resource managers and the public assess and monitor impacts of proposed projects in the coastal zone (Friel and Haddad 1992).

Haddad and McGarry (1989) developed a GIS for the Little Manatee River watershed in Florida. They recognize that a proactive approach to ecosystem management of the watershed and associated wetlands is necessary given the increasing development pressures in the Tampa bay area. The GIS was developed for watershed resource management and ecosystem research. Over 14 data layers were developed including 8 derived from remote sensing data. Multiple years of land cover data, soils, and elevation are examples of thematic layers developed. Land use plans, transportation, and jurisdictional boundaries are examples of ancillary data obtain from other agencies. Tabular data including water quality sampling data, fisheries data, and permitted discharges were also collected. Satellite images provided the base map to which other data layers were rectified.

Multiple data layers combined in a GIS enabled Haddad and McGarry (1989) to analyze land cover changes, agricultural runoff potential, future land use, and fisheries management. Land cover changes were compared using 1982 and 1950 data. Major increases in agriculture and urbanization occurred while undeveloped land declined. Agricultural areas for a subsection of the watershed were ranked as low, moderate, or high runoff potential based on Soil Conservation Service data. Haddad and McGarry (1989) 
also found that over half of the area in the 100-year flood zone was available for single family dwellings by using future land use data.

Haddad and McGarry (1989) also studied the relationship of habitat and species abundance. They suggested from preliminary results that seagrass habitat supports greater than $82 \%$ of juvenile spotted seatrout, an important species caught in Tampa Bay. The GIS also revealed that $35 \%$ of seagrass habitat had been lost. Thus, fisheries management benefited from the geographically specific information made available by remote sensing and GIS.

McCreary et al. (1992) used a GIS to assess the potential effects of land use change and urban expansion in the San Francisco Estuary and surrounding watersheds. Several data layers were constructed and compared to reveal current and potential land use impacts on wetlands. These layers included the Bay Area Spatial Information System created by the Association of Bay Area Governments from U. S. Geological Survey (USGS) Land Use Data maps, 12 county General Plan-based land use projection maps, U.S. Fish and Wildlife Service National Wetland Inventory (USFWS NWI) maps, and USGS Digital Line Graphs. McCreary et al. (1992) estimated that 15,992 hectares (ha) of wetlands and 152,632 ha of stream environments may be impacted under full build-out scenarios of county and city general plans. McCreary et al. (1992) also estimated the cumulative increase in non-point source pollutants from urban runoff based on a non-point source pollutant loading model.

A significant factor of the McCreary et al. (1992) work is the comprehensive geographic study of the San Francisco Estuary and surrounding watersheds. The GIS provides geographically specific information about the land use and wetland natural resources throughout the watershed. The study transcends political boundaries and establishes an ecosystem approach to environmental analysis based on the watershed as a landscape boundary. 
Dickert et al. (1980) developed thematic map layers on land use, land cover, soils, geology, and topography for the Elkhorn Slough watershed adjacent to Monterey Bay, California (figure 1-2). A time series analysis of the watershed using multiple dates of aerial photography was developed to derive historic anthropogenic and natural disturbances to the wetland watershed. The thematic maps were used to estimate a threshold below which human-induced disturbance would not increase the aggradation of wetland habitat. Estimates of non-point source pollution from sedimentation were based on field studies, land cover, and historical land uses. Land use disturbance targets were derived from areal estimates of land cover for 37 subwatersheds of the Elkhorn Slough drainage area.

After 1980, thematic maps from the Dickert et al. (1980) study were used to construct a computer-based GIS (Dickert and Tuttle 1985). The Geographical Resource Analysis Support System (GRASS) was used to construct a digital, raster-based erosion susceptibility map of the Elkhorn Slough watershed. Slope, land cover, and soils were used to estimate erosion in the watershed. The susceptibility map provided comprehensive coverage of the watershed with a ground resolution of $100 \mathrm{~m}$ grids (Dickert and Tuttle 1985).

Each of the studies discussed has a common tool-the use of a GIS. However, the methods and data used to development the GIS are distinctly different and difficult to interchange. The problem is that, historically, no standards existed for the continued development and expansion of geographic coverage. Although a watershed is an easily defined geographic boundary, the landscape and ecosystem is spatially and temporally continuous. Ideally, data derived for individual watersheds would be standardized so that multiple watersheds and other ecological components can be integrated and studied as an ecosystem over time. 


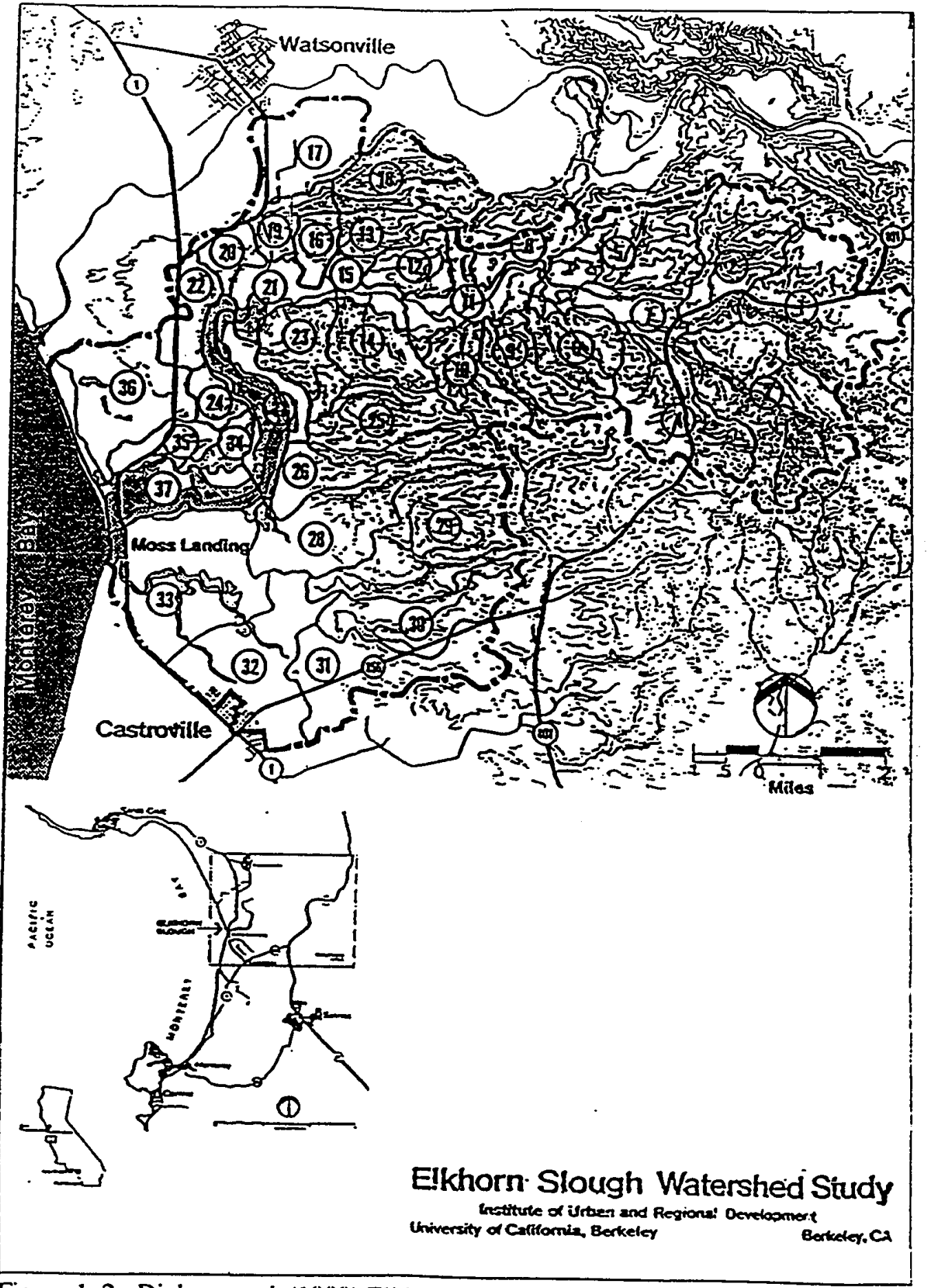

Figure 1-2: Dickert et al. (1980) Elkhorn Slough Watershed Study Area. Dashed Boundary Represents Watershed Study Area. Subwatersheds Number 1 to 37. Source: California Coastal Commission. 
1.5 NOAA'S CoastWatch Change Analysis Project Develops a Standard Protocol

NOAA's Coastal Ocean Program National Habitat Mapping mission is to: 1) establish a national operational protocol to provide a uniform basis of land cover classification; 2) generate and distribute habitat-classified data and maps; 3) determine habitat change; 4) remotely determine biomass, productivity, and health status of habitat; 5) archive and disseminate data; and 6) apply habitat classification and change analysis to research and management. C-CAP represents a nation-wide attempt to develop recommended minimum standards for a land cover database compatible with GIS analyses. The C-CAP protocol standardizes data processing and GIS techniques by establishing acceptable data requirements, image processing techniques, and data analysis techniques. Mapping of the Pacific coast was scheduled to occur in fiscal year 1993 starting with the National Estuarine Research Reserves, depending on funding (Thomas and Ferguson 1990). Projects are underway in the Chesapeake Bay and Columbia River. However, the C-CAP protocol has not been tested in California.

Dobson et al. (1993) developed the C-CAP protocol for the classification and analysis of land cover in coastal wetlands of the U.S. C-CAP recommends methods to document changes to wetlands, submerged habitats, and adjacent uplands in the U.S. using TM data and aerial photography on a 1 to 5 year cycle (Dobson et al. 1993).

C-CAP guidelines establish parameters for the selection of TM data. Ideally, acquisition of TM data should consider environmental factors affecting spectral response. The phenological cycle of vegetation should be selected to maximize spectral separability of wetlands from uplands. The tidal stage should be within 2 feet above mean low tide. The protocol does not discuss tidal stage for semi-diumal tidal cycles. Pacific Coast semidiurnal tidal cycles have two low tides in a 24 hour period. Mean lower low water (MLLW) maximum tidal stage requirements are not defined by the C-CAP protocol. However, the protocol acknowledges that the tidal stage varies greatly throughout the 
U.S., and is not synchronized with satellite overpasses. Precipitation should also be known for the period prior to the TM data capture. Thus, the selection of TM data under ideal conditions is limited significantly by the season, precipitation, and tidal influences.

Pulich and Hinson (1992) applied the C-CAP protocol in Galveston Bay, Texas. They classified TM data using supervised classification and image processing techniques recommended by C-CAP. The C-CAP Classification Scheme was applied to 2 USGS 7$1 / 2$ minute quadrangles in the study area. Pulich and Hinson (1992) found that classification accuracy for the area studied was $83.3 \%$, if the brackish marsh and freshwater marsh classes were combined. If these classes were kept separate, the overall classification accuracy was $65.5 \%$. These accuracies did not meet their ideal requirement of $90 \%$. Pulich and Hinson (1992) state that salinity regimes and associated plant composition were not separable by spectral signatures only.

Jensen et al. (1993) evaluated portions of the C-CAP protocol in South Carolina. They investigated techniques of post-classification comparison for 2 TM images over 2 geographic areas. Despite the use of "cluster-busting" image processing techniques, TM spectral data could not be used to distinguish between certain classes of aquatic habitat and land cover. They found that it was not possible to separate all pixels from TM data into all required C-CAP classes. Bare land and developed land were combined due to the high reflectance characteristics of sandy soils and concrete (Jensen et al. 1993). Cultivated land was not completely separable from other classes. They recommend selecting TM data to maximize the separability of wetland classes.

Jensen et al. also tested 4 change detection variations: 1) post-classification comparison, 2) post-classification comparison after a $3 \times 3$ pixel majority filter, 3) application of a "change-no change" mask prior to comparison, 4) application of the mask to the majority filtered images. The highest change detection accuracy was achieved with a comparison of majority filtered classifications. 
Jensen et al. (1993) examined the effect of tidal stage on post-classification comparison. They state that TM data captured at a tidal stage of 2 feet above mean low tide is acceptable, but a tidal stage above 2 feet is not acceptable. They found that an increase in tidal height decreases the area of wetland classified from the TM data. The decrease is due to the increased number of pixels classified as water (Jensen et al. 1993).

\subsection{Agency Efforts to Develop Cumulative Impact Assessment Tools in the Monterey Bay} Region

The MBNMS Research Advisory Committee has determined that a resource characterization of the Sanctuary is a priority research need. However, the techniques to characterize such a large area pose new problems. The extensive geographic area $(13,802$

$\mathrm{km}^{2}$ ), which approximately doubles with the need to monitor coastal drainage areas, cannot be covered economically with conventional field survey techniques. Furthermore, monitoring on a frequency comparable to land use impacts and development patterns that effect water quality and sensitive habitats is difficult, if not impossible, with required field surveys and reduced staffing. Therefore, methods of surveying that can provide synoptic and timely land cover information are important to the characterization and monitoring of the region.

The Association of Monterey Bay Area Governments (AMBAG) is conducting the Coastal and Marine Projects Information Transfer System (CAMPITS) under a federal grant for Water Quality Management Planning [Clean Water Act section 205(j)(2)] (AMBAG 1992). The primary objective of the project is the "...creation of a formalized system for coordination, integration, and dissemination of coastal aquatic and marine water quality and source-based land use and population information" (AMBAG 1992). This includes the development of a Regional Water Quality Resource Center utilizing a GIS for the compilation and analysis of water quality data within the Monterey Bay region. 
CAMPITS will define and design a system for gathering spatial and tabular water quality data to show the location and distribution of water quality impacts within the region.

AMBAG states:

The problems of a lack of assessment of cumulative impacts of point and non-point source discharges into Monterey Bay and Carmel Bay could have severe adverse impacts on the beneficial uses of the receiving waters, including water contact recreation, marine habitat, rare and endangered species, wildlife habitat, and shellfish harvesting (AMBAG 1992).

The Califomia Coastal Commission (the Commission) is also conducting a cumulative impacts assessment project entitled Regional Cumulative Assessment Project (ReCAP) (California Coastal Commission 1993). The purpose of ReCAP is to develop methodologies for cumulative impast assessment in priority issue areas of wetland, coastal hazards, and coastal access (California Coastal Commission 1992). ReCAP is a response to the Commission's 1992 findings (California Coastal Commission 1992) that they lack information and methodologies for:

1. The cumulative impact of individual Coastal Act violations.

2. The data necessary for understanding, tracking, and managing coastal resource impacts.

3. The oversight and integration of local coastal programs.

4. The long-range planning necessary to effectively manage the cumulative impacts of growth and development.

Correcting these shortcomings is viewed as "...the single most important programmatic changes that the Commission could pursue..." (California Coastal Commission 1992). The region chosen for ReCAP is the Monterey Bay, with provisions for Projects of Special Merit, which includes the Elkhom Slough watershed. 
Remote sensing and GIS are fundamental tools for monitoring the MBNMS (AMBAG 1992; California Coastal Commission 1993; Sharp 1993). In order to facilitate the development of a remote sensing and GIS for cumulative impact assessments for a watershed of the MBNMS, the author established the following criteria:

1. Historical data should be available.

2. Data should completely cover the selected geographic units (watersheds).

3. Data should be easy to acquire, process, disseminate, and archive for future use.

4. Data should be quantifiably accurate.

5. Data should be in digital form.

6. Remote sensors should be capable of covering large areas (approximately $13,802 \mathrm{~km}^{2}$ of coastal watersheds).

7. Remote sensors should be able to detect change in land cover as a function of a change in reflectance or emissivity of the ground material.

\subsection{Will the C-CAP Protocol Work on California Coasts?}

While studies have applied the C-CAP protocol to southern and eastern regions of the U.S., no studies have applied the C-CAP protocol in California. California contains the largest acreage of coastal wetlands in the U.S. Western Region (NOAA 1990). The physiography of the west coast is substantially different than other areas. East coast wetlands are characterized by low-relief topography that contributes to relatively larger areas of wetland. West coast wetlands are characterized by high-relief topography that contributes to small, narrow wetlands. The natural cycles of climate, water, and vegetation in California are highly variable. Annual precipitation can vary dramatically, and 
anthropogenic alteration of the hydrologic regime effects wetland morphology and geographic distribution.

Two points make the study of wetland in California particularly important: 1) California wetlands are ecologically different than wetlands in other parts of the U.S., and 2) $75 \%$ of coastal wetlands in California have been lost (NOAA 1992). Therefore, several questions were posed to evaluate the use of C-CAP in central California. These questions include:

1. Can NOAA's C-CAP protocol be applied to the development of an environmental monitoring system in the MBNMS?

2. What are the specific capabilities and limitations of using satellite imagery with regard to its ability to detect disturbance to wetland habitat and to archive habitat distribution?

3. Can TM data be used to derive information of the Elkhorn Slough watershed valuable to scientists and resource managers?

4. Can change detection techniques be used to locate and quantify disturbance to upland or wetland areas in the Elkhom Slough Watershed?

5. Can maps derived from different sources or agencies be used to create accurate quantitative maps of habitat change over time?

6. Can the C-CAP Classification Scheme be used to produce land cover information and provide a standard classification scheme of value to those who monitor and study the Elkhorn Slough watershed?

7. Can the maps developed under C-CAP protocol requirements be used to assess cumulative impacts over time and space? 


\subsection{Elkhorn Slough Watershed Study Site}

The Elkhom Slough is the second largest estuary in California, and the largest estuary in the MBNMS. Elkhom Slough is located at the eastern apex of the Monterey Bay Submarine Canyon. Elkhorn Slough is an elongated, narrow estuary extending $17.7 \mathrm{~km}$ inland through the Aromas Sands geological formation (Schwartz 1983). Slough waters cover approximately 1070 ha. The Slough is a part of the Pacific flyway and one of the most important estuarine ecosystems on the coast (Browning 1972). Protection of this estuary system has been an ongoing effort at Federal, State, and local levels. Non-profit foundations and agencies, including the Elkhom Slough National Estuarine Research Reserve, conduct wetlands research to protect the Slough's sensitive habitats. Data and monitoring methodologies, such as C-CAP and TM data evaluations, will greatly assist conservation efforts.

Several problems associated with land use, including historical diking, dredging and filling, erosion and sedimentation, and high levels of coliform bacteria and agricultural pesticides, occur or have occurred in the Elkhom Slough watershed (ABA Consultants 1989). The Elkhom Slough watershed, including the Elkhorn, Moro Cojo, Bennett, Tembladero and McCluskey sloughs, Moss Landing, and apex of the Monterey Bay Submarine Canyon, form an ideal contiguous hydrologic study site. The sloughs and the associated upland drainage area cover approximately $585 \mathrm{~km}^{2}$ (Stmad and Hyman 1993).

The area for this study includes the same watershed boundary defined by Dickert et al. (1980). Their boundary excludes the drainage area of the Tembladero Slough and Old Salinas River Channel. Water inputs from these areas drain into the south end of the Moss Landing Harbor, rather than directly into the Elkhorn Slough.

The Elkhorn Slough and its drainage area defined by Dickert et al. (1980) constitute the study site for this evaluation of the C-CAP protocol (figure 1-3). The study area covers $139 \mathrm{~km}^{2}$. This portion of the Elkhom Slough estuarine drainage area is not 


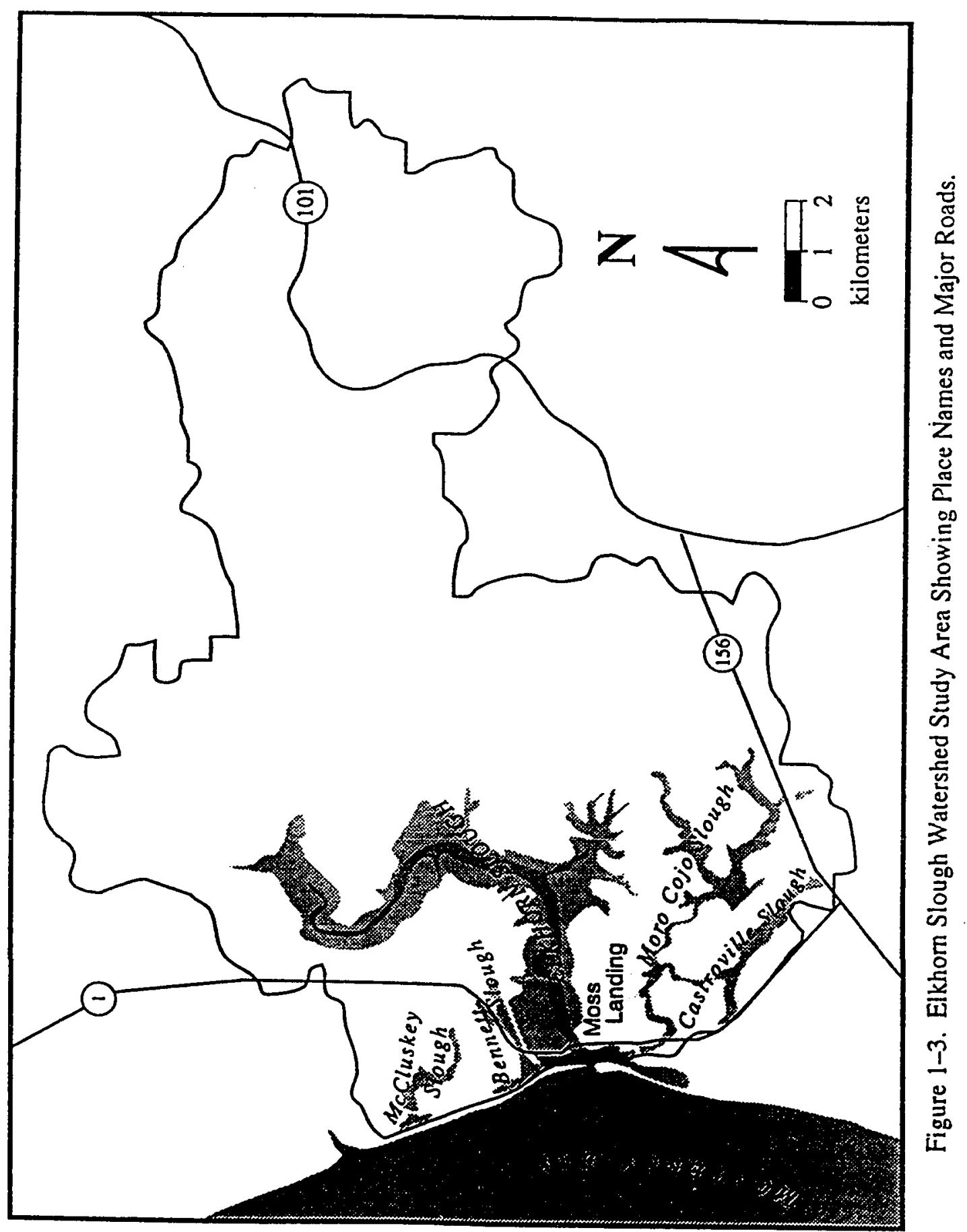


intensively developed. However, non-point source pollution from various land cover types within the watershed is the primary source of pollution impacting wetland and coastal water quality (NOAA 1992). Management of the watershed will be an example for the management of the wetland and marine environments of the MBNMS.

The regional importance of the estuary, inclusion in the MBNMS, the geographic and climatic conditions, and the non-point source pollution problems of the area make the Elkhorn Slough watershed an important study site for the application of the C-CAP protocol.

\subsection{Hypothesis}

The C-CAP protocol has established national standards for remote sensing and land cover data base development. The protocol has been tested in parts of the U.S. where physiography is different than in California. Yet, the protocol has not been tested in the largest marine sanctuary in the U.S. Therefore, hypotheses to test the C-CAP protocol in the Elkhom Slough watershed within the MBNMS are:

1. Maps derived from TM image data will show sufficient detail and accuracy to identify wetland, water, and upland spatial units in the Elkhom Slough watershed necessary to quantify areal land cover.

2. The C-CAP Classification Scheme can be used to classify wetlands, water, bare ground, cropland, grassland, and developed land to produce a "from-to" land cover map of value to those who monitor and study the Elkhorn Slough watershed.

3. TM image data can provide synoptic, timely, and cost effective land cover change information valuable to cumulative impact assessments and monitoring in the Elkhorn Slough watershed. Specifically, C-CAP land cover units derived 
from TM data can be compared with the U.S. Fish and Wildlife Service National Wetland Inventory digital maps.

These hypotheses will be used to test the remote sensing and digital data base development standard recommended by C-CAP. Investigation guided by these hypotheses will provide some of the answers to questions necessary for cumulative impact assessment methodologies in the Elkhom Slough watershed. 


\section{CHAPTER 2}

\section{METHODOLOGY}

\subsection{Introduction}

The methodology developed for this study is based on C-CAP protocol recommendations (Dobson et al. 1993). Five major components comprise the methodology, each of which involves data manipulations and operations commonly found in remote sensing and GIS literature. A diagram of the general process is shown in figure 2-1. The five major methodological components down the left side in figure 2-1 are: 1) Data Acquisition, 2) Data Processing, 3) Accuracy Assessment, 4) Change Detection, and 5) Map Products. Two sources of data, satellite and ancillary, pass through these processes to produce geographically and categorically specific habitat and land cover change information. Ancillary data is defined here as digital land cover maps available from other sources.

\subsection{Data Acquisition}

Landsat TM is the preferred satellite sensor for C-CAP. The C-CAP protocol stresses that temporal, spatial, spectral, and radiometric conditions be held as constant as possible to minimize change detection errors when two TM images are compared. Remote sensing data captured at approximately the same time of day and on near-anniversary dates minimizes the effects of daily and seasonal sun angle. Remote sensors with the same instantaneous-field-of-view and look angle minimize spatial distortions. The same sensor systems, or different systems which approximate spectral bands, are best to capture the radiant flux of ground objects. 


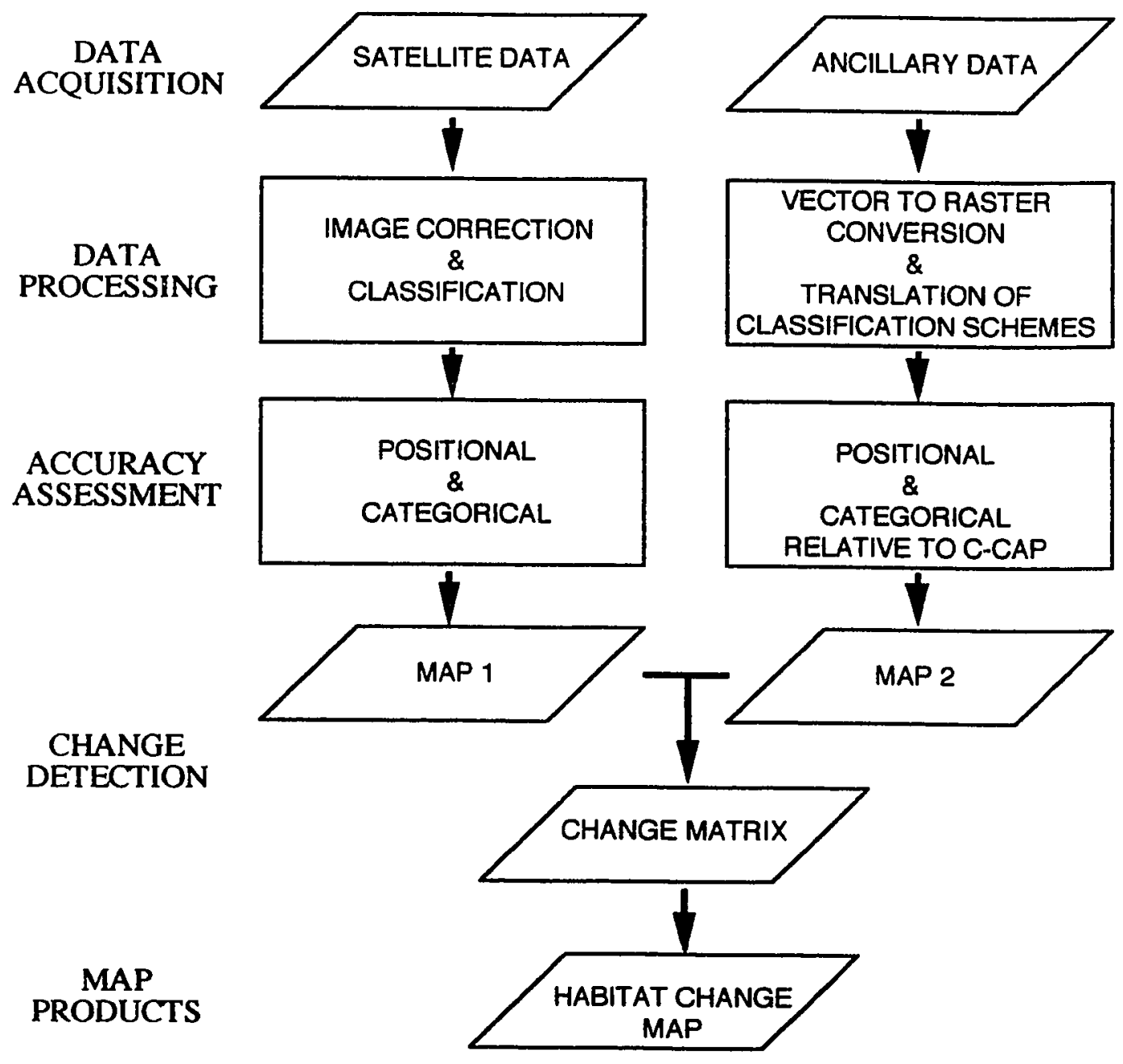

Figure 2-1. Diagram of the Major Components in the Change Comparison Methodology. 
The TM satellite platform enables synoptic and periodic coverage of large geographic areas. TM sensors capture data at a spatial resolution of $28.5 \mathrm{~m}$ per pixel in 6 of 7 spectral bands. The spectral bands are: 1) 0.45 - 0.52 micrometers $(\mu \mathrm{m}), 2) 0.52$ $0.60 \mu \mathrm{m}$, 3) $0.63-0.69 \mu \mathrm{m}, 4) 0.76-0.90 \mu \mathrm{m}$, 5) $1.55-1.75 \mu \mathrm{m}$, and 7) $2.08-2.35$ $\mu \mathrm{m}$. Band 6, $10.4-12.5 \mu \mathrm{m}$, has a spatial resolution of $120 \mathrm{~m}$ per pixel. The TM satellite has a temporal resolution of 16 days. Detailed information on the functional and orbital characteristics of TM data is found in Lillesand and Kiefer (1988).

Environmental factors also affect or obstruct reflectance. Temperature, moisture, and other climatic factors alter emmisivity of land covers. Cloud, haze, or other atmospheric matter obstructs remote sensing. Remote sensing should account for or avoid noisy atmospheres. Soil moisture conditions should be the same for the dates of the imagery. Vegetation phenological cycles should also be known for the seasons in which the imagery was captured because of the varying seasonal reflectance characteristics of vegetation. Agricultural cropping patterns should also be understood as they affect reflectance. Tidal stage should be constant between dates of TM imagery, or be near mean low tide. Higher tides may submerge wetland areas and cause them to be incorrectly classified as water.

Although two TM images were not compared in this study, the environmental factors are important to consider when selecting data sets. One TM image was compared with two sources of ancillary land cover data. The C-CAP protocol did not contain specifications for the use of ancillary data in change detection comparison with TM data. However, many agencies have developed land cover information that may be useful in land cover change comparisons. Therefore, the focus of this study was on the comparison of TM data and ancillary data.

TM image scene number 5230218061, including the San Francisco Bay area and the Monterey Bay region, was supplied by the USGS EROS Data Center at the National 
Aeronautic and Space Administration (NASA)-Ames Research Center, Moffett Field, California. The image data was of excellent quality and contained no cloud cover over the study region. The data acquisition date was June 20,1990 . The approximate time of TM overpass was 9:45 a.m. Pacific Standard Time. The TM scene was not optimal under the C-CAP protocol recommendations for optimum season and tidal stage. The summer season was not considered the best time of year to acquire wetland information due to the dry season and the California drought. The last rainfall greater than 0.5 inches prior to the data capture date was May 28, 1990.

Jensen et al. (1993) recommended a maximum acceptable tidal height of 2 feet above mean low tide for data capture. The estimated tide height at Moss Landing, California during the TM overpass was 3.7 feet above MLLW. The C-CAP protocol did acknowledge the variation in tidal prisms across the United States. Therefore, acceptable tide heights should be established for each region. In the case of the Elkhorn Slough, discussions with a local biologist suggested that not all wetlands would be submerged at 3.7 feet above mean lower low water (De Vogelaere 1993). Observation of the TM image indicated that most of the vegetated wetlands were not submerged. Thus, the value of classifying this TM image data as a base date was affirmed based upon the opportunity to obtain land cover information.

Wetland land cover information for 1972 was obtained from USFWS NWI map overlays for Moss Landing and Prunedale USGS 7-1/2 minute quadrangles. These wetland boundaries were interpreted by trained USFWS personnel using 1972 black and white aerial photographs at 1:80,000 scale (Shaffer 1993). The maps were obtained in USGS Digital Line Graph (DLG) format using the Universal Transverse Mercator (UTM) zone 10, North American Datum (NAD) 1927. The DLGs consisted of a quadrangle boundary polygon along with polygons and lines labeled according to the USFWS wetland 
classification scheme (Cowardin et al. 1979). An alternative source for upland information was necessary because the overlays did not contain upland land cover data.

Dickert et al. (1980) derived land cover information from 1980 1:12,000 scale color infrared aerial photography of the Elkhom Slough watershed. Planimetric maps generated from the land cover information were transferred to GRASS, a public domain GIS, by personnel at the University of California, Berkeley. The data were apparently hand encoded into digital form between 1980 and 1992 (Gardels 1992). Unfortunately, no explicit documentation of the transfer was available. The GRASS data set was obtained from the San Francisco State University, Geography Department, GIS laboratory. The absence of information about the creation of digital files introduced significant unknowns regarding the 1980 land cover layer. Nonetheless, for the purpose of this study, it represented the most recent and only land cover information available in digital form.

The C-CAP coastal land cover classification scheme is designed to integrate upland and wetland classification schemes for a consistent land cover information data base (Klemas et al. 1993). The hierarchical C-CAP Classification system (see Appendix A) is a hybrid of the USFWS classification scheme (Cowardin et al. 1979) and the USGS Anderson classification scheme (Anderson et al. 1976). The three C-CAP super classes are: 1.0 Upland, 2.0 Wetland, and 3.0 Water and Submerged Land. Each class contains subclasses of finer detail. Further subdivisions of classes are possible and encouraged as long as the subdivisions can be aggregated back to major classes.

C-CAP classes required by the protocol are listed in table 2-1. All C-CAP classes in table 2-1 were used in classifying the $1990 \mathrm{TM}$ subset, except for class 3.3 Marine Estuarine Aquatic Bed. This class was excluded from the classification because estuarine aquatic beds could not be distinguished from the TM data due to TM's coarse spatial resolution. C-CAP recommended higher spatial resolution aerial photography for the detection of this land cover class. 
Table 2-1. Required C-CAP Classes

\begin{aligned} & \hline \hline Class \# Class Name \\ & \hline 1.11 High Density Developed Land \\ & 1.12 Low Density Developed Land \\ & 1.2 Cultivated Land \\ & 1.3 Grassland \\ & 1.4 Woody Land \\ & 1.5 Bare Land \\ & 2.22 Sand (beach/dune) \\ & 2.23 Mud (marine/estuarine) \\ & 2.3 Estuarine Emergent Wetland \\ & 2.8 Palustrine Emergent Wetland \\ & 2.9 Palustrine Woody Wetland \\ & 3.1 Water \\ & 3.3 Marine/ Estuarine Aquatic Bed \\ & \hline \\ & Note: Class 3.3 Marine/Estuarine Aquatic Bed \\ & was not used in this study. \end{aligned}

\subsection{Data Processing}

Data processing in preparation for change detection analysis requires several steps. First, the TM data must be corrected for radiometric and geometric distortions. Second, geo-referencing also must be performed to ensure accurate registration of the data. In this study, the TM data were preprocessed to remove distortions and to attach geo-referenced coordinates. Ancillary data must also be accurately geo-referenced. Third, the TM data must be classified according to the C-CAP classification scheme. Image processing techniques to cluster and label the TM data must be conducted. Fourth, ancillary data must be transformed to a compatible format-vector-to-raster conversion, in this case. Fifth, the classification scheme of the ancillary data must be translated to the C-CAP classification. Differences in each scheme must be resolved before comparison.

A subregion of the TM image data was extracted from the full scene captured June 20,1990 (see figure 3-1). The rectangular area of interest encompasses the northern portion of the Elkhorn Slough watershed, as defined by Dickert et al. (1980). This subset contained 626 rows x 807 columns of pixels, each representing a $28.5 \times 28.5 \mathrm{~m}$ 
area on the ground.

The TM subregion was classified using the C-CAP recommended procedures and classification scheme. Six of the seven spectral bands of the TM subset were simultaneously classified using unsupervised classification techniques. Band 6 , the thermal channel, was excluded from the classification. The image data were processed into 150 clusters using the ISODATA and MAXCLAS functions, a maximum likelihood sequential classifier, of ERDAS version 7.5. Clusters represented a group of pixels within a narrow range of brightness values. Clusters of pixels were identified with particular classes.

Each cluster was assigned to a C-CAP class using on-screen techniques similar to photointerpretation (Westmoreland and Stow 1992). The clustered data were displayed simultaneously with the original TM subregion bands 4, 3, and $2=$ RGB using ERDAS Imagine $^{\circledR}$ software version 8.0.2. This produced a false color infrared image similar to color infrared aerial photographs. All pixels within a cluster were assigned to a C-CAP class by the interpreter. Image interpretation was assisted by two sets of high altitude color-infrared aerial photography, dated September 4, 1991, and October 15, 1991, by field visits in the fall of 1993, and by ancillary vector data from the USFWS NWI Maps.

Some clusters contained pixels that were clearly associated with two or more CCAP classes. For example, some pixels located in wetland areas with restricted tidal flow in the upper reaches of the Elkhorn Slough were clustered with pixels in upland forest areas dominated by eucalyptus trees (Myrtaceae spp.). Other pixels known to correspond with cultivated land areas were in clusters identified as forested land. Separation of confused clusters was necessary to improve the classification.

A "cluster busting" procedure was used to separate the mixed pixels within a cluster (Jensen et al. 1993). Clusters containing mixed pixels were used to create a binary mask. The mask was applied to the original TM subregion data to extract the data from only the 
areas of confusion. The extracted areas were isolated and clustered using the ISODATA and MAXCLAS functions. The new clusters were then assigned to the appropriate C-CAP class. The effect of the procedure was to increasingly fragment the clusters until the confusion was removed.

The "cluster-busting" procedure was applied 3 times in an attempt to separate mixed pixels, particularly between wetland and woody land classes. The unconfused clusters, now assigned the appropriate C-CAP classes, were merged back with the original classification for a final tally of 180 clusters, each labeled with a C-CAP class. The 180 labeled clusters were recoded to 12 labeled clusters corresponding to the first $12 \mathrm{C}$-CAP classes found in table 2-1.

Comparison of the C-CAP classification with ancillary data required that the ancillary data be in a compatible form. In this study, the C-CAP classification was in raster (grid) form. The USFWS NWI overlays were in vector (polygon) form. Thus, the USFWS NWI data had to be transformed to raster format. The comparison also required that the classification scheme be identical; thus, the USFWS NWI data and the Dickert et al. (1980) data were translated to the C-CAP scheme.

The USFWS wetland classification scheme and its compatibility with the C-CAP classification scheme is documented by Klemas et al. (1993) and Dobson et al. (1993). Subclasses of the C-CAP super class 2.0 Wetland is designed to directly translate freshwater and saltwater classes. The C-CAP scheme also includes descriptors, such as emergent wetland and unconsolidated bottom, identical to the USFWS wetland classification system.

The USFWS wetland classification scheme is hierarchical and composed of five levels (Cowardin et al. 1979). The hierarchical classification system in decreasing order is system, subsystem, class, subclass, species dominance type, and modifying terms. The five systems are: Marine, Estuarine, Lacustrine, Palustrine, and Riverine. The subsystems 
are defined by hydrology (e.g., 1-intertidal, 2-subtidal). Class and subclass are determined by dominant vegetation or substrate. The fifth level, species dominance type, is intended to identify species but is not found in the USFWS NWI Moss Landing and Prunedale polygon labels. Modifying terms are special descriptors for water chemistry, water regime, soils, and human influence (e.g., artificially flooded).

Labels for polygons in the USFWS NWI DLGs are capital letters and numbers representing each level of classification from left the right. For example, E1OWL means SYSTEM Estuarine, SUBSYSTEM Subtidal, CLASS Open Water (OW), WATER REGIME Subtidal (L). Thus, in the table 2-2, the C-CAP translation can be interpreted with the aid of the USFWS wetland classification key (see Appendix B).

The USFWS NWI DLGs for the Moss Landing and Prunedale quadrangles were imported into ARC/INFO. The coverages were joined using the MAPJOIN commands. The joined, vector-based map was converted to a raster-based map using ARC/INFO GRID software. The vector overlay was converted to a grid overlay with a cell, or pixel, size of $28.5 \mathrm{~m}$ on a side. The GRID layer was import to the ERDAS Imagine software with ERDAS import commands. The rasterized USFWS NWI map was recoded to the CCAP classification scheme based on the listing in table 2-2.

The Dickert et al. (1980) GRASS land cover data was in raster form. The Dickert et al. (1980) GRASS land cover/land use layer, in UTM Zone 10 Northern Hemisphere coordinates, NAD 1927, was imported to ERDAS using its import utilities. The spatial resolution of the GRASS layer was $50 \mathrm{~m}$ /pixel. The pixel resolution was different than the C-CAP classification. No information was available on the layer's spatial accuracy.

Land use is determined by the cultural practices at a place, and may not be visible as a land cover feature. Land cover is the vegetation, soil, or rooftop areas that are visible. Land uses, such as a school yard compared to a park, cannot be determined using spectral analysis. The C-CAP scheme avoids land use in favor of land cover. The C-CAP 
Table 2-2. Translation of USFWS NWI Wetland Classes to C-CAP

\begin{tabular}{|c|c|}
\hline NWI Class & C-CAP Class \\
\hline $\begin{array}{l}\text { E1OWL } \\
\text { M1OWL } \\
\text { R2OWZ } \\
\text { R1OWV } \\
\text { L2FLKY }\end{array}$ & $\begin{array}{c}.1 \text { Water } \\
" \\
" \\
" \\
"\end{array}$ \\
\hline $\begin{array}{l}\text { ElUBKL } \\
\text { ElUBL }\end{array}$ & 2.23 Mud (marine/estuarine) \\
\hline $\begin{array}{l}\text { E2EMN } \\
\text { E2EMP } \\
\text { E2FLKN } \\
\text { E2FLN }\end{array}$ & $\begin{array}{c}\text { 2.3 Estuarine Emergent Wetland } \\
\qquad " \\
"\end{array}$ \\
\hline $\begin{array}{l}\text { PEMY } \\
\text { PEMKW } \\
\text { PEMKY } \\
\text { PEMR } \\
\text { PEMU } \\
\text { PEMW } \\
\text { PFLKY } \\
\text { P2FLKY } \\
\text { PFLW } \\
\text { POWKY } \\
\text { POWKZ } \\
\text { POWW } \\
\text { POWZ } \\
\text { POWZK }\end{array}$ & $\begin{array}{c}2.8 \text { Palustrine Emergent Wetland } \\
\text { " } \\
" \\
" \\
" \\
" \\
" \\
" \\
" \\
" \\
" \\
"\end{array}$ \\
\hline $\begin{array}{l}\text { PFOW } \\
\text { PFOY } \\
\text { PSSW } \\
\text { PSSY }\end{array}$ & $\begin{array}{c}\text { 2.9 Palustrine Woody Wetland } \\
" ~ \\
" ~\end{array}$ \\
\hline
\end{tabular}


classification scheme is designed for land cover defined by remote sensing (Klemas et al. 1993). The USGS Anderson et al. (1976) scheme is highly compatible with the C-CAP classification scheme except where land uses, such as industrial, commercial, school, church, and others cannot readily be determined with remote sensing (Klemas et al. 1993).

The Dickert et al. (1980) classification scheme contains USGS Anderson et al. (1976) land use classes with land cover classes. The Dickert et al. (1980) classes were converted to land cover based on the land cover most closely associated with the land use. Translation decisions were based upon the estimated ability of TM satellite sensor to detect a corresponding brightness value (i.e., industrial and commercial land uses were lumped into high intensity developed land). The Dickert et al. (1980) land cover map was translated to the C-CAP classification scheme in table 2-3.

Spatial resolution of each layer must be identical in order to perform a change detection algorithm. The spatial resolution of the 1990 C-CAP data was aggregated to $50 \mathrm{~m}$ to match the Dickert et al. (1980) data using a nearest neighbor algorithm. Nearest neighbor resampling preserved the original data values. Next, a binary mask was generated from the Dickert et al. watershed data and applied to the 1990 C-CAP classification $(50 \mathrm{~m})$ to extract only the area bounded by the Elkhorn Slough watershed. The result was a $1990 \mathrm{C}$-CAP raster data set that matched pixel for pixel the area represented by the Dickert et al. (1980) definition of the watershed.

\subsection{Change Detection}

Image rectification is important for accurate change detection. Errors in rectification increase errors in change detection. The USFWS NWI rasterized map and the TM subset bands 4,3 , and 2 =RGB were visually overlain on screen to verify the alignment of the TM and USFWS NWI UTM coordinates. The original vector coverage was also displayed. A visual examination of the three layers indicated that the only common permanent feature of 
Table 2-3. Translation of Dickert et al. (1980) Classes to C-CAP Classes

\begin{tabular}{|c|c|}
\hline Dickert et al. Classes & C-CAP Classes \\
\hline $\begin{array}{l}\text { Urban } \\
\text { Commercial } \\
\text { Highway } \\
\text { Industrial } \\
\text { Railroad } \\
\text { School }\end{array}$ & $\begin{array}{c}1.11 \text { High Density Developed Land } \\
\text { " } \\
\text { " } \\
\text { " }\end{array}$ \\
\hline $\begin{array}{l}\text { Row Crops } \\
\text { Strawberries } \\
\text { Orchard }\end{array}$ & $\begin{array}{r}1.2 \text { Cultivated Land } \\
\text { " } \\
\end{array}$ \\
\hline $\begin{array}{l}\text { Grassland } \\
\text { Alluvial Fans }\end{array}$ & 1.3 Grassland \\
\hline $\begin{array}{l}\text { Brushland } \\
\text { Oak Brushland } \\
\text { Eucalyptus } \\
\end{array}$ & $\begin{array}{r}.4 \text { Woody Land } \\
\text { " } \\
\end{array}$ \\
\hline $\begin{array}{l}\text { Bare ground } \\
\text { Salt Pond }\end{array}$ & $1.5 \quad$ Bare Land \\
\hline $\begin{array}{l}\text { Sand dune land } \\
\text { Mud Flat } \\
\text { Salicornia } \\
\text { Wet grassland } \\
\text { Open Water }\end{array}$ & $\begin{array}{l}\text { 2.22 } \text { Sand (beach/dune) } \\
2.23 \text { Mud (marine/estaurine) } \\
2.3 \text { Estuarine Emergent Wetland } \\
2.8 \text { Palustrine Emergent Wetland } \\
\text { 3.1 } \text { Water }\end{array}$ \\
\hline
\end{tabular}


each layer was the north jetty of the Moss Landing Harbor. This was insufficient for a first or second order transformation of the data. Nonetheless, the coordinates of the jetty were examined for each layer. Simple measurement of the coordinates of the west end of the north jetty on a paper topographic quad 1:24,000 was made using an engineer scale. The map coordinates were compared to the TM pixel coordinates and the USFWS NWI pixel coordinate for the same point. Measurement indicated a difference between the TM and USFWS NWI x coordinate of approximately 38 meters, roughly 1.33 pixels. A visual examination of the habitat polygons and TM data displayed on-screen also indicated a general discrepancy of 1 pixel. Therefore, the USFWS NWI grid layer received a one pixel linear shift to the west based on the lack of common, fixed points between the USFWS NWI and TM data, and visual examination of the polygons compared to the TM overlay.

A significant operation in the preparation of ancillary data was the translation of classification schemes to the C-CAP classification scheme. The translation was a possible source of classification errors due to discrepancies in class definitions between different classification schemes. Generalization of classification schemes to the C-CAP classification scheme was necessary to match the classification of TM data. Therefore, some classification details in the ancillary data were lost.

As in the USFWS NWI maps, no precise permanent ground features such as road intersections or jetties were imbedded into the Dickert et al. (1980) land cover layer. Onscreen visual overlay of the GRASS data and TM data revealed significant misregistration, as much as 3 pixels $(150 \mathrm{~m}$ ) in the hills of the watershed. Without information on the production of this layer, accurate correction of the distortions was not possible. Documentation on the production of land cover maps in the 1980 study indicated that the data were derived from uncorrected color infrared aerial photographs at 1:12,000 scale (Dickert et al. 1980). Although photogrammetric techniques were used to minimize 
distortion, the manual transfer from low altitude aerial photographs to acetate overlays; then, to base maps using hand-held planimeters; finally, to the unknown transformation process into GRASS can cause significant distortion.

The GRASS data were rectified to the TM thematic classification based solely on land use pixels bordering roads, urban areas, or other features considered relatively permanent. Twenty-five control points were selected between the GRASS data (50 m pixels) and the TM subset (28.5 m pixels). The coordinates of control points were used in a second order transformation of the GRASS land use layer. The root mean square error (RMSE) was $\pm 25.055657 \mathrm{~m}$, which is approximately half a $50 \mathrm{~m}$ pixel. RMSE of \pm 0.5 pixel is a requirement of C-CAP. However, the position accuracy of the GRASS data was not assumed, even after transformation, to meet this requirement. Visual display of the transformed GRASS land cover layer overlain with the TM subset bands 4, 3, 2=RGB revealed improvement of geographic distortions.

The methodology for monitoring change is based on the comparison of georeferenced land cover information to produce a change matrix. A change detection algorithm mentioned, but not cited, in the C-CAP guidelines is multi-date change detection using an ancillary data source as map 1 and TM imagery as map 2 (Dobson et al. 1993). The algorithm involves the comparison of data other than satellite imagery to detect land cover changes in the watershed.

Multi-date change detection using ancillary data is a form of post-classification change comparison. TM data is classified to produce a thematic image, and then compared to the ancillary data already in thematic form. The technique requires identical classification schemes and accurate map-to-map registration. The process multiplies the first thematic layer (map 1) by the number of classes (e.g., 12). Map 1 is algebraically added to the second thematic layer (map 2) to produce $n^{2}-n$ (Jensen et al. 1993) change categories. Table 2-4 illustrates the change matrix principle. The values in each cell represent the 
number of pixels for each "from-to" combination. Thus, 400 pixels essentially did not change (FROM wetland TO wetland, or FROM water TO water). The unchanged pixels reside in the major diagonal. Twenty-five pixels went from wetland to water. Fifty pixels went from water to wetland. The number of possible changes is $2^{2}-2=2$.

Table 2-4. Example of Change Detection Matrix

\begin{tabular}{|c|c|c|}
\hline FROM & $\begin{array}{l}\text { TO } \\
\text { Wetland }\end{array}$ & Water \\
\hline Wetland & 300 & 25 \\
\hline Water & 50 & 100 \\
\hline
\end{tabular}

A graphic representation of a post classification change detection process is shown in figure 2-2.

An advantage of post-classification change detection using ancillary data is the use of an authoritative and documented data source, such as the USFWS NWI. Another advantage is the avoidance of detrimental variations in environmental factors between two dates of imagery. The disadvantages are that the conditions under which the ancillary data were produced can vary tremendously, and consequently, cause excessive errors. Causes of errors include the digitization and transformation of vector-based data to raster-base (satellite) data, a process that can introduce unacceptable error (Lunnetta et al. 1991), and variations in the preparation and interpretation of the source data.

Post-classification change comparison using an ancillary data source as date 1 and TM imagery as date 2 was used in this study based on the availability of USFWS NWI maps in digital form and TM image data. Two data sets were separately used as date 1: a vector-based, USFWS NWI map generated from 1972 aerial photos, and a raster-based land cover/land use map derived from Dickert et al. (1980). The vector-based digital maps are generally believed to be accurate maps of wetland boundaries but do not contain any upland information. The Dickert et al. raster-based digital map containing wetland and 


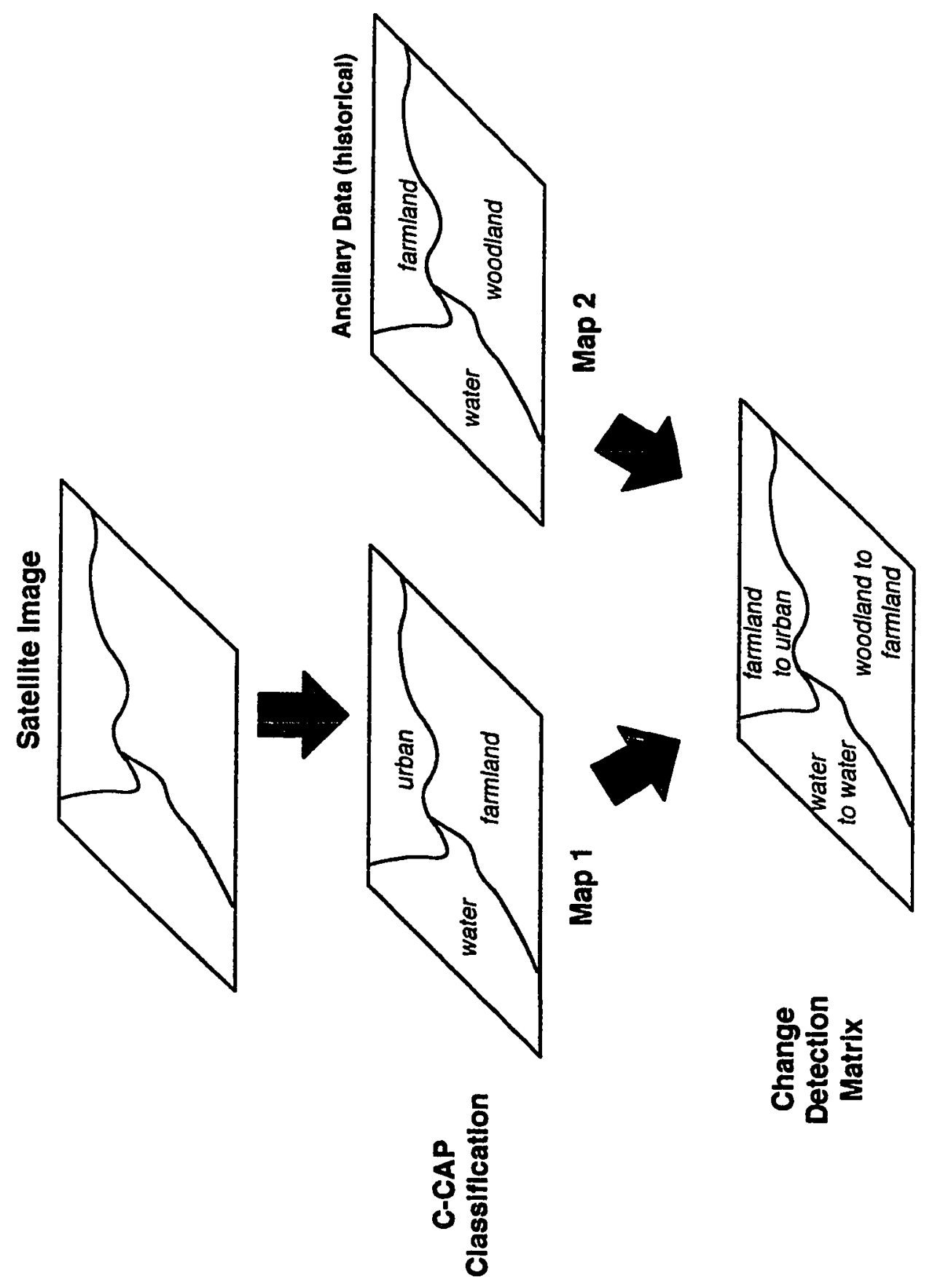

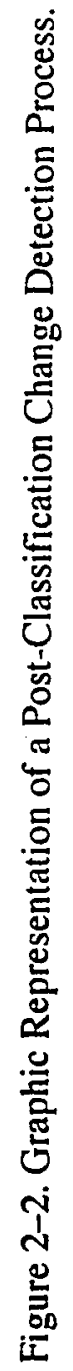


upland land cover information for the entire Elkhorn Slough watershed drainage area was also tested.

The comparison of the USFWS NWI maps to the 1990 C-CAP classification was generated using a change detection matrix. The procedure algebraically expands the $\mathrm{C}$ CAP classification layer's 12 C-CAP classes, plus 1 for a background class, by squaring it (i.e., $\left.(n+1)^{2}=(12+1)^{2}\right)$. The USFWS NWI map layer is algebraically added to the expanded $1990 \mathrm{C}$-CAP classification layer. The result is a change detection matrix with "from-to" classes. The USFWS NWI data only contained thematic information on wetlands and water. Thus, an unbalanced matrix was produced due to the absence of upland information in the USFWS NWI maps. Any value from the rows 1.11 High Density Developed Land through 2.22 Sand have no pixels associated with the "from-to" value. Therefore, the actual viable combinations of change are limited to 72 , which is $13 \mathrm{x}$ $6-6$.

The comparison of the Dickert et al. (1980) land cover layer to the 1990 C-CAP classification layer was generated using the same change detection algorithm mentioned above. The 1980 data contained 11 C-CAP classes (no 2.9 Palustrine Woody Wetland). In this case, 169 classes, excepting the major diagonal values (13) and no 2.9 Palustrine Woody Wetland class (12), made 144 possible "from-to" changes from the Dickert et al. (1980) land cover map to the 1990 C-CAP classification image. Any combination of the "from-to" classes can be displayed on-screen by selecting the desired "from-to" values and assigning a display color. For example, matrix cell 120 colored red and displayed on screen will show areas that have changed "from" estuarine emergent wetland "to" cultivated land. 


\subsection{Accuracy Assessment}

Two types of accuracy assessment, positional and categorical, were required to ensure that the C-CAP classification met protocol standards for the TM data. Spatial, or positional, accuracy requirement of the TM data was \pm 0.5 pixel. The requirement was designed to minimize change detection comparison errors caused by misregistration. Categorical, or classification, accuracy was required to minimize change detection errors caused by incorrect classification. No minimum classification accuracy was established by the protocol. However, $85 \%$ overall classification accuracy was adopted based on the work of Jensen et al. (1993).

\subsubsection{Positional Accuracy Assessment}

The positional accuracy of the TM subregion was tested using ground control points collected with a GPS during field visits. Use of the GPS was not originally planned for the study. However, a differential GPS unit was loaned by Moss Landing Marine Labs on a limited basis. Coordinates of stable, permanent locations such as road intersections, parking lots, or buildings visible in the TM image were recorded with the GPS mounted in the pickup truck. Corners of intersections were recorded, as opposed to centers, due to roadway hazards. The perimeter of two parking lots were surveyed also with the GPS. The GPS unit was placed directly on top of one national geodetic marker located on the east end of the north harbor jetty. The GPS coordinates were recorded for this marker.

The assessment of positional accuracy of USFWS NWI wetland polygons was not tested although the USFWS NWI maps are designed to overlay USGS topographic quadrangles. The digital USFWS NWI overlays did not contain sufficient permanent points clearly visible in the TM imagery for positional assessment. However, the single permanent feature, the north jetty at Moss Landing Harbor, and relative positions of wetland polygons to TM wetland data were compared for image-to-image rectification. 
Visual assessment of the vector USFWS NWI data and the TM data indicated a spatial discrepancy east to west. Visual assessment was conducted with the USFWS NWI rasterized map and the TM subregion bands 4, 3, and $2=$ RGB visually overlain on-screen to verify the alignment of the TM and USFWS NWI UTM coordinates.

\subsubsection{Classification Accuracy Assessment}

Ideally, a change comparison matrix would have a classification accuracy requirement standard. However, an accuracy assessment method for change detection matrices was not endorsed by the C-CAP protocol because theoretical and methodological problems associated with multi-temporal data were still under study. However, accuracy of a change detection matrix must be related to the two land cover data sets used in the algorithm. Therefore, accuracy assessment of the individual data sets was attempted.

The overall classification accuracy of the C-CAP data was evaluated with limited field ground observation work and two sets of high altitude color-infrared aerial photography, dated September 4, 1991 and October 15, 1991, respectively. These transparencies were the best near-anniversary photographs readily available. Nearanniversary dates of photography were recommended by the C-CAP protocol to reduce effects of seasonal vegetation changes. Each set, one $9 \times 9$ inch and the other $9 \times 18$ inch frame format, was of good quality. Two dates were necessary because the September photographs contained cloud cover that obscured the coastline in some frames. The October date also contained some cloud cover, but in different areas.

The accuracy of $1990 \mathrm{C}$-CAP classification was evaluated by stratified random sampling of 191 points. Five hundred samples points of $3 \times 3$ pixel blocks were randomly generated using the RANDCAT function of ERDAS version 7.5. The random sample was stratified by total area of each class (e.g., grassland had proportionally more samples than sand). All homogeneous blocks, defined as those having 9 pixels of the same class, were 
selected for the accuracy assessment. The center pixel coordinates of the 191 blocks were displayed on screen with the original unclustered TM subset, and located on the aerial photographic transparencies. Each center pixel coordinate was assigned a classification using the 12 C-CAP classes in Table 2-1. Sample blocks that could not be readily determined from the aerial photographs were field checked. The thematic class for each point was recorded. The interpreted class and reference class were used to create an accuracy table (also known as a confusion matrix).

A classification accuracy error matrix was generated by comparing the thematic classification of each sample block with the photointerpreted or field data classification. The error matrix was used to describe the overall accuracy and assess errors of omission and commission (Congalton, 1991; Story and Congalton 1986; Congalton et al. 1983).

An hypothetical example error matrix is presented in table 2-5.

Table 2-5. Hypothetical Error Matrix
\begin{tabular}{|c|c|c|c|c|}
\hline & Water & Urban & Wetland & Total \\
\hline Water & 10 & 1 & 5 & 16 \\
\hline Urban & 3 & 8 & 0 & 11 \\
\hline Wetland & 1 & 4 & 20 & 25 \\
\hline Total & 14 & 13 & 25 & 52 \\
\hline
\end{tabular}

Reference class totals are in the columns. Image class totals are in the rows. Each row and column is labeled with its respective class. The reference values are intrepreted by the field investigation of a sample point. The image values are taken from the classified image sample point. Thus, in the example, the Reference column Water has 10 samples classified as Water by the field observation and by the Image, 3 samples classified as Water by the field team and as Urban by the Image, and 1 sample classified as Water by field observation and as Wetland by the Image. The column totals, 14, 13, and 25 are the number of samples classified as Water, Urban, and Wetland respectively by the field team. 
The major diagonal, 10,8 , and 20 , for the matrix in table $2-5$ represents the number of samples correctly classified by the Image and the Reference. Overall accuracy is the sum of the major diagonal, 38, divided by the total number of samples, 52 . Therefore, the overall accuracy of the hypothetical example is $73 \%$.

Reference Data accuracy (also call producer's accuracy or errors of omission) is the number correct of a Reference Data column divided by the Reference Data column total. The percentage indicates the probability that a sample pixel will be classified correctly in the image (errors of omission). For example, Reference Data column Water in table 2-5 has 10 samples correctly classified and 14 samples total. The accuracy of the Image Data for Water classification is 10 divided by 14 , or $71 \%$. Therefore, the probability that a sample point labeled as Water in the image is correct relative to Reference Data is $71 \%$.

Conversely, Image Data accuracy (also called user's accuracy or errors of commission) is the number correct of an Image Data row divided by the Image Data row total. The user's percentage indicates the probability that a sample pixel actually is that class on the ground (errors of commission). Thus, in table 2-5, the Image Data row Wetland has 20 samples correct divided by the Image row total, 25. Thus, the Image Data accuracy is $80 \%$.

A measure of confidence in the accuracy of an image classification is the lower confidence limit. The $95 \%$ lower confidence limit was calculated using the following equation (Jensen 1986):

$$
P=p^{\sim}-\left[1.645 \sqrt{\frac{p^{\sim} \times q^{2}}{n}}+\frac{50}{n}\right]
$$

where $P=$ accuracy of the map at the lower $95 \%$ confidence limit

$P^{\sim}=$ number of correct samples/ total number of samples expressed as a percent

$q=100-p^{\sim}$

$n=$ total number of samples 
Thus, using the values in table $2-5$ :

$$
\begin{aligned}
& P=73-\left[1.645 \sqrt{\frac{73(100-73)}{52}}+\frac{50}{52}\right] \\
& P=62 \%
\end{aligned}
$$

If $P$ is greater than the required accuracy, then the thematic layer can be said to exceed the required accuracy with $95 \%$ confidence. In this hypothetical case, $62 \%$ accuracy at the lower confidence limit suggests that the example does not meet accuracy requirements of $85 \%$ at the lower confidence limit.

The error matrix method of accuracy assessment, measured against the $95 \%$ lower confidence limit, was used to calculate the overall accuracy of the C-CAP classes. The error matrix method, measured against the $95 \%$ lower confidence limit, was also used to assess the accuracy of wetland classes in the C-CAP classification.

Scientists and managers working in the MBNMS are interested in the wetland areas. However, wetland classes represented only about $4 \%$ of the TM image. The large amount of non-wetland area can result in a biased representation of land cover accuracy because wetland classes contribute little to the overall accuracy assessment. Therefore, the wetland classes were assessed in a separate accuracy analysis.

An accuracy assessment for a particular class, rather than the overall image, requires special consideration for errors of omission and errors of commission. In this case, errors of commission are pixels incorrectly labeled as wetland, thus, inflating the actual total wetland area. Errors of omission are pixels incorrectly assigned to other classes that are actually wetland. A sample stratified purely from the thematic layer wetland classes would not have addressed errors of omission. Therefore, collateral data from a vectorbased map of the wetland areas was used to extract potential areas of omission. A merge 
procedure was devised to unite geographic areas labeled as wetlands by the USFWS NWI digital maps and the geographic areas labeled as wetlands from the thematic (C-CAP) classification. Essentially, this was a stratification of the thematic image based on reliable ancillary data. The purpose of the union was to increase the probability that errors of omission would be assessed in the accuracy table.

A subset of the thematic image was extracted to coincide with the geographic area of the USFWS NWI maps. A mask was generated by the union of all wetland classes from the USFWS NWI maps and all wetland classes from the thematic layer. The mask was used to extract all pixels from the thematic layer that were classified as, or had a high probability of actually being, wetland on the ground. Pixels extracted by the masking procedure encompassed all areas once classified as wetland by the USFWS. The potential wetland areas were united with all pixels classified as wetland by the 1990 C-CAP interpretation. The result included areas of the $1990 \mathrm{C}$-CAP classification layer where omission and commission are most likely to occur. What is not included in the union are possible wetland areas not detected by the USFWS NWI and not detected by the C-CAP classification of the TM subset.

Fifty-six sample sites were field checked to determine the accuracy of wetland classes. The samples were generated from a random sample set of $1503 \times 3$ pixel blocks using the RANDCAT algorithm applied to the union of wetland areas from the C-CAP classification and the USFWS NWI maps. Only the homogeneous $3 \times 3$ pixel blocks were field checked. The coordinates of the $563 \times 3$ pixel blocks were plotted at 1:24,000 scale. The plot was used as an overlay on the USGS Moss Landing and Prunedale quadrangles, and taken into the field.

Field checking was conducted in November and December of 1993 using a Trimble Navigation 4000 series differential Global Positioning System (GPS) and conventional field techniques (Kvitek 1993). Ten of the 56 sample locations were located with the 
assistance of a GPS. Conventional field techniques using a compass, topographic quadrangles, and an engineering scale were used to orient to the remaining 46 sample points.

The GPS was mounted in the bed of a pickup truck and connected to a laptop computer in the cab. Coordinates of the center pixel of each sample block were downloaded to the laptop computer and plotted on the screen. Real-time differential GPS coordinates were also plotted, making it possible to drive to the sample block site. Accuracy of the GPS unit in differential mode was assumed to be $\pm 5 \mathrm{~m}$ based on manufacturer's documentation (Kvitek 1993). No sample points were accessible by truck. Therefore, the GPS was driven to the nearest accessible location. From the truck, site visits were measured by meter tape, paces, or estimated depending on the degree of access difficulty. Consequently, positional error for field checked sample pixels can range from \pm $5 \mathrm{~m}$ to $\pm 28.5 \mathrm{~m}$.

Assessments of the classification accuracy for the USFWS NWI and Dickert et al. (1980) data sets were not known to exist. Although the USFWS NWI data was originally considered highly reliable, no quantitative assessment for the Moss Landing and Prunedale USFWS NWI overlays was available. However, the use of black and white aerial photography at 1: 80,000 indicated that the separation of wetland habitats based on vegetative cover was limited. Furthermore, the Dickert et al. (1980) classification accuracy was also unknown. No information on an accuracy assessment for the 1980 data was found.

\subsection{Wetland Gain and Loss Comparison Maps Using a Land Cover Change Matrix}

A land cover change detection matrix enables a geographically and categorically specific comparison of habitat change over multiple dates of land cover data. Maps convey the spatial relationship of land cover changes that tabular data cannot. Specific types of 
change, such as palustrine emergent wetland to cultivated land, can be displayed and quantified. The change detection matrices were used to produce wetland gain and loss comparison maps between the USFWS NWI maps and the C-CAP classification, as well as the Dickert et al. (1980) data and C-CAP classification of the Elkhom Slough watershed.

The change matrix comparison of the USFWS NWI maps to the C-CAP classification was used to construct a map of wetland changes between 1972 and 1990 . Wetland gains were geographically shown by selecting all classes in the matrix representing a change from an upland or water class to wetland classes. Pixels corresponding to the selected matrix cells were highlight by changing their color look-up table. Wetland losses were shown by selecting and highlighting all classes in the matrix representing a change from wetland classes to upland classes. Submerged wetlands were geographically shown by selecting and highlighting matrix cells representing wetland to water classes.

Submerged new wetlands were geographically shown by selecting and highlighting matrix cells that changed from upland to water classes.

The change matrix comparison of the Dickert et al. (1980) land cover to the C-CAP classification was used to a construct map of wetland changes between 1980 and 1990 . The map was color coded using the same highlighting techniques described for the comparison of the USFWS NWI to the C-CAP data. 


\section{CHAPTER 3}

\section{RESULTS}

\subsection{Introduction}

The products of this study were digital data files generated during the transformation, classification, and change comparison of land cover data. Results presented in this chapter include: 1) images of the data, 2) tables of the data, 3) land cover change matrices, 4) the geographic coordinates of ground observation data, and 5) wetland area gain and loss maps. Results of the overall classification accuracy assessment, the wetland classification accuracy assessment, and the positional accuracy assessment are also presented.

\subsection{Data Processing}

A subregion was extracted from the fult TM image data captured June 20, 1990 (figure 3-1). The geographic area of the subregion, which contained no clouds or haze, extended beyond the Elkhom Slough watershed boundaries defined by Dickert $e t$ al. (1980). The approximate latitude and longitude coordinates for the area were $36^{\circ} 45^{\prime} 0^{\prime \prime} \mathrm{N}$ to $36^{\circ} 53^{\prime} 0^{\prime \prime} \mathrm{N}$, and $121^{\circ} 37^{\prime} 0^{\prime \prime} \mathrm{W}$ to $121^{\circ} 45^{\prime} 30^{\prime \prime} \mathrm{W}$. The exact geographic boundaries of the TM subregion in UTM zone 10 Northern Hemisphere coordinates, NAD 1927, were lower-left $606604 \mathrm{mE}, 4066843.5 \mathrm{mN}$ and upper-right $629603.5 \mathrm{mE}, 4084684.5 \mathrm{mN}$.

The area contains $410 \mathrm{~km}^{2}$ including Watsonville south to Castroville; then, inland to San Juan Bautista. The land cover in the subregion is primarily rural and undeveloped, with a few urban and suburban areas. Vegetated and non-vegetated sand dunes stretch along the coastline. Cultivated land and grassland dominate the lower elevations of the 
Figure 3-1. The TM subregion extracted for the study. TM bands 4, 3, and $2=\mathrm{RGB}$ are shown as a false color infrared image. Lush, green vegetation, such as cropland, appears as bright red. Senescent vegetation, such as grassland, appears as blue-green. Water appears as blue. Trees and some wetlands appear as dark red. High reflectance areas, such as sand or urban areas, appear as gray or white. 


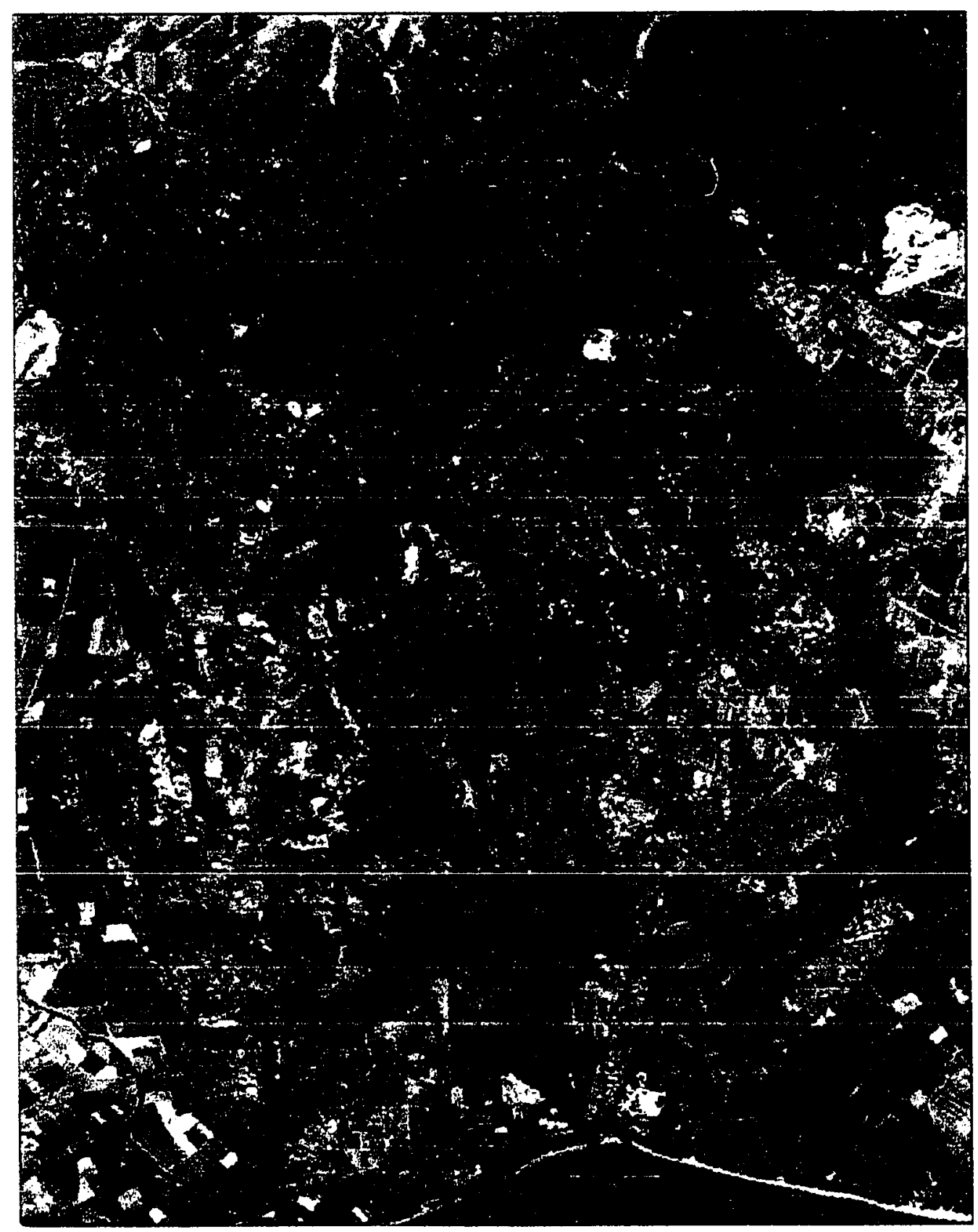


watershed. Grasslands and row crops abutt coastal woodland and oak savanna habitats eastward over the rolling hills into the Santa Clara valley.

The Elkhorn slough is the large water body stretching inland in the shape of an Elkhorn (figure 3-1). It begins at the Moss Landing Harbor and winds $17.7 \mathrm{~km}$ inland to the Carneros Creek. Moss Landing Harbor runs north-south, perpendicular to the Elkhorn Slough. At the southem end of the harbor, the Moro Cojo Slough begins and stretches inland in a southeast direction. Most of the Moro Cojo Slough does not contain surface water. The Elkhom Slough watershed covers at least two-thirds of the TM subregion, and extends from Moss Land Harbor south to Castroville, east to San Juan Bautista and north toward Watsonville.

Classification of the TM subregion using the C-CAP scheme resulted in 12 C-CAP classes (see table 2-1). The 1990 C-CAP classification of the TM subregion is shown in figure 3-2. The classes 1.2 Cultivated Land, 1.3 Grassland, and 1.4 Woody Land covered $84.87 \%$ of the TM subregion. Class 1.2 Cultivated Land contained 10,957 ha primarily in the western area near the coastal and valley lowlands. Class 1.3 Grassland contained 13,816 ha distributed mainly in the eastern area of the subregion. Coastal scrub and forested lands of class 1.4 Woody Land covered 10,148 ha in the center of the subregion. Developed Land classes and 1.5 Bare Land covered 8.25\%. All wetland classes, including 2.23 Mud/Organic and 2.22 sand, covered $4.14 \%$ of the image. The remaining $2.74 \%$ was covered by water. Number of pixels and land area in hectares for each class listed in table 2-1 are shown in table $3-1$.

\subsubsection{Vector to Raster Conversion of USFWS NWI Maps of Moss Landing and} Prunedale Quadrangles

The USFWS NWI quadrangle map overlays represented the extent of the Elkhorn Slough watershed wetland area for 1972 , as determined by the USFWS. The wetland area 
Figure 3-2. C-CAP Classification Map of TM data 


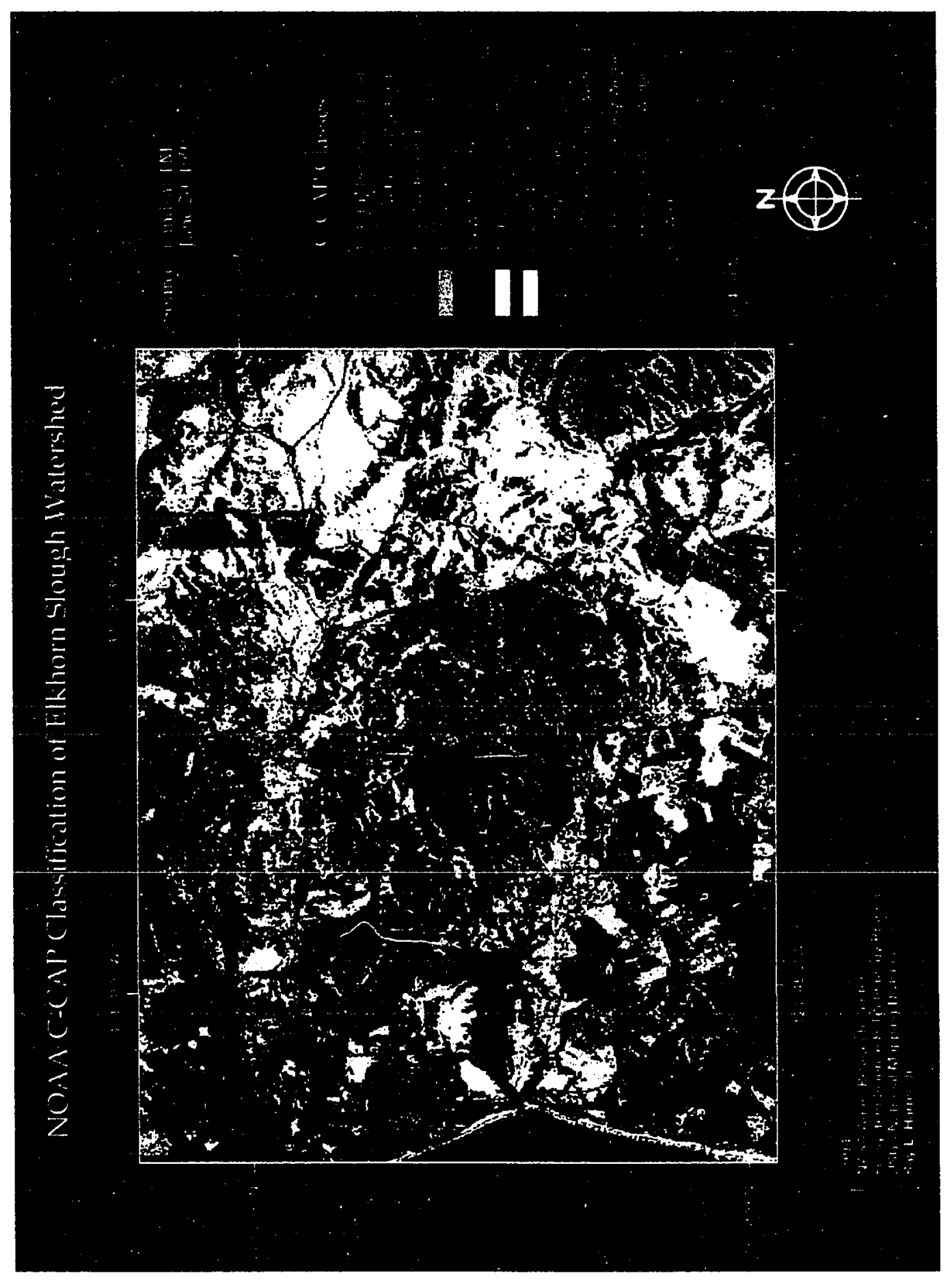


Table 3-1. Number of Pixels and Land Area in the 1990 C-CAP Classification

\begin{tabular}{|c|c|c|c|}
\hline $\begin{array}{ll}\text { Class\# } & \text { Class Name } \\
\end{array}$ & Pixels & 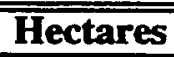 & Percent \\
\hline 1.11 High Density Dev. Land & 17,367 & 1410.63 & $3.43 \%$ \\
\hline 1.12 Low Density Dev. Land & 15,422 & 1252.65 & $3.04 \%$ \\
\hline 1.2 Cultivated Land & 134,893 & 10956.68 & $26.63 \%$ \\
\hline 1.3 Grassland & 170,100 & 13816.37 & $33.58 \%$ \\
\hline 1.4 Woody Land & 124,943 & 10148.50 & $24.66 \%$ \\
\hline 1.5 Bare Land & 8,998 & 730.86 & $1.78 \%$ \\
\hline 2.22 Sand & 1,129 & 91.70 & $0.22 \%$ \\
\hline 2.23 Mud/Organic & 1,744 & 141.66 & $0.34 \%$ \\
\hline 2.3 Estuarine Emergent Wetland & 9,375 & 761.48 & $1.85 \%$ \\
\hline 2.8 Palustrine Emergent Wetlanc & 4,519 & 367.06 & $0.89 \%$ \\
\hline 2.9 Palustrine Woody Wetland & 4,234 & 343.91 & $0.84 \%$ \\
\hline 3.1 Water & 13,887 & 1127.97 & $2.74 \%$ \\
\hline Total & 506,611 & 41149.48 & $100.00 \%$ \\
\hline
\end{tabular}


was dominated by estuarine habitat (figure 3-3). However, large areas of wetland were classified as palustrine by the USFWS. No information on the classification decision methodology for estuarine or palustrine wetland, nor the classification accuracy, were available for the USFWS NWI data. Nonetheless, some common themes emerged: 1) all palustrine areas in the Elkhorn Slough occurred on the shoreward side of tidal gates and dikes bisecting the slough, and 2) abrupt transitions between estuarine and palustrine wetland areas occurred at dikes or tidal gates (figure 3-3). This indicated that tidal gates were the interpreted boundary between saltwater and fresh water.

The vegetation of the Elkhorn Slough and Moro Cojo Slough exhibited a saltwater/freshwater gradient not limited to dikes and tidal gates. The Elkhorn Slough was bisected by an elevated railroad that did not represent a boundary between salt and freshwater (De Vogelaere 1993). The Moro Cojo Slough, just south of the Elkhorn Slough, was defined by the USFWS as palustrine. This classification was also doubtful. Therefore, USFWS interpretation of these tidal gates and dikes as boundaries between saltwater and freshwater presented classification problems.

The USFWS NWI Moss Landing and Prunedale quadrangle overlays were intersected with the 1990 TM subregion. The geographic coordinates of the intersection in UTM, zone 10 Northern Hemisphere, NAD 1927, were lower-left $606604 \mathrm{mE}, 4067841$ $\mathrm{mN}$ and upper-right $622763.5 \mathrm{mE}, 4081492.5 \mathrm{mN}$. This area included all of the sloughs in the Elkhorn Slough watershed study area, and was the area used in the change detection algorithm. It did not completely encompass the geographic bounds of the Moss Landing quadrangle because the western portion of the quandrangle boundary extends farther into the Pacific Ocean than the TM subregion extraction. The USFWS NWI Moss Landing and Prunedale quadrangles latitude, longitude boundaries, were slightly incongruent to the UTM boundary of the TM subregion because of the different grid projections. The TM subregion is 557 pixels larger than the USFWS NWI Moss Landing and Prunedale 
Figure 3-3. USFWS NWI overlays for Moss Landing and Prunedale quadrangles converted to raster format and colored by class order. Red indicates palustrine, or freshwater, areas. Orange indicates palustrine open water, mainly irrigation ponds. Brown is estuarine intertidal emergent wetland. Blue and shades of light blue show marine, estuarine, or riverine open water. Gray and white are estuarine unconsolidated bottoms. Purple and cyan are palustrine forested wetlands. Green is estuarine subtidal area. Black indicates no data. 


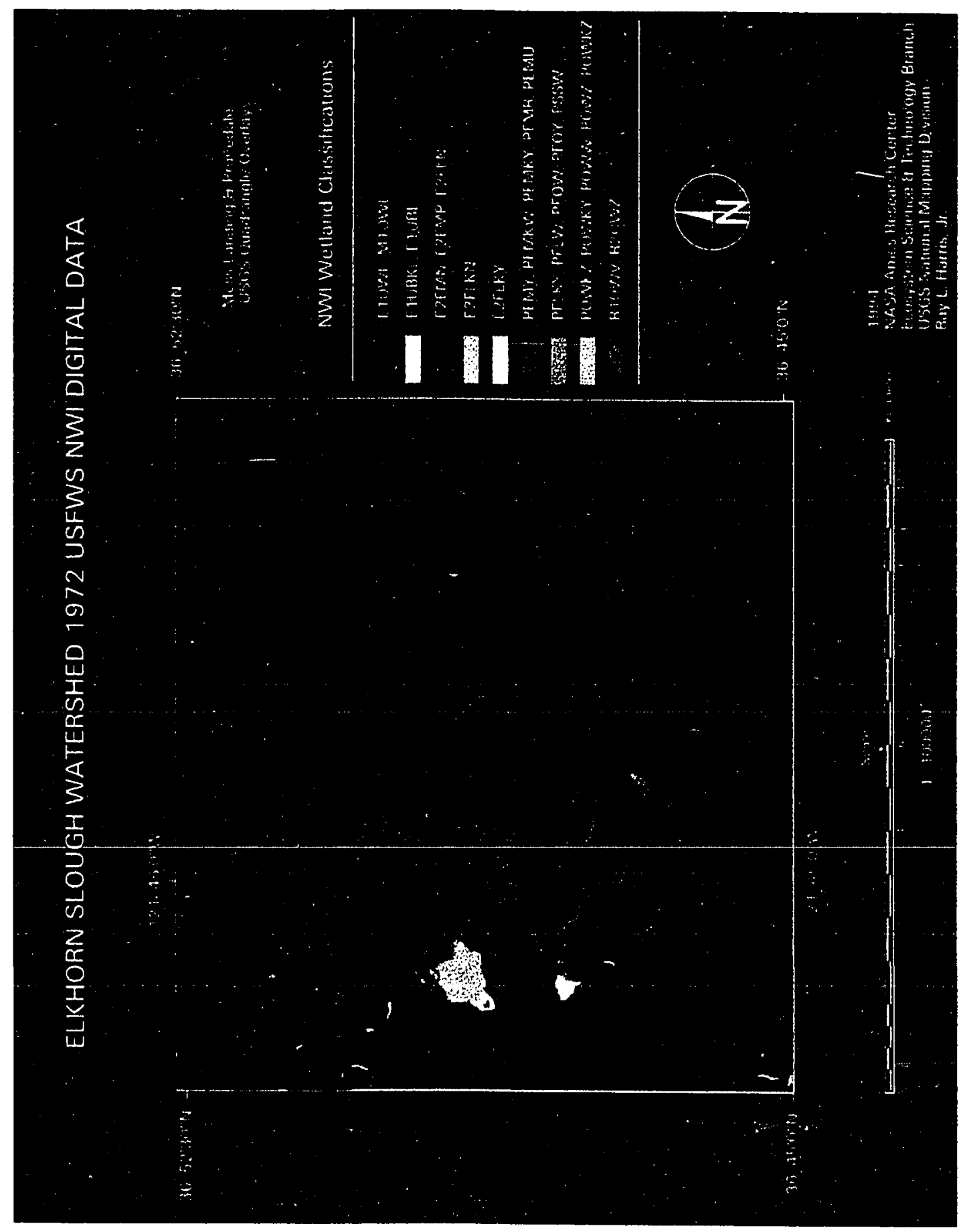


quandrangle subset to accommodate their orientation. Number of pixels and land area in hectares of USFWS NWI classes for the intersection are shown in table 3-2. The USFWS NWI polygon labels are key codes derived from the USFWS wetland classification scheme (Cowardin et al. 1979). A key to interpret the class code is in Appendix B.

The USFWS NWI classes were translated to C-CAP classes (table 3-2). The translated area contained 6 C-CAP classes: $2.23 \mathrm{Mud} / \mathrm{Organic}, 2.22 \mathrm{Sand}$, 2.3 Estuarine Emergent Wetland, 2.8 Palustrine Emergent Wetland, 2.9 Palustrine Woody Wetland, and 3.1 Water. A background, or no data, class represented areas without data. The relatively small amount of wetland area was evident in a comparison of these classes with the background area. The 6 C-CAP class containing all the 1972 USFWS NWI data contained $11.09 \%$ of the USFWS NWI rasterized subset area. Water contained $5.38 \%$ of the area. Therefore, the wetland area was only $5.71 \%$ of the area covered in the subset. The background covered $88.91 \%$ of the area.

\subsubsection{Conversion, Class Translation, and Resampling of Dickert et al. Data}

The Dickert et al. (1980) land cover classes were translated to C-CAP classes (see table 2-3). The original digital data were generalized at $50 \mathrm{~m}$ per pixel resulting in large, homogenous areas of land cover. This was an effect of the translation of the Dickert et al. (1980) classification scheme to the C-CAP classification scheme when residential density unit measures were dropped. The incompatibility of the classification schemes, the $50 \mathrm{~m}$ per pixel resolution, and the digitization of the data limited its utility in a comparison with the 1990 C-CAP data. Figure 3-4, colored according to the C-CAP classification legend in figure 3-2, shows the Dickert et al. (1980) data after the translation and the image-to-image rectification with the TM data.

The Dickert et al. (1980) data represented land cover of wetland and upland areas in the Elkhom Slough watershed in 1980 . The land cover data contained 72 classes from 
Table 3-2. Number of Pixels and Land Area of USFWS NWI Classes

\begin{tabular}{|c|c|c|c|c|}
\hline NWI Class & C-CAP Class & $\overline{\text { Pixels }}$ & Hectares & Percent \\
\hline Background & OBackground & 247,904 & 20136.00 & $88.91 \%$ \\
\hline E1UBKL & 2.23 Mud (marine/estuarine) & 156 & 12.67 & $0.06 \%$ \\
\hline EIUBL & " & 78 & 6.34 & $0.03 \%$ \\
\hline E2EMN & 2.3 Estuarine Emergent Wetland & 4,214 & 342.28 & $1.51 \%$ \\
\hline E2EMP & 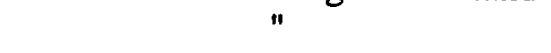 & 770 & 62.54 & $0.28 \%$ \\
\hline E2FLKN & " & 1,351 & 109.74 & $0.48 \%$ \\
\hline E2FLN & $"$ & 28 & 2.27 & $0.01 \%$ \\
\hline P2FLKY & 2.8 Palustrine Emergent Wetland & 5 & 0.41 & $0.00 \%$ \\
\hline PEMKW & $"$ & 4 & 0.33 & $0.00 \%$ \\
\hline PEMKY & $"$ & 37 & 3.01 & $0.01 \%$ \\
\hline PEMR & $"$ & 679 & 55.15 & $0.24 \%$ \\
\hline PEMU & $"$ & 24 & 1.95 & $0.01 \%$ \\
\hline PEMW & " & 7 & 0.57 & $0.00 \%$ \\
\hline PEMY & $"$ & 7,428 & 603.34 & $2.66 \%$ \\
\hline PFLKY & " & 53 & 4.31 & $0.02 \%$ \\
\hline PFLW & $"$ & 3 & 0.24 & $0.00 \%$ \\
\hline POWKY & $"$ & 360 & 29.24 & $0.13 \%$ \\
\hline POWKZ & $"$ & 11 & 0.89 & $0.00 \%$ \\
\hline POWW & $"$ & 2 & 0.16 & $0.00 \%$ \\
\hline POWZ & $"$ & 142 & 11.53 & $0.05 \%$ \\
\hline POWZK & $"$ & 31 & 2.52 & $0.01 \%$ \\
\hline PFOW & 2.9 Palustrine Woody Wetland & 69 & 5.61 & $0.02 \%$ \\
\hline PFOY & $"$ & 188 & 15.27 & $0.07 \%$ \\
\hline PSSW & $"$ & 2 & 0.16 & $0.00 \%$ \\
\hline PSSY & $"$ & 257 & 20.88 & $0.09 \%$ \\
\hline E1OWL & 3.1 Water & 3,871 & 314.42 & $1.39 \%$ \\
\hline L2FLKY & $"$ & 216 & 17.55 & $0.08 \%$ \\
\hline M1OWL & $"$ & 10,462 & 849.78 & $3.75 \%$ \\
\hline R1OWV & $"$ & 317 & 25.75 & $0.11 \%$ \\
\hline R2OWZ & " & 148 & 12.02 & $0.05 \%$ \\
\hline & Totals & 278,817 & 22646.91 & $100.00 \%$ \\
\hline
\end{tabular}

Note: Class names are USFWS NWI key codes from Appendix B. 
Figure 3-4. The Dickert et al. (1980) Land Cover Data Translated to the CCAP Classification. Colors match the C-CAP Map in figure 3-2. 


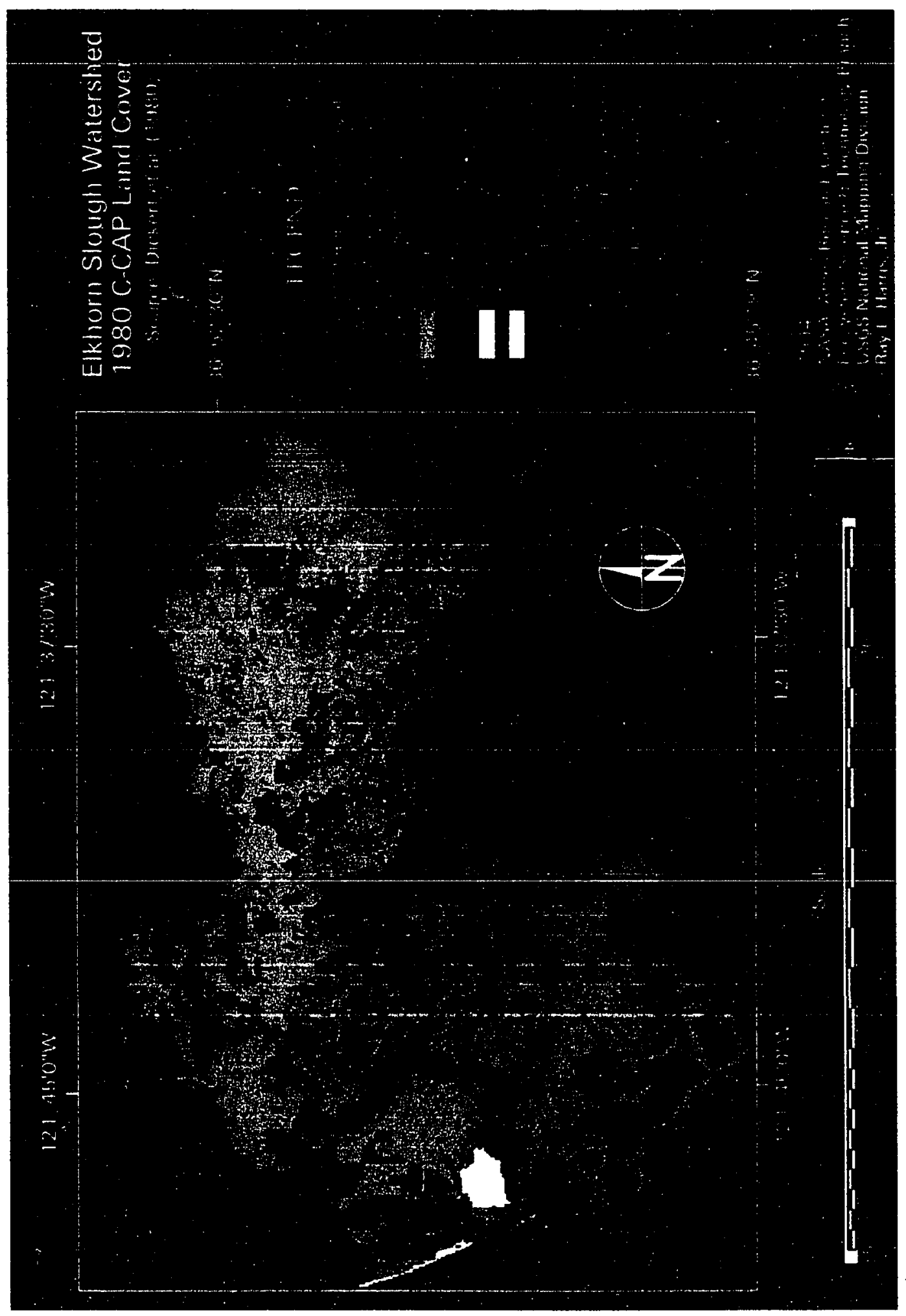


their Technical Appendix C-VII Land Use - Elkhorn Slough Watershed Part I - Acreages

(Dickert et al. 1980). Most of the 72 classes (shown in table 3-3) had numbers adjacent to the class names. The numbers indicated a residential density unit measure, assigned by Dickert et al. (1980), for each of the vegetation classes found in their technical appendix. Residential density units were estimated by counting rooftops and calculating dwelling units per acre of land cover class. For example, in table 3-3, Grassland - 0.21 (AH) indicated grassland land cover with 0.21 dwelling units per acre. Totals in the digital GRASS land cover layer were not exactly equal to their published appendix. Therefore, discrepancies were found between the digitized GRASS land cover information and the published appendix (Dickert et al. 1980). However, the differences were not significant.

The residential density unit numbers assigned to land cover classes in Dickert $e t$ al. (1980) were not translated to a corresponding C-CAP class for this study. Two reasons prevented the translation: 1) Dickert et al. (1980) did not state an average area for roofs counted, and 2) the residential density unit calculation did not account for other construction materials, such as concrete or asphalt, that also covered a percentage of an acre beyond the ". rops. The C-CAP protocol required estimates of all constructed material surfaces. Therefore, the residential density unit range was ignored in favor of the dominant land cover (e.g. Grassland - 0.21 (AH) was translated to C-CAP as 1.3 Grassland). The inability to translate the Dickert et al. (1980) residential density unit measure to a C-CAP low density developed land class was a problem that effectively rendered the change detection comparison of low density developed land invalid.

\subsection{Accuracy Assessment}

\subsubsection{Positional Accuracy Assessment}

The RMSE for the TM subregion (figure 3-1) did not meet the C-CAP positional accuracy requirement RMSE of \pm 0.5 pixel. The RMSE of the TM subregion was 
Table 3-3. Dickert et al. (1980) Land Cover Classes

\begin{tabular}{|c|c|c|c|c|}
\hline Dickert et al Class & C-CAP Class & Pixels & Hectares & Percent \\
\hline Background & 0 & 4,613 & $1,153.25$ & $8.11 \%$ \\
\hline Brushland - 0 (A) & 1.4 & 5,089 & $1,272.25$ & $8.94 \%$ \\
\hline Brushland -0.001 (A) & $"$ & 67 & 16.75 & $0.12 \%$ \\
\hline Brushland - 0.033 (A) & " & 8 & 2.00 & $0.01 \%$ \\
\hline Brushland - 0.65 (A) & " & 80 & 20.00 & $0.14 \%$ \\
\hline Brushland - 0.11 (A) & n & 81 & 20.25 & $0.14 \%$ \\
\hline Brushland - $0.21(\mathrm{~A})$ & " & 153 & 38.25 & $0.27 \%$ \\
\hline Brushland - 0.42 (A) & $"$ & 401 & 100.25 & $0.70 \%$ \\
\hline Brushland - 1.1 (A) & " & 22 & 5.50 & $0.04 \%$ \\
\hline Grassland - $\mathbf{0}(\mathrm{AH})$ & 1.3 & 18,696 & $4,674.00$ & $32.86 \%$ \\
\hline Grassland - $0.001(\mathrm{AH})$ & " & 4,024 & $1,006.00$ & $7.07 \%$ \\
\hline Grassland - $0.02(\mathrm{AH})$ & " & 1,314 & 328.50 & $2.31 \%$ \\
\hline Grassland $-0.033(\mathrm{AH})$ & $"$ & 1,085 & 271.25 & $1.91 \%$ \\
\hline Grassland $-0.065(\mathrm{AH})$ & " & 1,404 & 351.00 & $2.47 \%$ \\
\hline Grassland - $0.11(\mathrm{AH})$ & $"$ & 2,240 & 560.00 & $3.94 \%$ \\
\hline Grassland $-0.21(\mathrm{AH})$ & " & 1,301 & 325.25 & $2.29 \%$ \\
\hline Grassland - $0.42(\mathrm{AH})$ & " & 2,554 & 638.50 & $4.49 \%$ \\
\hline Grassland - 1.1 (AH) & " & 869 & 217.25 & $1.53 \%$ \\
\hline Grassland - $2.2(\mathrm{AH})$ & n & 151 & 37.75 & $0.27 \%$ \\
\hline Grassland $-4.0+(A H)$ & " & 47 & 11.75 & $0.08 \%$ \\
\hline Row crops -0.001 (AR) & 1.2 & 1,709 & 427.25 & $3.00 \%$ \\
\hline Row crops -0.033 (AR) & $"$ & 846 & 211.50 & $1.49 \%$ \\
\hline Row crops -0.065 (AR) & " & 1,514 & 378.50 & $2.66 \%$ \\
\hline Row crops - 0.11 (AR) & " & 76 & 19.00 & $0.13 \%$ \\
\hline Row crops - 0.21 (AR) & $"$ & 16 & 4.00 & $0.03 \%$ \\
\hline Row crops - 0.42 (AR) & n & 29 & 7.25 & $0.05 \%$ \\
\hline Row crops - 0 (AR) & " & 3,796 & 949.00 & $6.67 \%$ \\
\hline Strawberries - 0 (AS) & $"$ & 2,908 & 727.00 & $5.11 \%$ \\
\hline Strawberries - 0.001 (AS) & $"$ & 805 & 201.25 & $1.41 \%$ \\
\hline Strawberries - 0.02 (AS) & $"$ & 75 & 18.75 & $0.13 \%$ \\
\hline Strawberries - 0.065 (AS) & " & 112 & 28.00 & $0.20 \%$ \\
\hline Strawberries - 0.11 (AS) & $n$ & 17 & 4.25 & $0.03 \%$ \\
\hline Strawberries - 0.21 (AS) & $n$ & 17 & 4.25 & $0.03 \%$ \\
\hline Railroad (RR) & 1.11 & 167 & 41.75 & $0.29 \%$ \\
\hline Salt pond (SALT PON) & 1.5 & 483 & 120.75 & $0.85 \%$ \\
\hline Sand (SAND) & 2.22 & 14 & 3.50 & $0.02 \%$ \\
\hline School (SCHOOL) & 1.11 & 119 & 29.75 & $0.21 \%$ \\
\hline
\end{tabular}


Table 3-3. Dickert et al.(1980) Land Cover Classes (continued)

\begin{tabular}{|c|c|c|c|c|}
\hline Dickert et al Class & C-CAP Class & Pixels & Hectares & Percent \\
\hline Oak brushiand - 0.001 (B) & 1.4 & 259 & 64.75 & $0.46 \%$ \\
\hline Oak brushland $-0.065(\mathrm{~B})$ & $n$ & 45 & 11.25 & $0.08 \%$ \\
\hline Oak brushland - 0.11 (B) & n & 311 & 77.75 & $0.55 \%$ \\
\hline Oak brushland -0.21 (B) & n & 151 & 37.75 & $0.27 \%$ \\
\hline Oak brushland $-0.42(\mathrm{~B})$ & " & 413 & 103.25 & $0.73 \%$ \\
\hline Oak brushland - 1.1 (B) & $n$ & 306 & 76.50 & $0.54 \%$ \\
\hline Oak brushland - $2.2(\mathrm{~B})$ & " & 59 & 14.75 & $0.10 \%$ \\
\hline Oak brushland - 0 (B) & $n$ & 8,986 & $2,246.50$ & $15.79 \%$ \\
\hline Bare ground (BG) & 1.5 & 76 & 19.00 & $0.13 \%$ \\
\hline Commercial (C) & 1.11 & 890 & 222.50 & $1.56 \%$ \\
\hline Alluvial fans (F) & 1.3 & 40 & 10.00 & $0.07 \%$ \\
\hline Highway (HWY) & 1.11 & 35 & 8.75 & $0.06 \%$ \\
\hline Industrial (I) & $n$ & 526 & 131.50 & $0.92 \%$ \\
\hline Mud flats (MUD) & 2.23 & 609 & 152.25 & $1.07 \%$ \\
\hline Eucalyptus - 0 (D) & 1.4 & 2,111 & 527.75 & $3.71 \%$ \\
\hline Eucalyptus - 0.11 (D) & $n$ & 88 & 22.00 & $0.15 \%$ \\
\hline Eucalyptus - 0.42 (D) & n & 8 & 2.00 & $0.01 \%$ \\
\hline Eucalyptus - O (D) & n & 124 & 31.00 & $0.22 \%$ \\
\hline Orchard - $0(0)$ & 1.2 & 214 & 53.50 & $0.38 \%$ \\
\hline Orchard - $0.065(0)$ & n & 10 & 2.50 & $0.02 \%$ \\
\hline Orchard - $0.11(0)$ & n & 59 & 14.75 & $0.10 \%$ \\
\hline Orchard - $0.21(\mathrm{O})$ & " & 25 & 6.25 & $0.04 \%$ \\
\hline Open water (OW) & 3.1 & 1,370 & 342.50 & $2.41 \%$ \\
\hline Sand dune land (SDL) & 2.22 & 128 & 32.00 & $0.22 \%$ \\
\hline Salicornia (S1) & 2.3 & 1,203 & 300.75 & $2.11 \%$ \\
\hline Salicornia (S2) & "n & 187 & 46.75 & $0.33 \%$ \\
\hline Salicornia (S3) & " & 102 & 25.50 & $0.18 \%$ \\
\hline Salicornia (S4) & " & 224 & 56.00 & $0.39 \%$ \\
\hline Urban - 2.2 (URB) & 1.11 & 413 & 103.25 & $0.73 \%$ \\
\hline Urban - 4.0+ (URB) & 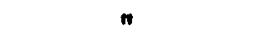 & 414 & 103.50 & $0.73 \%$ \\
\hline Wet Grassland (WGC) & 2.8 & 174 & 43.50 & $0.31 \%$ \\
\hline Wet Grassland (WG1) & 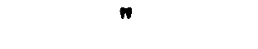 & 883 & 220.75 & $1.55 \%$ \\
\hline Wet Grassland (WG3) & 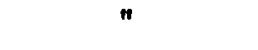 & 72 & 18.00 & $0.13 \%$ \\
\hline Wet Grassland (WG5) & 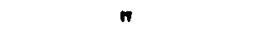 & 270 & 67.50 & $0.47 \%$ \\
\hline Wet Grassland (WG) & $"$ & 3 & 0.75 & $0.01 \%$ \\
\hline & Totals & 56,902 & $14,225.50$ & $100.00 \%$ \\
\hline
\end{tabular}

Source: Dickert et al.(1980) Land Cover Data Digital File 
$\pm 14.342341 \mathrm{~m}$ for a $28.5 \mathrm{~m}$ pixel. Therefore, the RMSE was \pm 0.50324 pixels. However, no resampling of the TM subset data was performed. The positional accuracy assessment was performed with a limited number of ground control points in the lower elevations of the study area that may have biased that accuracy result. The UTM Zone 10 Northem Hemisphere coordinates, NAD 27, ground control point coordinates and the image control point coordinates for the points used in the calculation are shown in table 3-4.

\subsubsection{Classification Accuracy Assessment}

The C-CAP classification of TM data exceeded the $85 \%$ accuracy requirement adopted from Jensen et al. (1993). The overall classification accuracy of the TM subregion was $90.58 \%$ using 191 sample points compared with aerial photographs (table 3-5). The overall accuracy was $86.84 \%$ at the $95 \%$ lower confidence limit.

Most of the C-CAP classes containing $85 \%$ of the land area exceeded the $85 \%$ accuracy requirement. Class 1.4 Woody Land accuracy at the $95 \%$ lower confidence limit was $96.18 \%$ for errors of commission and $89.37 \%$ for errors of omission. Class 1.3 Grassland accuracy at the $95 \%$ lower confidence limit was $91.46 \%$ for errors of commission and $91.46 \%$ for errors of omission. Class 1.2 Cultivated Land, at $76.97 \%$, did not meet the accuracy requirement for errors of commission. It did meet the requirement for errors of omission with a $90.61 \%$ accuracy at the $95 \%$ lower confidence limit. Class 1.2 Cultivated Land was confused with 2.3 Estuarine Emergent Wetland, 1.4 Woody Land, 1.3 Grassland, and 1.12 Low Density Developed Land. Class 3.0 Water was confused with 1.4 Woody Land.

Samples from the remaining classes contributed relatively little to the overall accuracy. Some of the small area classes did exceed the classification accuracy requirement, but the calculation was based on 1 or 2 sample points. Reliable assessments could not be drawn. These classes included wetland classes, but wetland areas accounted 


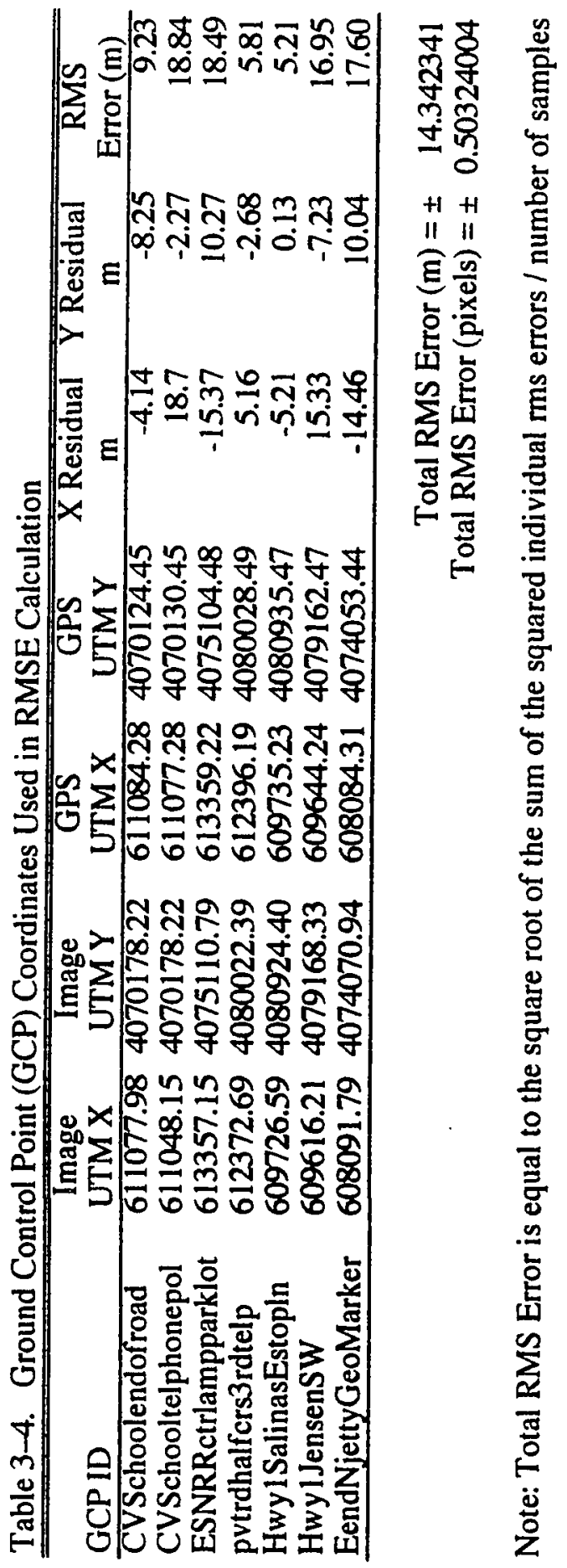


7uT 'juoJ JəMoT \%S6

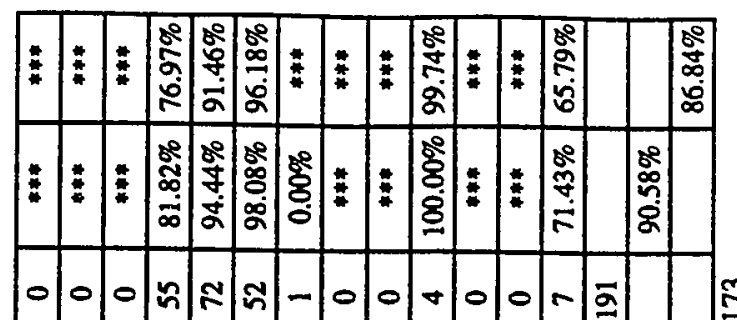

[ETOL MOY

purnaM Кро0 M aụnsnifd $6 \%$

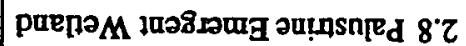

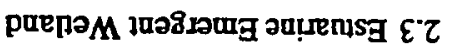

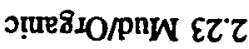

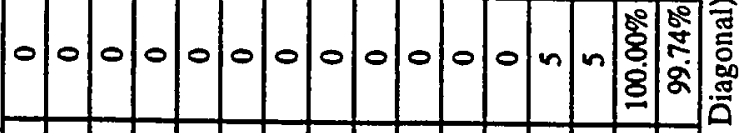

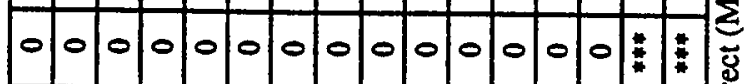

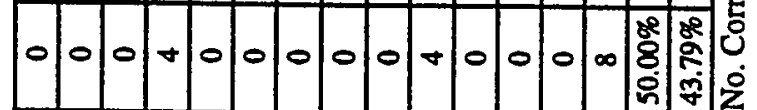

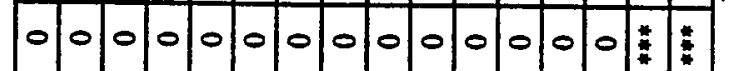
purs $z \tau\ulcorner$ pure T areg $\varsigma$ I

pur] KpooM $\bullet \cdot I$

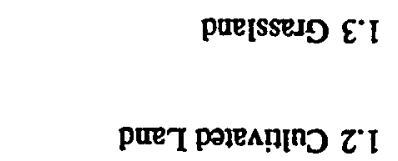

递

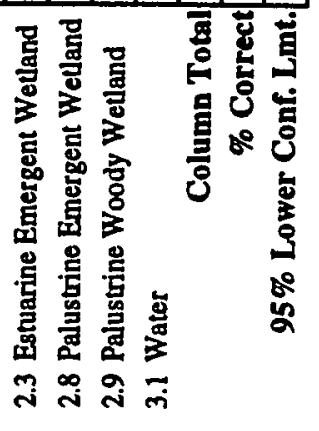


for only $4 \%$ of the total land area of the subregion. The small number of samples points for wetland areas could not be relied upon for accuracy measurements.

The classification accuracy of wetland classes was evaluated separately. Overall wetland classification accuracy was $76.79 \%$ (table 3-6). The overal accuracy was $66.62 \%$ at the $95 \%$ lower confidence limit. Therefore, classification accuracy of a stratified random sample of 56 ground observation points (table 3-7) in wetland areas did not exceed the $85 \%$ accuracy requirement.

Some of the wetland classes did exceed the accuracy requirement. Class 2.3 Estuarine Emergent Wetland accuracy was $100.00 \%$ for errors of commission and $72.09 \%$ for errors of omission. The accuracy was $99.11 \%$ at the $95 \%$ lower confidence limit for errors of commission and $61.34 \%$ at the $95 \%$ lower confidence limit for errors of omission. Class 2.9 Palustrine Emergent wetland accuracy was $1.08 \%$ at the $95 \%$ lower confidence limit for errors of commission and 38.12\% at the $95 \%$ lower confidence limit for errors of omission. This means that the C-CAP classification incorrectly labeled 10 of 11 samples for the errors of commission, and omitted 1 of 2 samples for errors of ommission.

The accuracy table showed confusion between the estuarine and palustrine wetland classes (table 3-6). Ten samples in the C-CAP classification were actually 2.3 Estuarine Emergent Wetland from ground observation data. Separation between saltwater marsh and freshwater marsh was not successful in the classification of the TM subregion data. Therefore, the sample points for estuarine and palustrine classes were combined and evaluated.

The 85\% accuracy requirement for this study was exceeded when the estuarine and palustrine emergent wetland classes were aggregated. The overall wetland classification accuracy increased to $88.80 \%$ at $95 \%$ lower confidence limit. The new class, 2.0.1 Emergent Wetland accuracy was $99.11 \%$ at the $95 \%$ lower confidence limit for errors of 


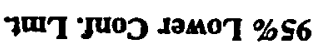

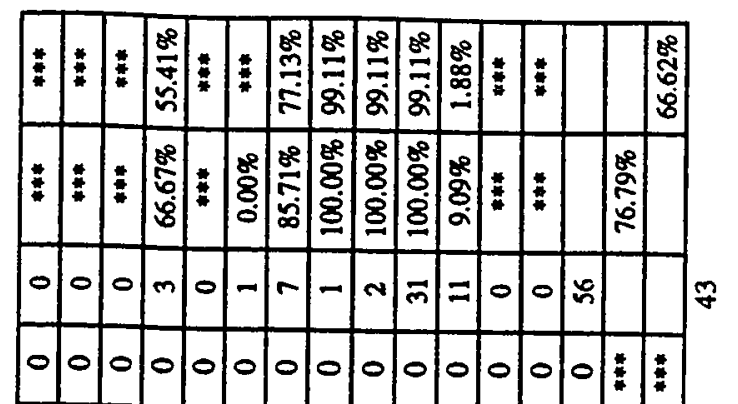

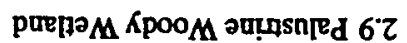

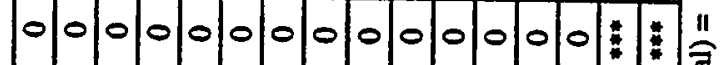

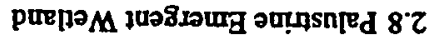

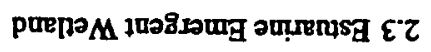

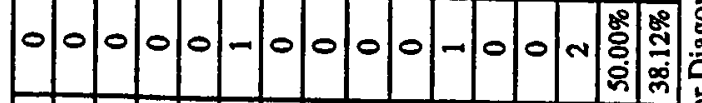

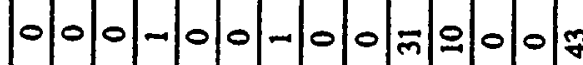

วฺฺนมีว

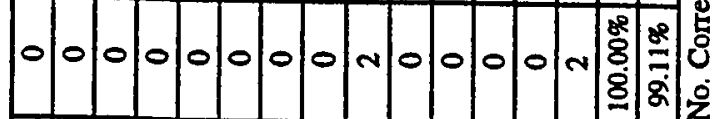

purs $z 2 \tau$

00000000000000

8

риет атя $\varsigma$ I

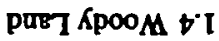

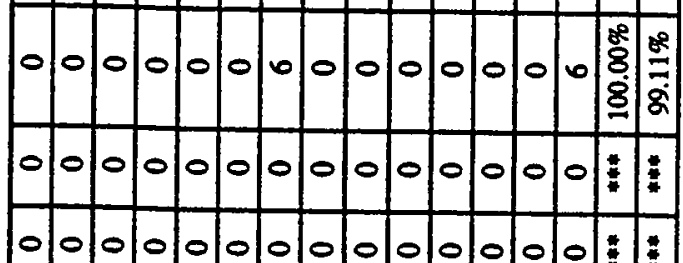

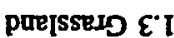

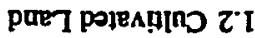

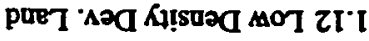

1101000

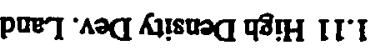

- $0000000000000001:$

0000000000000000

punarsygeg 0

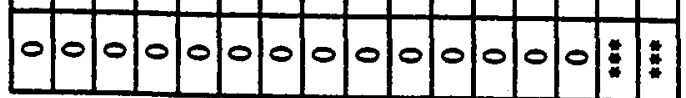

苟

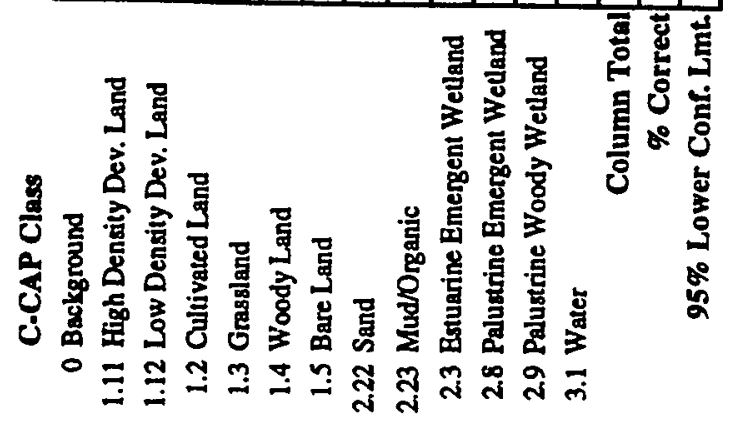


Table 3-7. Coordinates and Class of Ground Observation Samples

\begin{tabular}{ccccc}
\hline $\begin{array}{c}\text { Sample Point } \\
\text { Number }\end{array}$ & UTM X & UTM Y & $\begin{array}{c}\text { C-CAP } \\
\text { Class no. }\end{array}$ & $\begin{array}{c}\text { Reference } \\
\text { Class no. }\end{array}$ \\
\hline 2 & 611192.50 & 4075108.50 & 9 & 9 \\
11 & 610508.50 & 4074909.00 & 9 & 9 \\
20 & 610537.00 & 4075137.00 & 9 & 9 \\
32 & 611734.00 & 4071717.00 & 3 & 9 \\
37 & 611563.00 & 4077616.50 & 9 & 9 \\
42 & 613244.50 & 4070890.50 & 10 & 10 \\
48 & 611648.50 & 4077303.00 & 9 & 9 \\
57 & 611791.00 & 4075621.50 & 9 & 9 \\
65 & 612161.50 & 4075308.00 & 9 & 9 \\
66 & 611819.50 & 4077132.00 & 9 & 9 \\
70 & 611563.00 & 4074424.50 & 9 & 9 \\
73 & 609226.00 & 4075194.00 & 6 & 6 \\
80 & 611990.50 & 4076704.50 & 9 & 9 \\
84 & 611620.00 & 4069978.50 & 3 & 3 \\
90 & 608998.00 & 4075450.50 & 6 & 6 \\
93 & 608969.50 & 4072857.00 & 6 & 6 \\
94 & 611762.50 & 4075308.00 & 9 & 9 \\
95 & 611107.00 & 4075051.50 & 9 & 9 \\
97 & 608798.50 & 4072857.00 & 6 & 6 \\
102 & 610109.50 & 4075165.50 & 9 & 9 \\
110 & 611933.50 & 4077331.50 & 9 & 9 \\
111 & 611107.00 & 4074966.00 & 9 & 9 \\
113 & 612047.50 & 4077388.50 & 9 & 9 \\
115 & 611705.50 & 4074510.00 & 9 & 9 \\
122 & 611648.50 & 4077445.50 & 9 & 9 \\
123 & 608713.00 & 4075108.50 & 6 & 9 \\
126 & 611420.50 & 4079611.50 & 9 & 9 \\
128 & 611677.00 & 4077274.50 & 9 & 9 \\
130 & 611848.00 & 4077189.00 & 9 & 9 \\
133 & 611221.00 & 4075137.00 & 9 & 9 \\
135 & 609026.50 & 4072885.50 & 6 & 6 \\
137 & 612760.00 & 4076733.00 & 9 & 9 \\
140 & 611848.00 & 4076106.00 & 9 & 9 \\
145 & 616379.50 & 4079554.50 & 3 & 3 \\
152 & 612959.50 & 4077246.00 & 9 & 9 \\
153 & 609140.50 & 4075251.00 & 6 & 6 \\
156 & 611762.50 & 4077075.00 & 9 & 9 \\
158 & 609596.50 & 4074909.00 & 8 & 8 \\
161 & 612104.50 & 4080067.50 & 10 & 9 \\
162 & 609682.00 & 4074880.50 & 8 & 8
\end{tabular}


Table 3-7. Coordinates and Class of Ground Observation Samples (cont.)

\begin{tabular}{|c|c|c|c|c|}
\hline $\begin{array}{c}\text { Sample Point } \\
\text { Number }\end{array}$ & UTM X & UTM Y & $\begin{array}{c}\text { C-CAP } \\
\text { Class no. }\end{array}$ & $\begin{array}{c}\text { Reference } \\
\text { Class no. }\end{array}$ \\
\hline 163 & 609055.00 & 4075735.50 & 9 & 9 \\
\hline 167 & 612076.00 & 4080067.50 & 10 & 9 \\
\hline 170 & 612874.00 & 4076961.00 & 9 & 9 \\
\hline 178 & 610964.50 & 4074937.50 & 9 & 9 \\
\hline 183 & 610594.00 & 4074852.00 & 9 & 9 \\
\hline 185 & 610964.50 & 4074510.00 & 9 & 9 \\
\hline 187 & 612617.50 & 4077702.00 & 10 & 9 \\
\hline 192 & 611905.00 & 4080153.00 & 10 & 9 \\
\hline 195 & 612532.00 & 4077616.50 & 10 & 9 \\
\hline 197 & 606974.50 & 4069038.00 & 7 & 7 \\
\hline 199 & 611762.50 & 4080067.50 & 10 & 9 \\
\hline 204 & 612275.50 & 4071916.50 & 5 & 10 \\
\hline 211 & 611677.00 & 4080010.50 & 10 & 9 \\
\hline 222 & 611848.00 & 4080238.50 & 10 & 9 \\
\hline 234 & 612218.50 & 4080039.00 & 10 & 9 \\
\hline 246 & 612133.00 & 4080295.50 & 10 & 9 \\
\hline Class \# & \multicolumn{4}{|l|}{ Class Name } \\
\hline 0 & \multicolumn{4}{|l|}{0 Background } \\
\hline 1 & \multicolumn{4}{|c|}{ 1.11 High Density Dey. Land } \\
\hline 2 & \multicolumn{4}{|c|}{ 1.12 Low Density Dev. Land } \\
\hline 3 & \multicolumn{4}{|c|}{ 1.2 Cultivated Land } \\
\hline 4 & \multicolumn{4}{|l|}{1.3 Grassland } \\
\hline 5 & \multicolumn{4}{|l|}{ 1.4 Woody Land } \\
\hline 6 & \multicolumn{4}{|l|}{ 1.5 Bare Land } \\
\hline 7 & \multicolumn{4}{|l|}{2.22 Sand } \\
\hline 8 & \multicolumn{4}{|c|}{2.23 Mud/Organic } \\
\hline 9 & \multicolumn{4}{|c|}{ 2.3 Estuarine Emergent Wetland } \\
\hline 10 & \multicolumn{4}{|c|}{ 2.8 Palustrine Emergent Wetland } \\
\hline 11 & \multicolumn{4}{|c|}{ 2.9 Palustrine Woody Wetland } \\
\hline
\end{tabular}


commission and $86.96 \%$ for errors of omission. Table 3-8 shows the effect of merging wetland classes.

\subsection{Change Detection}

The USFWS NWI data intersected with the C-CAP classification data were used in a change detection matrix to compare wetland changes between 1972 and 1990 (tabie 3-9). Wetland losses were identified by the intersection of wetland class rows with the upland class columns in table 3-9. Combined wetland classes changed 522 ha to upland classes. Class 2.23 Mud/Organic lost 81 ha to upland classes. Class 2.3 Estuarine Emergent Wetland changed 50 ha to upland classes. Class 2.9 Palustrine Woody Wetland changed 13 ha to upland classes. The largest single category change was 379 ha of Palustrine Emergent Wetland to upland classes. Half, $189 \mathrm{ha}$, of the 2.8 Palustrine Emergent Wetland change was to 1.2 Cultivated Land.

Wetland gains were identified by the intersection of background and water rows with the wetland columns in table 3-9. Wetland classes, except 2.22 Sand, gained 512 ha from 0 Background and 3.1 Water. The largest single category gain was 219 ha of Estuarine Emergent Wetland. However, the upland land cover source of wetland gains could not be determined from the USFWS NWI data. Gains from 0 Background to the wetland classes were areas of the USFWS NWI subset that had no data. For example, 121 ha of 2.9 Palustrine Woody Wetland from the 1990 C-CAP classification were not in the USFWS NWI data.

Wetland class changes to water class were identified by the intersection of wetland class rows with column 3.1 Water in table 3-7. Class 2.3 Estuarine Emergent Wetland had 93 ha from the 1972 USFWS NWI data that were submerged in the 1990 data. Class 2.8 Palustrine Emergent Wetland had 75 ha submerged. Class 0 Background had 51 ha 
7urT J JuoJ JวMOT \%S6

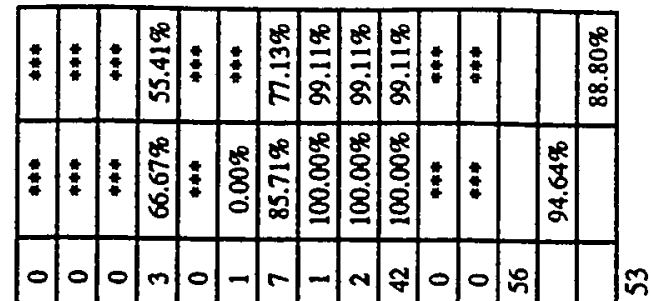

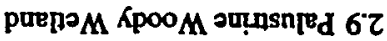

pasto \%

IEOL MOY

มี⿻ $M$ I' $\varepsilon$

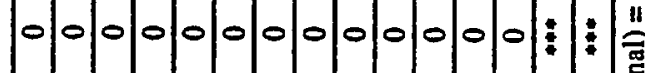

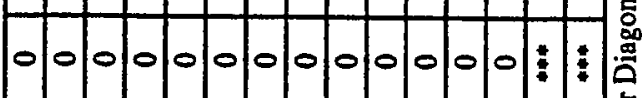

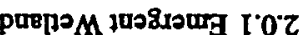

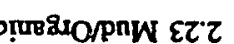

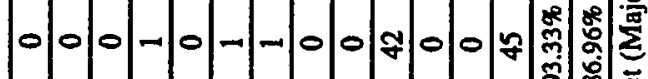

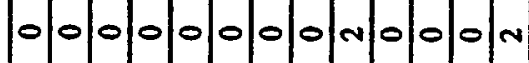

pures $z \tau \tau$

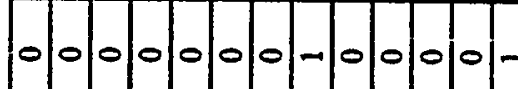

$\frac{2}{2}$

PUET 2REg $S \mathrm{I}$

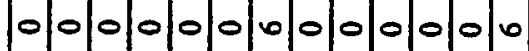

PUE] KPOOM * $\div$

$000010000000000001:$

pue[ssedo $\varepsilon$ I

000000000000000000

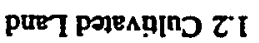

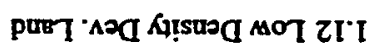

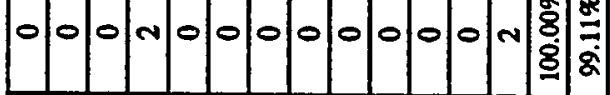

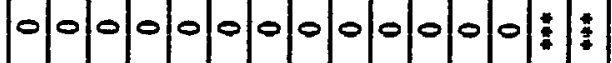

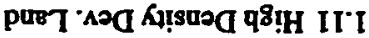

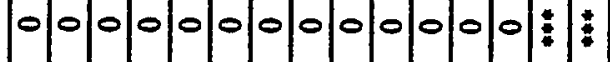

punorsyreg 0

$00000000000000:$

吉

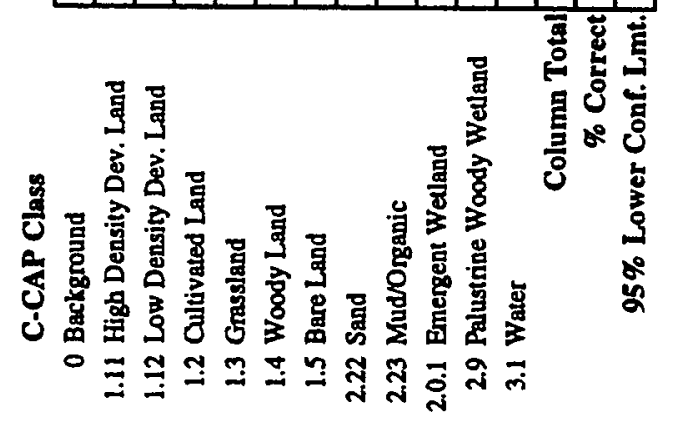




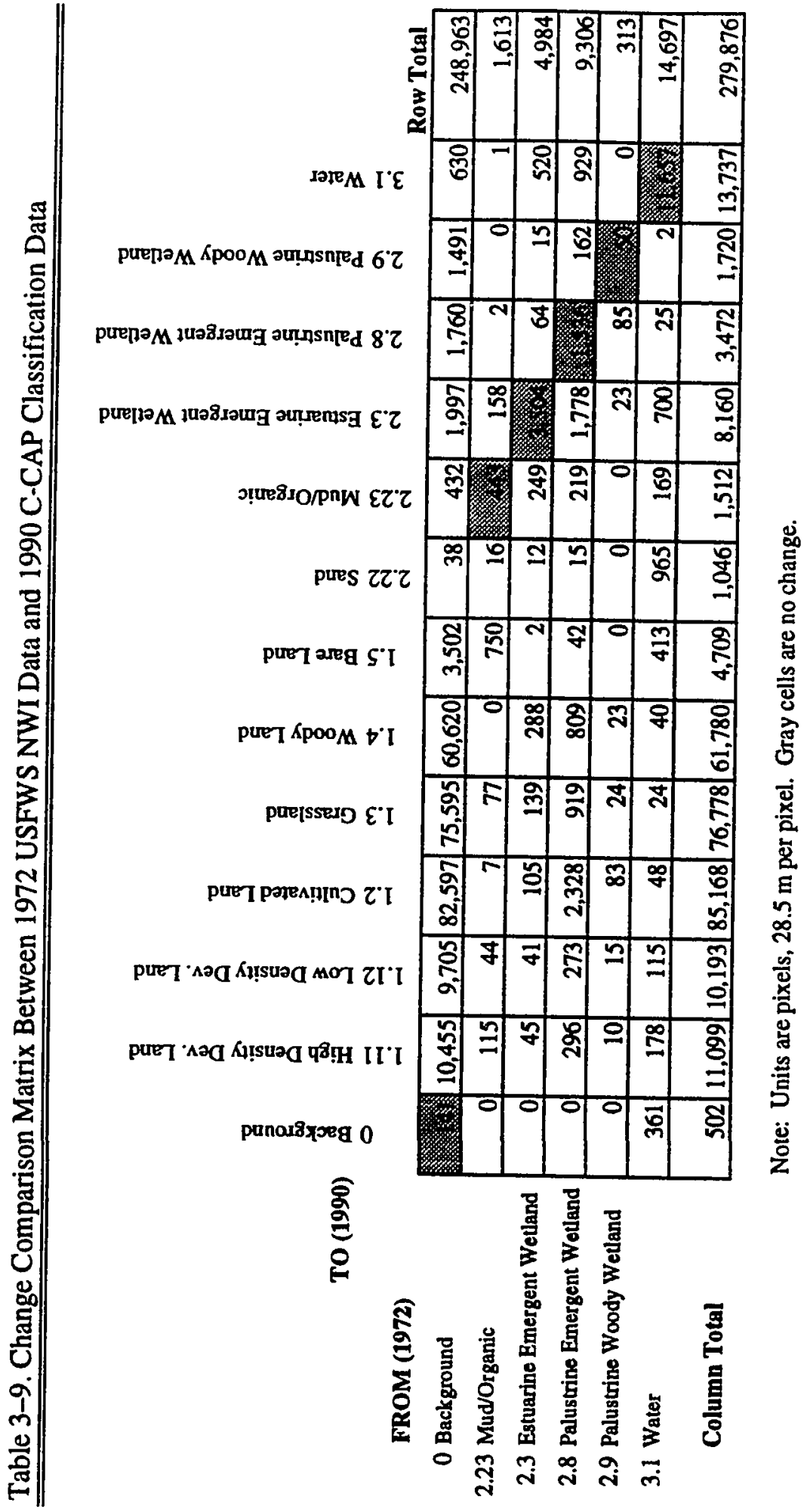


submerged, meaning that upland classes were converted to water, or that water area was missed by the USFWS NWI.

Changes were detected to mud flats. Dry 2.23 Mud/Organic, a wetland class, areas were identified by the intersection of $2.23 \mathrm{Mud} / \mathrm{Organic}$ row with the 1.5 Bare Land column in table 3-7. Sixty-one ha of 2.23 Mud/Organic class were classified as 1.5 Bare Land at a location near the mouth of the Elkhorn Slough. Field visits confirmed that this area was a former salt pond with no vegetation.

The USFWS NWI data and C-CAP classification change detection comparison provided detailed land cover change information in geographic and tabular form. However, the USFWS NWI data only contained land cover data for wetlands. Therefore, a second change detection matrix (table 3-10) was developed using the rectified Dickert et al. (1980) data (figure 3-4) and the resampled 1990 C-CAP classification (figure 3-5).

The rectified Dickert et al. (1980) land cover data (figure 3-4) and the 1990 C-CAP classification comparison provided land cover change data on the upland areas of the watershed (table 3-10). However, the detail of the comparison was reduced to a $50 \mathrm{~m}$ per pixel resolution. Although land cover changes were still detected, much of the wetland detail was lost.

Wetland losses in this second change comparison matrix were identified by the intersection of wetland rows with upland columns (table 3-10). Combined wetland classes lost 204 ha to upland classes between 1980 and 1990. The largest single category change was 150 ha of Palustrine Emergent Wetland to upland classes. Eighty-eight percent of the 2.8 Palustrine Emergent Wetland loss was to 1.2 Cultivated Land, 56 ha; 1.3 Grassland, 40 ha; and 1.4 Woody Land, 36 ha.

Wetland gains from the second change comparison matrix were identified from the intersection of upland and water rows with the wetland columns in table 3-10. Wetland classes, except 2.22 Sand, gained 559 ha from developed land classes and 3.1 Water class 


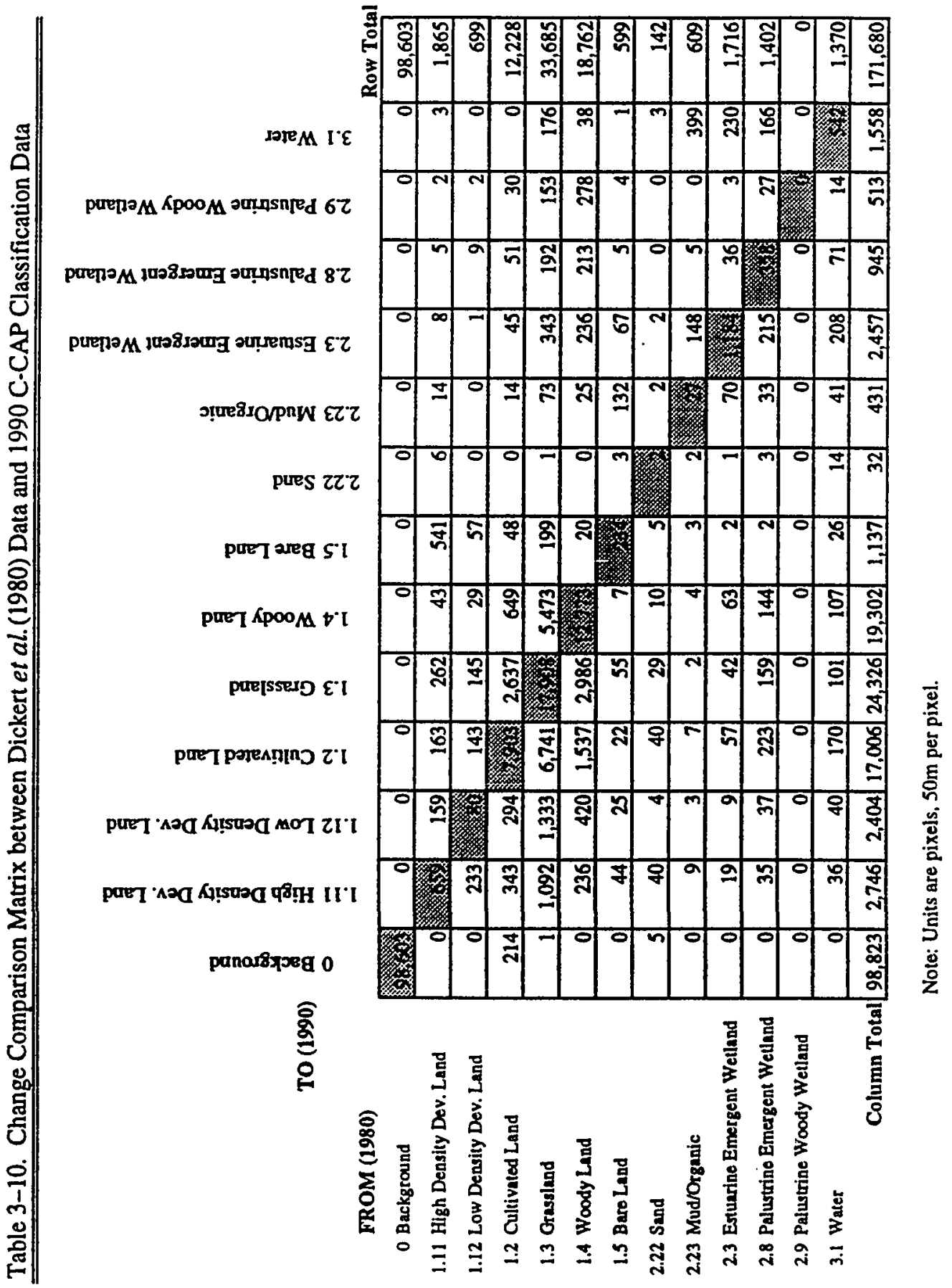


Figure 3-5. The 1990 C-CAP Classification Masked to Match the Watershed and Resampled to $50 \mathrm{~m}$ per pixel. 


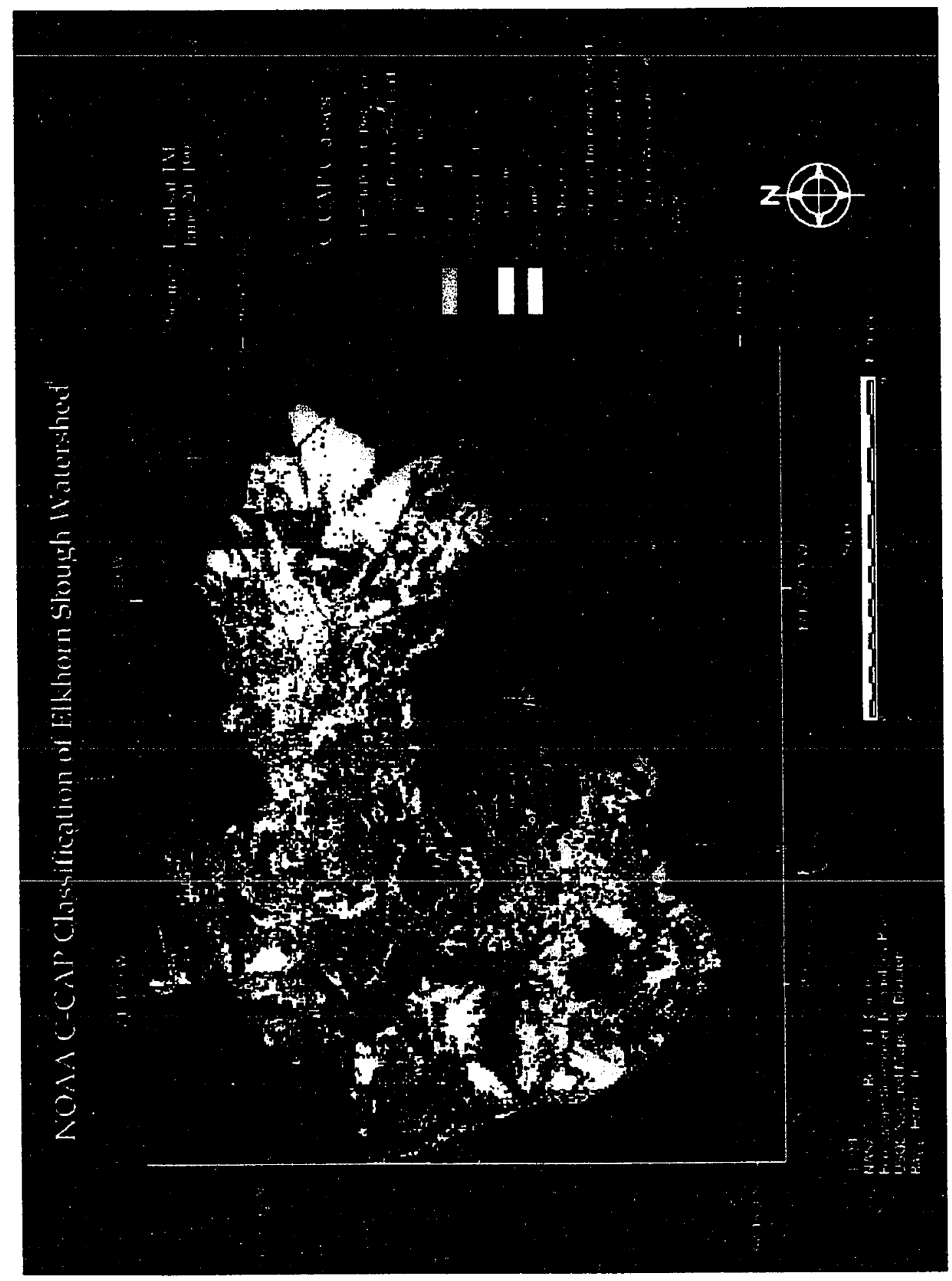


for the same area. The largest single category gain was 227 ha of 2.3 Estuarine Emergent Wetland. Sixty-four percent of the Estuarine Emergent Wetland gain came from 1.3 Grassland, 86 ha, and 1.4 Woody Land, 59 ha.

The Dickert et al. (1980) and C-CAP classification change comparison provided data not available from the USFWS NWI comparison. Upland land cover changes were possible with the Dickert et al. (1980) data. Upland class change comparison revealed that the two largest upland land area changes within the watershed were grassland decrease and cultivated land increase. Class 1.3 Grassland changed 197,212.5 ha to other classes between 1980 and 1990, with $84,262.5$ ha changed to 1.2 Cultivated Land. Class 1.2 Cultivated Land increased $113,798.5$ ha. Thus, the watershed experienced an intensification of agriculture between 1980 and 1990.

\subsection{Geographic Characteristics of Wetland Changes}

3.5.1 Wetland Gain and Loss Comparison Between 1972 USFWS NWI data and $1990 \mathrm{C}-$ CAP Classification

In general, wetland changes were distributed spatially across the study area with significant losses outside of the Elkhorn Slough. Losses and gains of wetland area were distinctly fragmented and patchy. Patch size varied substantially.

Geographic distribution of wetland gain and loss from the 1972 and 1990 comparison is shown in figure 3-6. All classes that changed from mud or wetland classes to upland classes are characterized as a wetland loss (shown in red). Classes that changed from upland classes to mud or wetland classes are shown as wetland gains (shown in green). Submerged wetlands, as a result of tidal stage, are geographically identified from the change matrix intersection of wetland classes to water (shown in magenta). Submerged new wetland are geographically identified from the change matrix intersection of upland classes to water (shown in yellow). Water is shown in gray. 
Figure 3-6. Map of the Geographic Distribution of Wetland Gain and Loss Comparison in the Elkhorn Slough Watershed between 1972 USFWS NWI Maps and the 1990 C-CAP Classification. 


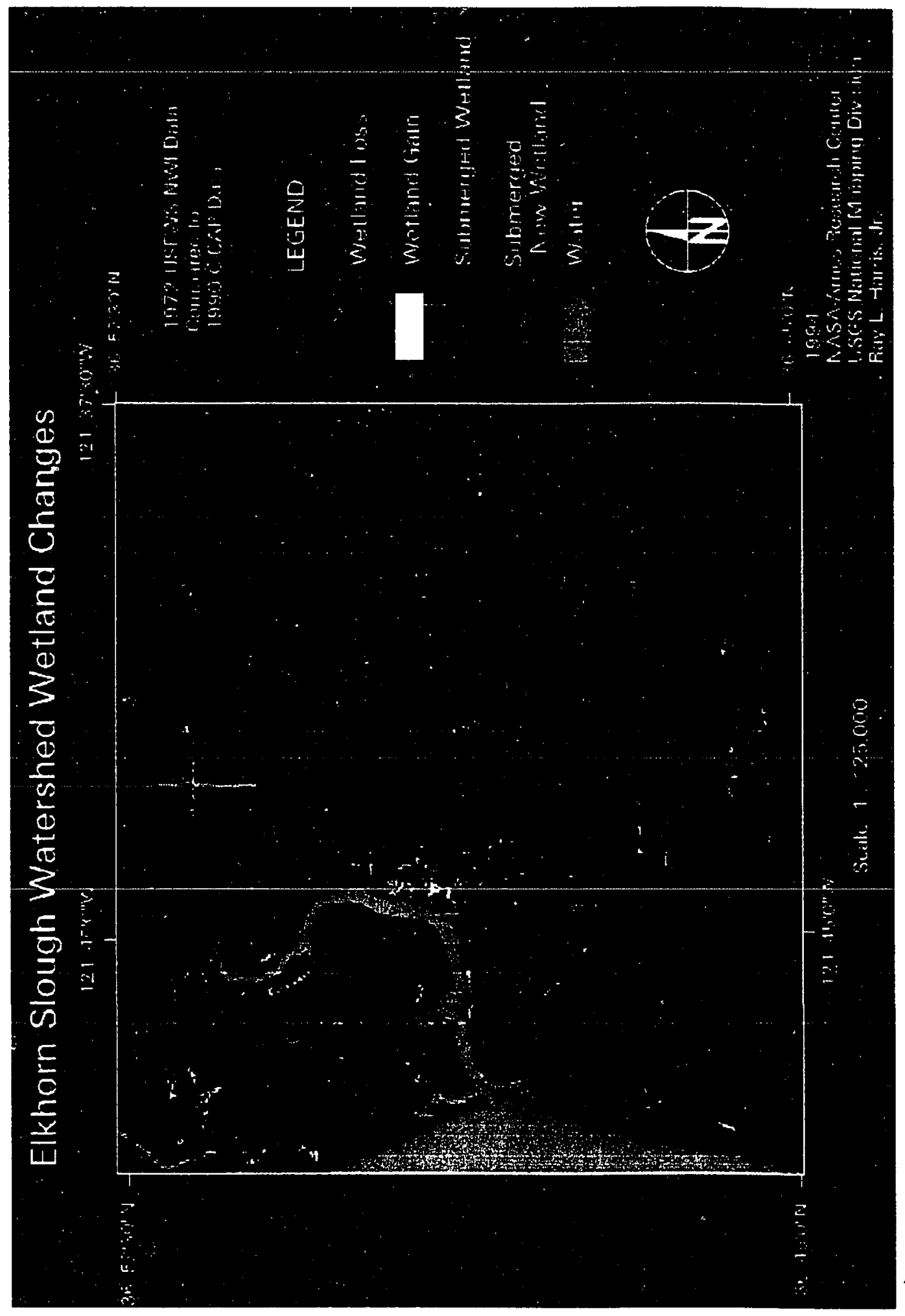


Wetland losses in the Elkhorn Slough occurred in small patches distributed around the slough's perimeter. Some of the losses occurred in small canyons or fingers throughout the slough where steep slopes drain, or where creeks or streams enter the estuary. However, wetland changes near the edges of habitat boundaries were difficult to substantiate. Change detection errors as a result of misregistration or incorrect classification of the data were more probable at habitat edges.

A large wetland change from 2.23 Mud/Organic to 1.5 Bare Land occurred at a former salt pond near the mouth of the Elkhorn Slough. The area, shown in red in figure $3-6$, was dry in 1993 and had a high reflectance in the summer of 1990 . Thus, it was classified as 1.5 Bare Land. However, characterization as a wetland loss was a misrepresentation. The correct C-CAP classification, based on ground observation, was 2.2 Estuarine Unconsolidated Shore. However, conditions artificially controlled by a dike and tidal gate were not identifiable from the TM imagery. Therefore, the area was retained as 1.5 Bare Land based on the area's spectral response.

Wetland losses also occurred at the northeastern point of the Elkhorn Slough. Here, the Cameros Creek drains into the slough. The circular red area at the north end of the Elkhom Slough in figure 3-6 was a wetland change to cultivated land. The USFWS NWI data labeled the area as Palustrine Emergent Wetland Semi-permanent (PEMY). The 1990 C-CAP classification labeled it as 1.2 Cultivated Land. Aerial photos from 1991 used in the accuracy assessment showed the area under cultivation. Field visits found the area flooded and tidally influenced in December, 1993. Therefore, the wetland loss was accurate for 1990 , but may no longer be accurate. This substantiated the possibility that land cover had changed between 1991 and 1993. Thus, classification accuracy could be effected by the time gap between the TM data and the field checking.

Wetland losses were numerous in the area south of the Elkhorn Slough (see figure 3-6) particularly in the Moro Cojo Slough area, which includes the elongated wetland area 
(shown in red) referred to as the Castroville Slough. The Castroville Slough runs along the north and northwest side of Castroville towards the Moss Landing Harbor entrance. This slough was classified as PEMY by the USFWS NWI maps and as 1.2 Cultivated Land by the $1990 \mathrm{C}-\mathrm{CAP}$ data. Field visits in 1993 confirmed that the entire area was cultivated, except for narrow drainage channels filled with Salicornia virginica (pickleweed). Ditches diverted water from the fields directly to the channels.

Wetland changes to high density developed land in the Castroville Slough were also found. Field visits at sample point \#84 (table 3-7) at the southeastern end of the Castroville Slough also revealed landfill from development. Broken concrete slab landfill was piled up $10 \mathrm{~m}$ above the southem bank of the drainage ditch. The fill supported urban housing pads in a new subdivision. This fill location was also part of sample point \#84 location recorded with the GPS unit.

Landfill was also discovered to the northeast of the Castroville Slough on the upper Moro Cojo Slough at the Castroville High School property. Sample point \#42 (table 3-7) was found $40 \mathrm{~m}$ east of a practice field down a tiered slope to the top of a manhole cover. Thus, the sample area was actually a combination of low density developed land and palustrine emergent wetland. This area was classified PEMY, palustrine emergent wetland, by the the USFWS NWI mapsfrom 1973. The 1990 C-CAP classification identified the sample point as 2.8 Palustrine Emergent Wetland. The 1993 field visist identified it as landfill encroaching on the edge of palustrine emergent wetland. Mature Salix spp. (willows) were growing from the slope. Typha spp. (cattails) were present only $47 \mathrm{~m}$ further east.

The Moro Cojo Slough had an extensive patchwork of wetland losses from 1972 to 1990. Losses occurred in the upper reaches of some fingers of Moro Cojo Slough as a result of changes to cultivated land, grassland, or developed land. Two sample points, \#32 and \#204 (table 3-7), in the northeastern areas of the Moro Cojo Slough northwest of the 
high school, were classified as PEMY (palustrine emergent wetland) by the USFWS NWI data. Sample point \#32 was classified as wetland by the C-CAP data, but sample point \#204 was classified as 1.4 Woody Land. Field visits in 1993 identified both areas as 2.8 Palustrine Emergent Wetland. These points were found in areas not dominated by Salicornia virginica. No standing water was found at these points. Alteration of the land cover was evident from the impact of cattle hooves and manure, double ditches and dikes, commercial farming, and ranchette property gardening.

The McCluskey Slough, north of the harbor entrance, was a whip-tail shaped wetland portrayed as a wetland loss (figure 3-6). This area was incorrectly classified as cultivated land in the C-CAP classification. Field visits confirmed that a narrow wetland was still present but cultivated land completely surrounded the wetland.

Wetland gains (shown in green) concentrated around the Elkhorn Slough. Areas East and Southeast of the railroad track that bisects the Elkhorn Slough contained substantial gains. This area has received much of the preservation and restoration work associated with the Elkhorn Slough National Estuarine Research Reserve.

Wetland gains also occurred across the channel along the northwest edge of the Elkhorn Slough. These areas were classified as 2.9 Palustrine Woody Wetland. Quercus agrifolia (Coast Live Oak) occurred in these areas that drain the irrigated plateau to the west. Similar riparian areas were found close to the Pajaro River in the northwest corner of the study area. However, these areas drained to the Pajaro River watershed.

Wetland gains dotted the eastern half of the study area (figure 3-6). Some of these wetlands gains were located well into the hills east of the estuary. Gains in the hills and elevations above the sloughs were highly unlikely. The "salt and pepper" effect of wetland distribution was attributed to hill and tree shadows.

Submerged wetland and submerged new wetland were identified at the southeast end of the Elkhorn Slough. Submerged wetland and submerged new wetland areas 
occurred east of dikes and tidal gates along the railroad tracks that traverse the slough. A large area of 42 ha changed from 2.3 Estuarine Emergent Wetland to 3.1 Water.

The V-shaped boundary separating submerged new wetland (shown in yellow) and submerged wetland (shown in cyan) was a line where a dike failed between 1972 and 1990. The old pasture to the north of the boundary flooded with the collapse of the dike, and was returning to wetland with restoration efforts in 1993.

\subsubsection{Wetland Gain and Loss Comparison Between 1980 Dickert et al. data and 1990 C-}

\section{CAP Classification}

The geographic distribution of wetland changes for the Dickert et al. (1980) land cover and the C-CAP classification was similar to the USFWS NWI comparison. However, the coarse resolution of the $50 \mathrm{~m}$ pixels made delineation and interpretation difficult. Small canyons and fingers of the slough disappeared at this resolution, giving wetland morphology a blocky character.

Wetland losses were relatively few in the Elkhom Slough using the 1980 Dickert et al. and $1990 \mathrm{C}-\mathrm{CAP}$ change detection matrix. Small losses were found at the northern end of the slough, but large contiguous areas of wetland loss were not found. Figure 3-7 shows wetland changes for the watershed between the Dickert et al. (1980) data and the CCAP classification displayed in the same color scheme as the USFWS NWI and C-CAP comparison (figure 3-6).

As in the USFWS NWI comparison, submerged wetland and submerged new wetland occurred in the southeastern end of the Elkhorn Slough. The submerged areas also occurred on the shoreward side of tidal gates and dikes along the railroad line. Yet, the distribution of new submerged wetland did not have the characteristic " $V$ " shape.

The Moro Cojo Slough contained several patches of wetland loss, but the distinct, elongated Castroville Slough did not appear as a loss. This indicated that the Castroville 
Figure 3-7. Geographic Distribution of Wetland Gain and Loss in the Elkhom Slough Watershed Between the 1980 Dickert et al. Data and the 1990 C-CAP Classification. 


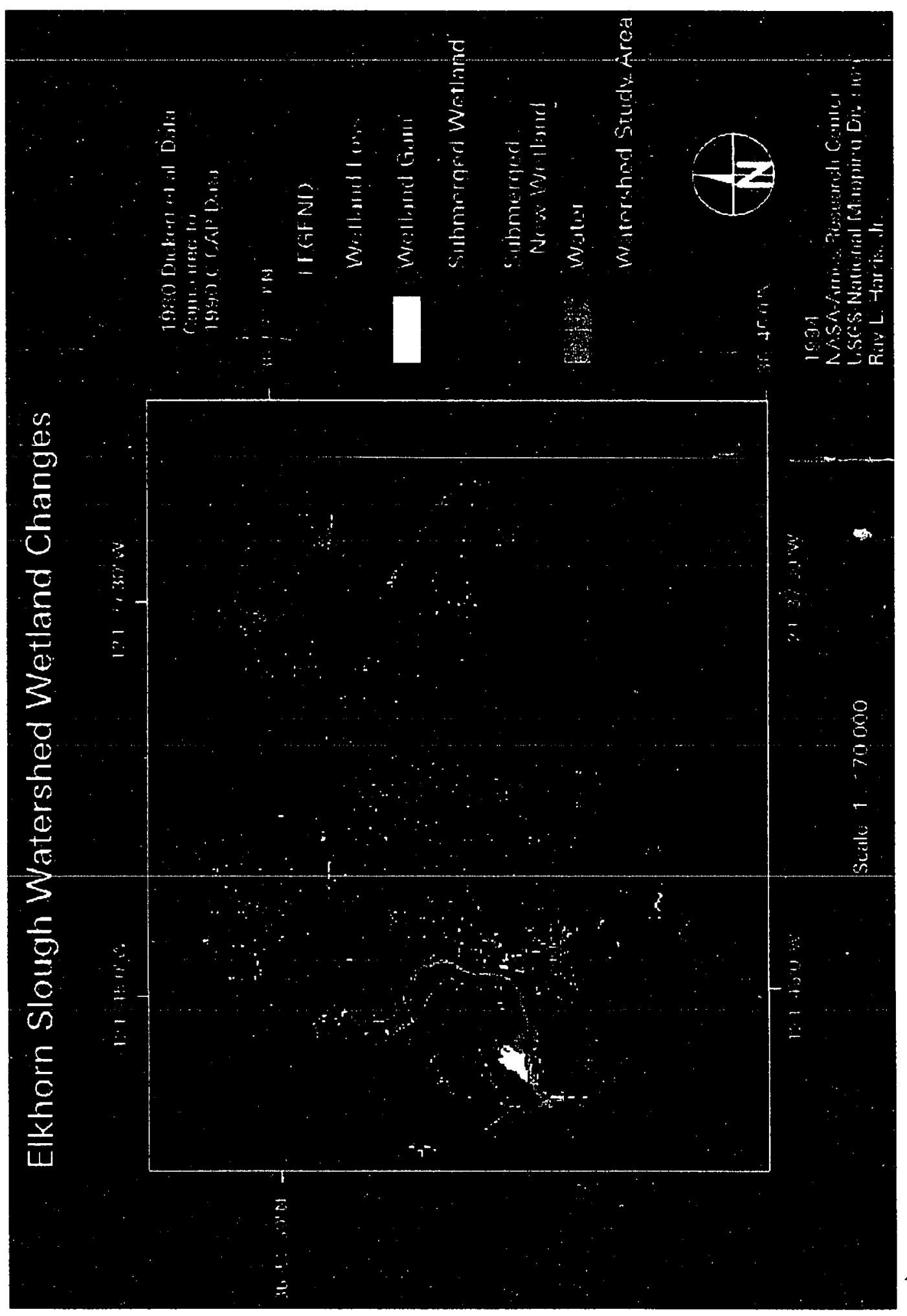


Slough was either classified differently by the USFWS NWI and the Dickert et al. (1980) study, captured at a spatial resolution ( $50 \mathrm{~m}$ per pixel) too coarse for detection, or that the area was actually converted to cultivated land prior to 1980 .

Wetland gains were distributed primarily as small patches throughout the watershed in the 1980 and 1990 comparison. However, a large wetland gain was identified at the mouth of the Elkhom Slough at the former salt pond. The original salt pond dike failed, and a new dike was constructed diagonally across the salt flat. The area southeast of the dike retumed to vegetated wetland habitat, and therefore, was characterized as wetland gain. Natural cycles regularly flooded this area.

Gains in the foothills to the east of the Elkhom Slough were unlikely wetlands. Some small wetland gains in the upper reaches of the watershed did correspond to riparian areas. However, precise delineation was difficult at the $50 \mathrm{~m}$ spatial resolution.

\section{$\underline{3.6 \text { Summary }}$}

TM imagery was capable of providing accurate and synoptic land cover data for the Elkhom Slough watershed. The $85 \%$ overall classification accuracy requirement was exceeded. However, some individual classes, important to scientist and managers, did not meet the $85 \%$ accuracy requirement. In particular, accurate determination of palustrine versus estuarine wetlands was unsuccessful. Accuracy requirements applied to wetland classes were exceeded by merging estuarine and palustrine classes.

Change detection results provided detailed land cover information when positional and classification accuracy standards were exceeded. Ancillary data was successfully used with the C-CAP classification to identify wetland area changes geographically and quantitatively. However, the spatial and categorical quality of the ancillary data effected the accuracy of the change detection analysis. Coarse spatial resolution, $50 \mathrm{~m}$ per pixel, was 
less adequate than $28.5 \mathrm{~m}$ per pixel resolution. Incompatibility of classification schemes reduced the categorical accuracy of change analysis.

The change detection analysis also revealed the spatial and temporal nature of land cover changes. Visualization of the changes in map form provided a comprehensive view of the complete wetland area as a component of the landscape. This comprehensive regional perspective is necessary for cumulative impact assessments and monitoring of sensitive habitats. 


\section{CHAPTER 4}

\section{DISCUSSION}

\subsection{Introduction}

This chapter reviews the results of the study in relation to the hypotheses proposed in chapter 1. The hypotheses asserted: 1) that TM data can be used to make detailed and accurate C-CAP land cover inventories of the watershed, 2) that the C-CAP classification scheme is adequate for TM data and ancillary data, and 3) that C-CAP land cover maps can be quantitatively compared with other land cover data sources. The hypotheses were intended to reveal the applicability of the C-CAP recommendations for monitoring land cover changes in the Elkhorn Slough watershed.

\subsection{C-CAP Classification Accuracy and Detail Using TM Data}

Hypothesis 1 was affirmed, in part, because TM data were successfully used to create a land cover map of the Elkhorn Slough watershed that exceeded the $85 \%$ overall accuracy requirement. The overall accuracy of the C-CAP classification was $86.84 \%$, which exceeded the guidelines recommended by Jensen et al. (1993). In addition, TM data were used effectively to classify some individual C-CAP classes. Grassland, woody land, and estuarine emergent wetland exceeded the $85 \%$ accuracy requirement. The effective overall classification, including these classes, was due to distinct spectral signatures in large, contiguous land cover areas.

However, overall accuracy provided little assurance that wetland areas were accurately classified. The overall accuracy was dominated by three upland classes that 
covered $84.87 \%$ of the area. The 3 upland classes received 179 of the 191 sample points for accuracy assessment (see table 3-5). Thus, the overall classification accuracy was dependent upon large area, non-wetland classes.

The stratified random sampling technique applied in the overall classification accuracy assessment was not valid for some individual wetland classes of the Elkhom Slough watershed. No sample points were located in the 2.8 Palustrine Emergent Wetland, 2.9 Palustrine Woody Wetland, 2.23 Mud/Organic, or 2.22 Sand classes. The absence of sample points in these wetland classes meant that classification accuracy was not tested in areas that were important to this study.

A separate classification accuracy assessment for wetland areas was successful for emergent wetland classes but did not work for other wetland classes. One class, 2.3 Estuarine Emergent Wetland, was $100.00 \%$ accurate for commission errors and $72.09 \%$ accurate for omission errors (see table 3-6). Yet, even with the separate accuracy assessment, other wetland classes contain very few sample points.

Therefore, hypothesis 1 was partly unsupported because the detail, or accuracy of individual C-CAP classes, could not be determined with the accuracy assessment method. Several limitations of the accuracy assessment method including misinterpretation, time differences, sample pool, sampling window size, and shape of land cover patches, reduced the effectiveness of the assessment.

The accuracy of the USFWS NWI classes could also not be determined. Possible incorrect classifications in the USFWS NWI data may have overtly influenced the $1990 \mathrm{C}$ CAP classification of these areas. Misinterpretation in the C-CAP classification was a problem for palustrine areas because of an assumption of high classification accuracy for the USFWS NWI data. For example, ten of 11 sample locations identified as palustrine emergent wetland by the USFWS NWI maps and by the C-CAP map were incorrect. These samples were classified as estuarine emergent wetland based on the 1993 ground 
observations. Accuracy assessment data for the USFWS NWI data may have avoided excessive reliance upon its assumed accuracy.

Time differences between the TM data and the ground observations may have affected classification accuracy. Land cover changed in the 3.5 years between the $1990 \mathrm{TM}$ data and the 1993 reference data. For example, land cover in the northeast end of the Elkhom Slough changed from wetland in 1972 to cultivated land in 1990 and 1991, then back to wetland in the 1993 field sampling. As a result, time lags between the TM data and ground observation altered the logical "either" wetland "or" cultivated lard decision to "either" wetland "or" cultivated land or "both" due to the possibility that both data sources were actually correct. One of the data sources had to be assumed correct because classification accuracy was dependent on "either-or" logic. Therefore, ground observations in 1993 were assumed correct for 1990.

The size of the $3 \times 3$ pixel window in relation to the shape of some wetland areas limited the selection of random sample points from the center of land cover polygons. The $3 \times 3$ pixel block homogeneous criteria favored sample points in land cover areas that were large and compact. Forty-three of 56 sample points from the wetland accuracy assessment were located in the Elkhom Slough, the largest wetland. Also, the $3 \times 3$ homogeneous block method of selecting sample pixels was too large for the small areas of some wetland classes. For example, $1503 \times 3$ pixel blocks were randomly generated for wetland classes, and of those, only 56 blocks contained homogeneous classes. The loss of roughly two thirds of the sample pool effectively eliminated many of the small wetland areas such as 2.9 Palustrine Emergent Woody Land.

The natural shape and orientation of wetlands in the Elkhorn Slough watershed was not compatible with the square shape of the $3 \times 3$ pixel window. Wetlands are usually wide at the bottom of the watershed, then taper off upstream. Small wetlands in the Elkhorn Slough watershed often were shaped like long trails a few pixels wide, making then 
impossible to sample. The probability that the sample window, when selected randomly, will fit precisely within the wetland decreases in the narrow reaches of the wetland. These narrow reaches were often the palustrine, or freshwater, areas of the wetland.

The $3 \times 3$ pixel block sampling method was unsatisfactory for evaluating the quality of C-CAP wetland classification in areas less than $85.5 \mathrm{~m} \times 85.5 \mathrm{~m}$. For example, no sample points were identified in the McCluskey Slough north of the Elkhorn Slough. This is a potentially serious problem because long, narrow waterways were a characteristic of many wetlands and streams in the coastal drainage areas of the MBNMS and in California. The consequence of using the block method of sampling with the relatively large pixel size of the TM data was a confidence in the overall classification accuracy of the study area, but a lack of confidence in the classification accuracy of specific, narrow wetlands.

The quality of the C-CAP classification for specific wetland classes could not be assessed to the degree desired. Resource managers requiring detailed wetland delineation for wetlands less than $\mathbf{8 5 . 5} \mathrm{m}$ across cannot rely on this C-CAP classification. However, the wetland areas covered only a small percentage of the TM subregion, and overall, were within error tolerance proposed by Jensen et al. (1993) for C-CAP. An alternative accuracy assessment technique is needed to account for sampling in specific areas of interest from $28.5 \mathrm{~m} \times 28.5 \mathrm{~m}$ to $85.5 \mathrm{~m} \times 85.5 \mathrm{~m}$ within large watersheds. Confidence limits of C-CAP classifications in this spatial range need to be established to ensure the quality of C-CAP change detection products in small wetlands areas of the MBNMS.

A potential alternative to the homogeneous $3 \times 3$ pixel block sampling criteria used in this study is to reduce the pixel block size to a $2 \times 2$ block. However, the likelihood of classification errors caused by misregistration or habitat edges increases as the sample pixel blocks decrease in size. Sample block sizes smaller than $3 \times 3$ will require accurate positional control of the reference data as well. A reduction in sample block size should be 
accompanied by an increase in positional accuracy of the data. Therefore, ground observations should be conducted with a differential GPS.

Another potential alternative is to increase the spatial resolution of the source data. Aerial photography or airborne multi-spectral scanner data is a possible source for higher spatial resolution data of small wetlands of the MBNMS. The C-CAP protocol provides specifications for the use of aerial photography. However, the digitization of aerial photographs and the unstable aerial platform can increase classification errors and decrease the cost-effective interpretation of land cover. Also, the data processing and storage demands of higher resolution data can reduce productivity.

A possible strategy for overcoming the difficulties in accurate classification of sensitive habitats within a watershed is to use high spatial resolution data in limited areas and merge it with lower resolution data that covers the remainder of a watershed. For example, high resolution aerial photography of the wetland area in the Elkhorn Slough watershed could be digitized, classified, and assessed for accuracy. The high resolution classification could then be aggregated to TM data pixel size and merge with a C-CAP classification using the TM data. The merge C-CAP classification could then be assessed for accuracy. Assurance of accuracy for the C-CAP classification of the watershed and possession of the higher resolution classification in small sensitive habitat areas would be beneficial to local resource managers.

\subsection{The C-CAP Classification Scheme as a Universal Land Cover System}

Hypothesis 2 was affirmed because the C-CAP classification scheme successfully labeled land cover and provided a universal land cover classification scheme. Results demonstrated that C-CAP classification of the TM data contained the required 12 classes. These classes formed the baseline land cover classes to which the USFWS wetland 
classification scheme (Cowardin et al. 1979) and the Dickert et al. (1980) classification scheme were translated.

The C-CAP classification scheme integrated upland and wetland classes for a uniform and comprehensive classification of the Elkhorn Slough watershed. The C-CAP scheme was uniform because the classification system is hierarchical. A hierarchical system meant that major classes could be divided into finer detail as necessary depending on the quality of the source data. The C-CAP scheme was comprehensive because it integrated water, wetland, and upland land cover for complete classification of a watershed. Prior to the C-CAP scheme, a national standard classification scheme was not available to integrate wetland with upland classification.

The C-CAP classification scheme was generally compatible with the USFWS NWI classification schemes. The three wetland systems found in the USFWS NWI wetland classifications, marine, estuarine, and palustrine, translated directly to the C-CAP scheme. USFWS wetland classes for substrate material or vegetative form, such as unconsolidated bottom or emergent wetland, were also directly transferred to the C-CAP scheme. However, modifying terms were not compatible with the general required C-CAP classes derived from TM data.

The TM data could not be used to determine all of the details included in the USFWS NWI classifications. For example, a salt pond to the north of the Elkhorn Slough channel was categorized as Estuarine, Intertidal, Semi-permanently Flooded, Subtidal, Artificially Flooded, Regularly Flooded (E2FLKN) on the USFWS NWI map. "E2FLKN" could not be recognized with the TM data, since neither the artificial nature of the water regime nor the semi-permanent flooding could be determined from the spectral data of one TM scene. In addition, "artificially flooded" could only be determined if dikes or levees could be identified from the TM image, which was also not possible. Likewise, Palustrine Emergent Wetland Y-Saturated/Semi-permanent/Seasonal (PEMY) could not be 
determined, because the seasonal nature of the wetland could not be established from a single TM scene. As a result, USFWS NWI classifications with special modifiers for the water regime, including K-Artificially Flooded, F-Semi-permanently Flooded, and YSaturated/Semi-permanerit/Seasonal, had to be generalized to C-CAP to accommodate the limitations of TM data.

The C-CAP classification scheme was also generally compatible with the Dickert et al. (1980) classification scheme because that scheme used level I and II USGS Anderson et al. (1976) classifications, which were incorporated in the C-CAP scheme. Upland land cover classes from Dickert et al. (1980), such as "oak brushland" or "eucalyptus," were easily translated to 1.4 Woody Land. Classes such as "wet grassland" were more difficult to interpret due to the paradoxical use of words.

Classes defined by land use were not directly compatible with classes defined by land cover. The Dickert et al. (1980) classification scheme also contained land use classes such as "Railroad" and "School". The land use could not be determined using the TM data. Therefore, land use classes in the Dickert et al. (1980) study were translated to C-CAP land cover classes based upon a subjective estimation of the land cover components in a unit of land use. For example, land use class "School" contained buildings and athletic fields. The building would be classified as developed land and the fields would be classified as grassland. The combination of these land covers within a polygon indicated that Low Density Developed Land would be the appropriate C-CAP land cover class.

Special or unique measures of land use were not compatible with the C-CAP classification scheme. Dickert et al. (1980) used a residential density unit measure to modify the USGS Anderson et al. (1976) classification scheme for their study. The residential density unit could not be translated to the C-CAP developed land classes. For example, Grassland- 0.21 (AH) indicated grassland land cover with 0.21 dwelling units per acre. The geographic distribution of developed land within a polygon of Grassland - 
$0.21(\mathrm{AH})$ could not be determined because the density measure was averaged over the area of the polygon. Therefore, the residential density unit values were ignored. This decision effectively eliminated a low density developed land class from the change comparison using the Dickert et al. (1980) data and the C-CAP data.

The C-CAP classification scheme integrated upland and wetland classes for a uniform classification scheme across several data sources of the Elkhom Slough watershed. The classes associated with the TM data were rather general, and thus, have limited use in species level analysis of the land cover. Nonetheless, C-CAP land cover data derived from both TM and other sources for the watershed provided valuable information on habitat and land cover changes in the watershed. The data were valuable, not because it could delineate individual species, but because it could distinguish between vegetation canopy, such as grassland or woody land, or denatured habitat, such as high density developed land. Therefore, this level of C-CAP classification was beneficial to those who monitor habitat and land cover changes in the watershed.

\subsection{Land Cover Change Comparison Benefits and Limitations}

Hypothesis 3 was affirmed because a land cover change comparison of the TM data and the USFWS NWI data provided synoptic and timely land cover information of value to cumulative impact assessments in the Elkhom Slough watershed. Results showed that the C-CAP classification of the TM data and the translation of the USFWS NWI maps to CCAP classes were used successfully to detect large wetland changes in estuarine areas and to identify some wetland changes in palustrine areas. The wetland change information was valuable to the assessment of cumulative impacts in the Elkhorn Slough watershed because it provided quantified land cover comparison over time. The change comparison data can be used in an analysis similar to the work of Dickert et al. (1980), in which long-term land cover changes were evaluated to assess impacts to wetlands. 
Analysis at the regional scale aided the understanding of the cumulative effects of habitat change in relation to the areal extent of the wetlands in three primary ways. First, the change comparison analysis revealed trends in habitat changes for wetland ecosystems. For example, post-classification change comparison using ancillary data revealed substantial land cover changes in the 18 year period between 1972 and 1990 . Wetland gains and losses in the Elkhorn Slough watershed, viewed from the watershed perspective, revealed interesting trends. Wetland gains were most associated with the breach of dikes in the Elkhorn Slough. Wetland losses exhibited a characteristic "nibbling" effect, particularly in wetlands other than the Elkhom Slough. The nibbling effect is the incremental loss of habitat as a result of discrete, related actions occurring upon the same ecosystem component. For example, a property owner extended a field by draining and plowing 2 ha along the northeast section of the Moro Cojo wetland, another filled 0.5 ha for a building pad in the Castroville Slough. Over time and space, the incremental loss has significantly reduced the wetland area of the Moro Cojo Slough.

Second, change comparison revealed characteristic patterns of habitat fragmentation such as edge effect, area effect, and distance effect. A visual examination of wetland losses (figure 3-6) illustrates the habitat fragmentation effects mentioned in the beginning of this study. The McCluskey Slough characterizes distance effect by its isolation from other wetlands. It shows edge effect by its narrow, elongated whip-tailed wetland. In addition, area effect is demonstrated by its small size in comparison to other wetlands. The Moro Cojo Slough characterizes edge effect with long, narrow wetlands extending inland. The McCluskey Slough and Moro Cojo Slough are possible areas of habitat fragmentation and decline if, as conservation biologists assert, that area effect, edge effect, and distance effect lead to the decline in the quality of habitat and of species.

Third, the change matrix analysis provided geographically and categorically specific information on land cover changes. For example, change comparison results associated 


\section{PLEASE NOTE}

Page(s) not included with original material and unavailable from author or university. Filmed as recelved. 
Figure 4-1. Wetland Losses Colored According to Their 1990 C-CAP Class. Green areas represent wetland losses to cultivated land, yellow areas represent wetland losses to grassland, and blue areas represent wetland losses to developed land. Wetland losses to bare land were not shown. 


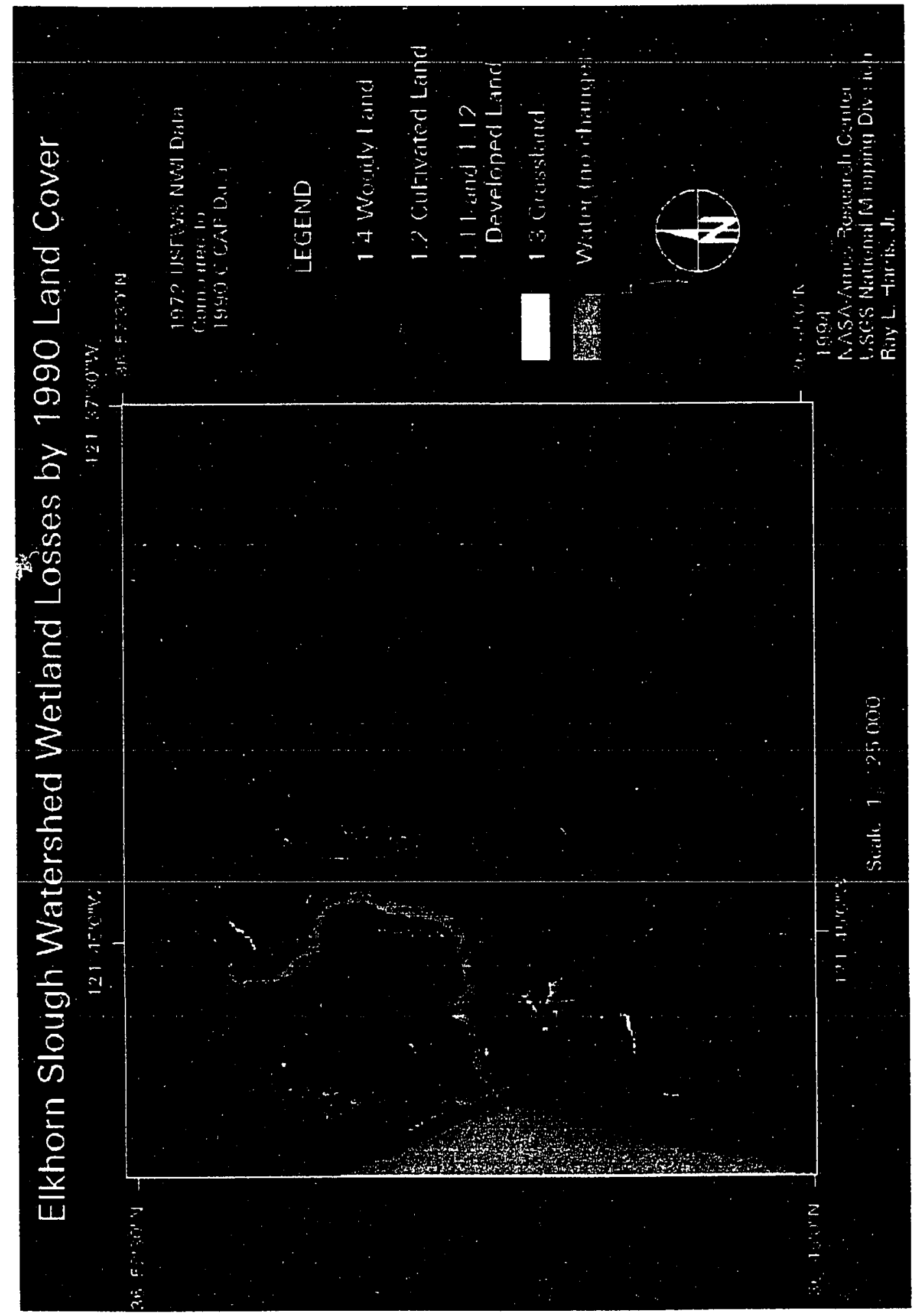


Results demonstrated that post-classification comparison between the Dickert et al. (1980) data and the C-CAP classification was not only possible, but revealed useful information. The comparison revealed a large upland change from 1.3 Grassland to 1.2 Cultivated Land (table 3-10). This indicated agricultural intensification during the 10 year period. Intuitively, agriculture intensification was a reasonable conclusion. However, the geographic reliability of the changes was difficult to substantiate because logical inconsistencies were apparent in the change comparison matrix (table 3-10). For example, changes from 1.11 High Density Developed Land to 1.12 Low Density Developed Land, or from 3.1 Water to 1.4 Woody Land, were illogical. Logical errors may have been magnified by the image-to-image registration and the coarse $50 \mathrm{~m}$ per pixel resolution of the original data. Also, the absence of an accuracy assessment of the input data made the accuracy of the change matrix unknown.

Logical inconsistencies in a change matrix, such as developed land to water, can indicate classification or registration errors. Although illogical changes are possible, they are certainly not probable. For example, the USFWS NWI and C-CAP change matrix (table 3-9) contains a change from 3.1 Water to 1.11 High Density Developed Land. The change is improbable, and more likely represents a change from water to sand, since sand was inseparable from developed land in some areas.

C-CAP acknowledges that an error assessment methodology for change matrices does not currently exist. Therefore, change comparison matrix data should be used with caution because post-classification comparison can compound errors. Nonetheless, possible sources of error can be identified.

Errors in the change matrix are a product of errors in the individual classifications used for comparison. Classification errors in the individual data sets can, theoretically, increase the number of errors in the change matrix. These errors can negatively affect the representation of change in a map of the watershed. For example, shadows in the hills to 
the east of the Elkhorn Slough were incorrectly interpreted as wetlands. The "salt and pepper" wetlands in the hills are consequently incorrectly represented as wetland gains in figure 3-3. The errors were retained as a true representation of the limitations because the C-CAP protocol requires that change comparison be performed at full pixel resolution rather than removing them through other processing techniques. The "salt and pepper" effect also provides an intuitive cautionary example. Therefore, ground observation is essential.

Errors in the change comparison matrix can also be caused by misregistration of the individual data sets. Misregistration error results in an "echo" pattern around polygons in the digital image. For example, a string of pixels characterized as a wetland loss around the rim of a lake could actually be a registration problem rather than a loss. Therefore, the change comparison matrix errors are compounded by classification and registration errors of the individual data sets.

Finally, the change comparison methods used in this study demonstrated some properties unique to C-CAP. The C-CAP classification and watershed scale change comparisons provided data on land cover change not currently available to resource managers. TM data used in the change comparison also provided synoptic land cover change data at the watershed scale, which represents a complete ecological unit as opposed to a political or jurisdictional boundary. The change comparison was a geographically specific, quantitative comparison of land cover area over two time periods. The digital form of the data allowed a flexible representation of the changes specific to the interest of the user. 


\section{CHAPTER 5 CONCLUSION}

\subsection{Findings Relevant to the Application of C-CAP in the MBNMS}

NOAA's C-CAP protocol has established national standards for digital data base development of long-term habitat and land cover change in estuarine drainage areas of the U.S. This study examined three hypotheses designed to test the application of the C-CAP protocol in the Elkhom Slough watershed, a coastal drainage area of the MBNMS. Hypothesis 1 tested TM image data as a source for habitat and land cover inventory data. Hypothesis 2 tested the C-CAP classification scheme as a universal water, wetland, and upland classification system. Hypothesis 3 tested post-classification change comparison methodology by comparison of the 1990 C-CAP classification with 1972 USFWS NWI classifications, and by comparison of the $1990 \mathrm{C}$-CAP classification with the Dickert et al. (1980) land cover data.

Results of this study demonstrated that the C-CAP protocol was successfully applied, with some modifications, to land cover inventory and comparison in the Elkhom Slough watershed. This conclusion was based upon the: 1) use of TM data to generate CCAP land cover maps of the Elkhom Slough watershed with an overall classification accuracy of $86.84 \%$, which exceeded the $85 \%$ accuracy requirement, 2 ) use of the C-CAP classification scheme to classify the TM data according to 12 required C-CAP classes, which were also used to integrate data from other classification schemes, and 3) postclassification change comparison using C-CAP data, USFWS NWI data, and Dickert et al. 
(1980) data to identify wetland and upland habitat changes in the Elkhorn Slough watershed.

TM image data was effective for the classification of wetland and upland areas at least $85.5 \mathrm{~m} \times 85.5 \mathrm{~m}$. The accuracy of C-CAP classification in wetland areas smaller than $85.5 \mathrm{~m} \times 85.5 \mathrm{~m}$ could not be determined with the accuracy assessment techniques employed. Therefore, the accuracy assessment technique patterned after Jensen et al. (1993), with respect to the $3 \times 3$ homogeneous pixel block sample method, was not applicable for the assessment of small wetland areas (less than $3 \times 3$ pixels) in the Elkhorn Slough watershed. Their elimination from the accuracy assessment sample pool prevented a determination of an absolute minimum measurement limit for the classification of small, individual C-CAP wetland classes derived from TM data.

Post-classification change comparison using C-CAP and ancillary data was an effective technique that revealed significant wetland changes from a watershed perspective. The comparison provided valuable information that quantified the nature and distribution of wetland changes. A "nibbling effect" pattern of wetland changes to upland within the Elkhorn Slough watershed was apparent in small wetland areas outside of the Elkhom Slough. Unfortunately, the accuracy of the change comparison findings were dependent upon the accuracies of the individual classifications, and therein was the problem. Neither of the ancillary data sets used in the comparisons contained accuracy assessments.

Limitations of the accuracy assessment method and the unknown accuracy of the input data were the most significant factors affecting the reliability of the land cover change data. Post-classification comparison was conducted without information on the accuracy of the ancillary data. The lack of accuracy assessments for the input data of the change comparison matrix meant that changes in small wetlands of the watershed could not be stated with confidence. Therefore, the precision for quantitative measures of wetland 
changes was unknown, although many of the wetland changes were known to have occurred or were verified by ground observation.

Accuracy assessment techniques that can establish an accurate minimum measurement limit for wetlands using TM data are needed for the application of the C-CAP protocol in MBNMS, since coastal wetlands within other watersheds of the MBNMS are smaller than the Elkhorn Slough. C-CAP classification products will likely be used for wetland change analysis, and therein, should provide specific information concerning the reliability of the data in these relatively small areas. Granted, the vast majority of watershed area is not wetland. However, resource managers and planners interested in general land cover trends and identification of rapid change areas will need to know the measurement limits and accuracy of C-CAP data products. Thus, the C-CAP protocol should suggest methods to determine minimum measurement limits regardless of the land cover type of interest.

\subsection{Modifications of the C-CAP Protocol for Use in the MBNMS}

The C-CAP guidelines are vague on some critical issues important for its use in the Central Coast of Califomia. These issues include the: 1) specific recommendations for accuracy assessment techniques, 2) measurement limitations of C-CAP land cover derived from TM, the preferred remote sensor data, and 3) use and integration of ancillary data in the C-CAP classification scheme. Modification of the C-CAP guidelines regarding these items are needed to apply the C-CAP methodologies to land cover inventory and change detection in the MBNMS.

An alternative method that may improve the accuracy assessment of C-CAP wetland classes is to decrease the $3 \times 3$ pixel block sample to a $2 \times 2$ pixel block size. The sample block pool should also be increased to increase the number of sample blocks for wetland areas. A $2 \times 2$ pixel block should improve the stratified random selection of sample sites in 
small narrow wetlands. However, classification errors caused by misregistration and variations in spectral response at habitat edges may increase as the sample block size decreases. Therefore, the probable minimum measurement limit to C-CAP land cover data derived from TM image data is between a $3 \times 3$ pixel block and a $2 \times 2$ pixel block.

Investigation of altemative sources of data with higher spatial resolution or better spectral resolution for mapping wetlands and sensitive habitats in the MBNMS is warranted given the nature of Central Coast wetlands. Alternative sources include other remote sensors or ancillary land cover data similar to USFWS NWI data. Other remote sensors such as Satellite Pour l'Observation de la Terre (SPOT) image data or airborne multispectral scanner data, may provide adequate spatial and spectral resolution for mapping small, narrow wetlands of the MBNMS. Digital data merges between TM and other, higher resolution data, should also be investigated for high resolution mapping. All alternative data sources, whether ancillary land cover or image data, must meet the C-CAP protocol requirements for positional and categorical accuracy.

Some agencies have or are developing GIS land cover data of the Central Coast of California. Ideally, independently generated land cover classifications should contain class definitions compatible with the C-CAP classification system. Modification of the C-CAP protocol to include a template for class translations of C-CAP, USFWS, USGS, U.S. Forest Service, and U.S. Environmental Protection Agency classification systems would aid the integration of ancillary data.

\subsection{Recommendations}

Many of the issues revealed by this study provide opportunities for further research in the development of C-CAP land cover change data bases. The following recommendations focus on the improvement of classification accuracy and accuracy assessment methods. 
1. Alternative methods for the delineation of land cover, such as on-screen digitization, should be investigated rather than eliminating or merging classes that cannot be distinguished using TM data alone. For example, bare land, high density developed land, and sand had similar reflectance characteristics that could not be separated using image processing.

2. Accuracy assessment methods should be suggested for individual C-CAP classes. Overall accuracy requirements provided little assurance that important, small area $C$ CAP classes were accurately classified.

3. A sampling method relative to the land cover morphology is needed for individual class accuracy assessments because sampling methodologies for overall classification accuracy may not be valid for small area land cover classes.

4. Higher spatial resolution data may be required for interpreting small wetland areas in coastal watersheds of the MBNMS, or in other parts of the Western Region of the U.S. with similar physiography.

5. Agencies that provide ancillary land cover data should ensure that detailed land cover classes can be aggregated back to the required C-CAP classes. In addition, accuracy assessment information should be required for all ancillary data, including the USFWS NWI maps.

These recommendations will improve the C-CAP methodology and data products applied in the Elkhom Slough watershed and in watersheds of the MBNMS. Improvement in the C-CAP methodology will also increase the quality of the data for use in cumulative impact assessments of the Elkhorn Slough watershed. 
5.4 Application of C-CAP Land Cover Data to Cumulative Impact Assessments in the Elkhorn Slough Watershed

As discussed in chapter 1, cumulative impact assessment has been hampered by theoretical and methodological problems. One problem of cumulative impact assessment and monitoring is the collection and analysis of multiple types of environmental and geographic information. C-CAP recommended methods and products represent an important component of a complex cumulative impact assessment methodology because $C$ CAP defines minimum standard methods of collecting and processing land cover data. The C-CAP protocol also defines a watershed as an appropriate spatial boundary for estuarine ecosystems and a 1 to 5 year cycle monitoring cycle as an appropriate temporal frequency. Therefore, C-CAP reduces methodological limitations of cumulative impact assessment by establishing standardized digital data base requirements.

Current and local efforts to develop a GIS for cumulative impact assessments of non-point source pollution can directly benefit from the C-CAP protocol. C-CAP recommended methodologies and products, with some improvements, can be used as to provide base maps in a multi-layer GIS of the Elkhorn Slough watershed. Examples of other data layers in the GIS include soils, elevation, permit locations, point source discharges, water and sediment quality data, and other environmental monitoring data. These GIS layers could also be used in non-point source pollution models. The C-CAP method applied in this study, when combined with other geo-referenced data related to nonpoint source pollution, constitutes a substantial segment of a cumulative impact assessment methodology. 
5.5 The Role of C-CAP Methodology and Products in a Comprehensive Environmental Monitoring System for the MBNMS

A comprehensive environmental monitoring system for the MBNMS needs consistent long-term, geo-referenced digital data collected under established standards. Remote sensing and GIS are necessary tools for coastal resource management in large areas, as demonstrated by the Florida Keys National Marine Sanctuary example. A modified C-CAP protocol can provide minimum standards for monitoring habitat and land cover change in coastal drainage areas of the MBNMS. This study demonstrates that land cover data bases developed using the C-CAP protocol can provide accurate land cover and habitat inventory and change information over entire watersheds to resource managers and scientists studying the MBNMS.

Therefore, C-CAP methodology and products represent important tools in the development of a comprehensive monitoring system. The products can provide valuable information to scientist, resource managers, and planners working to control non-point source pollution, to conserve sensitive habitat, and to protect water quality. NOAA's Sanctuaries and Reserves Division ideal of a comprehensive environmental monitoring system (NOAA 1992) is closer to reality with the use of this modified C-CAP protocol methodology for the Central Coast of California. 


\section{REFERENCES}

ABA Consultants. 1989. Elkhorn Slough Wetlands Management Plan. Prepared for the Monterey County Planning and the California Coastal Conservancy Department. Capitola, California.

Anderson, J. R., E. E. Hardy, J. T. Roach, and R. E. Witmer. 1976. A Land Use and Land Cover Classification System for Use with Remote Sensor Data. U.S. Geological Survey Professional Paper 962. Washington, DC: U.S., Geological Survey.

Association of Monterey Bay Area Governments (AMBAG). 1992. Work Plan for Water Quality Management Planning Program [Section 205(j)(2)] on Coastal and Marine Water Quality Information Coordination, Integration and Outreach: A Pilot Program for the Monterey Bay Region. Monterey, California. Unpublished paper.

Augenstein, E. W., Stow, D. A., and A. S. Hope. 1991. Evaluation of SPOT HRV-XS Data for Kelp Resource Inventories. Photogrammetric Engineering and Remote Sensing. 57(5): 501-509.

Bedford, B. L. and E. M. Preston. 1988. Developing the Scientific Basis for Assessing Cumulative Effects of Wetland Loss and Degradation on Landscape Functions: Status, Perspectives, and Prospects. Environmental Management 12(5): 751771 .

Browning, B. M. 1972. The Natural Resources of Elkhorn Slough: Their Present and Future Use. Coastal Wetland Series no. 4. Sacramento, California: California Department of Fish and Game.

California Coastal Commission. 1992. The California Coastal Commission's Enhancement Grant Strategy: Prepared Pursuant to Section 309 of the Coastal Zone Management Act. San Francisco, California. Unpublished paper. . 1993. Regional Cumulative Assessment Project (ReCAP) Matrix Working Draft. San Francisco, California. Unpublished paper.

Congalton, R. G. 1991. A Review of Assessing the Accuracy of Classifications of Remotely Sensed Data. Remote Sensing of Environment 37: 35-46.

Congalton, R. G., R. G. Oderwald, R. A. Mead. 1983. Assessing the Landsat Classification Accuracy Using Discrete Multivariate Analysis Statistical Techniques. Photogrammetric Engineering and Remote Sensing. 49(12): 16711678.

Cowardin, L. M., V. Carter, F. C. Golet, and E. T. LaRoe. 1979. Classification of Wetlands and Deepwater Habitats of the United States. Document FWS/OBS79/31. Washington, DC: U.S. Department of the Interior, U. S. Fish and Wildlife Service; reprinted 1992. 
Dahl, T. W. 1990. Wetland Losses in the United States 1780's to 1980's. Washington, D.C.: U.S. Department of the Interior, U.S. Fish and Wildlife Service.

DeVogelaere, A. and J. Holte. 1991. Elkhorn Slough Bibliography. Watsonville, California: Elkhorn Slough National Estuarine Research Reserve and ABA Consultants.

DeVogelaere, A. 1993. Elkhorn Slough National Research Reserve. Elkorn, California. Personal communication with the author, August.

Dickert, T. G., A. E. Tuttle, M. Bean, and T. Wischmann. 1980. Elkhorn Slough Watershed: Linking the Cumulative Impacts of Watershed Development to Coastal Wetlands. Berkeley: University of California, Institute of Urban and Regional Development. Grant \#048-M01-189.

Dickert, T. G. and A. E. Tuttle. 1985. Cumulative Impact Assessment in Environmental Planning: A Coastal Wetland Watershed Example. Environmental Impact Assessment Review 5: 37-64.

Dobson, J. E. and E. A. Bright. 1992. CoastWatch Change Analysis Program (C-CAP) Chesapeake Bay Regional Project. In ASPRS/ACSM '92 Technical Papers, Vol. 1. Global Change and Education. Bethesda: American Society for Photogrammetry and Remote Sensing. 1: 109-110.

Dobson, J. E., R. L. Ferguson, D. W. Field, L. L. Wood, K. D. Haddad, H. Iredale III, J. R. Jensen, V. V. Klemas, R. J. Orth, J. P. Thomas. 1993. NOAA CoastWatch Change Analysis Project: Guidance for Regional Implementation. Draft Version 1.0. Unpublished paper. Beaufort, NC. September 1, 1993.

Friel, C. and K. Haddad. 1992. GIS Brings New Outlook to Florida Marine Resources Management. GIS World November: 33-36.

Gardels, K. 1992. Email letter from Berkeley, to Andy Richardson, 3 March. Email file attached to directory containing GRASS digital data set.

Haddad, K. 1993. Presentation at the Technical Workshop on Environmental Information Systems, GIS and Telecommunications Networking. Elkhorn Slough National Estuarine Research Reserve, California. March 23, 1993.

Haddad, K. and D. R. Ekberg. 1987. Potential of LANDSAT TM Imagery for Assessing the National Status and Trends of Coastal Wetlands. O. T. Magoon, et al., ed. In Coastal Zone '87: Proceeding of the 5th Symposium on Coastal Ocean Management in Seattle, Washington:, May, 1987, by the American Society of Civil Engineers (ASCE). 5: 5192-5201.

Haddad, K. and B. A. Harris. 1985. Use of Remote Sensing to Assess Estuarine Habitats. O. T. Magoon, et al., ed. In Coastal Zone '85: Proceedings of the 4th Symposium in Coastal and Ocean Management, by the ASCE. 1: 662-675. 
Haddad, K. and B. A. Hoffman. 1987. The Role of Geographic Information Systems in Managing Florida's Coastal Wetland Resources. O. T. Magoon, et al., ed. In Coastal Zone '87: Proceeding of the 5th Symposium on Coastal Ocean Management in Seattle, Washington:, May, 1987, by the American Society of Civil Engineers (ASCE). 5: 5182-5191.

Haddad, K. and G. McGarry. 1989. Basin-wide Management: A Remote Sensing/GIS Approach. O. T. Magoon, et al., ed. In Coastal Zone '89: Proceedings of the 6th Symposium in Coastal and Ocean Management, by the ASCE. 1822-1836.

Jensen, J. R. 1986. Introductory Digital Image Processing: A Remote Sensing Perspective. Englewood Cliffs, NJ: Prentice Hall.

Jensen, J. R., D. J. Cowen, J. D. Althausen, S. Narumalani and O. Weatherbee. 1993. An Evaluation of the CoastWatch Change Detection Protocol in South Carolina. Photogrammetric Engineering and Remote Sensing. 59(6): 1039-1046.

Johnston, C. A., N. E. Detenbeck, and G. J. Niemi. 1990. The Cumulative Effect of Wetlands on Stream Water Quality and Quantity: A Landscape Approach. Biogeochemistry 10: 105-141.

Klemas, V. V., J. E. Dobson, R. L. Ferguson, and K. D. Haddad. 1993. A Coastal Land Cover Classification System for the NOAA CoastWatch Change Analysis Project. vournal of Coastal Research 9(3): 862-872.

Kvitek, R. 1993. Marine Ecologist. Moss Landing Marine Laboratories. Moss Landing, California. Personal communication with author. December, 1993.

Lee, L. C. and J. G. Gosselink. 1988. Cumulative Impacts on Wetlands: Linking Scientific Assessments and Regulatory Alternatives. Environmental Management 12(5): 591-602.

Lillesand, T. M. and R. W. Kiefer. 1988. Remote Sensing and Image Interpretation. 2d ed. New York: John Wiley and Sons.

Lunnetta, R. S., R. G. Congalton, L. K. Fensternaker, J. R. Jensen, K. C. McGwire, and L. R. Tinney. 1991. "Remote Sensing and Geographic Information System Data Integration: Errors Sources and Research Issues," Photogrammetric Engineering and Remote Sensing 57(6): 677-687.

McCreary, S., R. Twiss, B. Warren, C. White, S. Huse, K. Gardels, and D. Roques. 1992. Land Use Change and Impacts on the San Francisco Estuary: A Regional Assessment with National Policy Implications. Coastal Management 20: 219. 253.

National Oceanic and Atmospheric Administration (NOAA). National Ocean Service. 1990. The Distribution and Areal Extent of Coastal Wetlands in Estuaries of the West Coast Region. Washington, D.C.: U.S. Department of Commerce.

National Oceanic and Atmospheric Administration (NOAA). Sanctuaries and Reserves Division. 1992. Monterey Bay National Marine Sanctuary: Final 
Environmental Impact Statement/Management Plan. Washington, D.C.: U.S. Department of Commerce.

Preston, E. M. and B. L. Bedford. 1988. Evaluating Cumulative Effects on Wetland Functions: A Conceptual Overview and Generic Framework. Environmental Management . 12(5): 565-583.

Pulich, Jr., W. M. and J. M. Hinson. 1992. Methodology for Classifying Land Cover and Habitats from Landsat TM Imagery of the Texas Coastal Zone. In Needs and Solutions for Pollution Monitoring, Control, and Abatement: Proceedings of the Ist Thematic Conference Remote Sensing for Marine and Coastal Environments in New Orleans 15-17 June, 1992, by the Environmental Research Institute of Michigan: 855-868.

Schwartz, D. L. 1983. Geologic History of Elkhorn Slough, Monterey County, California. M. S. thesis, San Jose State University, 1983.

Shaffer, L. 1993. Chief Cartographer, U.S. Fish and Wildlife Service National Wetland Inventory, St. Petersburg, Florida. Personal Communication with author,
December.

Sharp, G. 1993. Report of the Technical Workshop on Environmental Information Systems, GIS and Telecommunications Networking. Monterey, California 1993: Cooperative Institute for Research in the Integrated Ocean Sciences (CIRIOS). Unpublished paper.

Soulé, M. E. 1986. Conservation Biology: the Science of Scarcity and Diversity. Sunderland, MA: Sinauer, Associates.

Soulé, M. E. 1991. Land Use Planning and Wildlife Maintenance: Guidelines for Conserving Wildlife in an Urban Landscape. Journal of the American Planning Association 57(3): 313-323.

Story, M. and R. G. Congalton. 1986 Accuracy Assessment: A User's Perspective. Photogrammetric Engineering and Remote Sensing 52(3): 397-399.

Strnad, L. and R. Hyman. 1993. A Watershed Approach to Coastal Zone Management for the Elkhorn Slough Estuarine Complex. Santa Cruz, California: California Coastal Commission, 1993. Unpublished paper.

Thomas, J. P. and R. L. Ferguson. 1990. National Oceanic and Atmospheric Administration's Habitat Mapping Under the Coastal Ocean Program. Federal Coastal Wetland Mapping Programs. Biological Report 90 (18):27-39. U.S. Fish and Wildlife Service. Washington, D. C.: U.S. Department of the Interior.

United States Geological Survey, Federal Geographic Data Committee (USGS FGDC). 1992. Wetlands Subcommittee. Application of Satellite Data for Mapping and Monitoring Wetlands. Reston, Virginia: U.S. Department of the Interior.

Welch, R., T. R. Jordan, and M. Ehlers. 1985. Comparative Evaluations of the Geodetic Accuracy and Cartographic Potential of LANDSAT-4 and LANDSAT-5 
Thematic Mapper Image Data. Photogrammetric Engineering and Remote Sensing 51(11): 1799-1812.

Welch, R. and M. Remillard. 1992. Integration of GPS, Remote Sensing, and GIS Techniques for Coastal Resource Management. Photogrammetric Engineering and Remote Sensing 58(11): 1571-1528.

Westmoreland, S. and D. A. Stow. 1992. Category Identification of Changed Land-Use Polygons in an Integrated Image Processing/Geographic Information System. Photogrammetric Engineering and Remote Sensing. 58(11): 1593-1599. 
APPENDIX A

\section{C-CAP COASTAL LAND COVER CLASSIFICATION SYSTEM}


Table 1. C-CAP Coastal Land Cover

Classification System (Klemas et al., 1993)'

1.0 Upland

1.1 Developed Land

1.11 High Intensity

1.12 Low Intensity

12 Cultivated Land

1.21 Orchards/Groves/Nurseries

1.22 Vines/Bushes

1.23 Cropland

1.3 Grassland

1.31 Unmanaged

1.32 Managed

1.4 Woodv Land

1.41 Scrub-Shrub

1.411 Deciduous

1.412 Evergreen

1.413 Mixed

1.42 Forest

1.421 Deciduous

1.422 Evergreen

1.423 Mixed

\subsection{Bare Land}

1.6 Tundra

1.7 Snow/tce

1.71 Perennial Snow/lce

1.72 Glaciers

2.0 Welland Excludes Bottoms, Reefs. Nonpersistent Emergent Wettands, and Aquaric Beds. all of which are covered under 3.0. Water and Submerged Land.)

2.1 Marine/Estuarine Rocky Shore

2.11 Beatrock

2.12 Rubble

22 Marine/Estuarine Unconsolidaled Shore (Beach. Flat, Bar)

2.21 Cobble-gravel

2.22 Sand

2.23 Mud/Organic
2.3 Estuarine Emergent Wetland

\begin{tabular}{ll}
\hline 2.31 & Haline (Salt Marsh) \\
2.32 & Mixohaline (Brackish Marsh)
\end{tabular}

2.4 Estuarine Woody Wetland

2.4I Scrub-Shrub

2.411 Deciduous

2.412 Evergreen

2.413 Mixed

2.42 Forest

2421 Deciduous

2422 Evergreen

2423 Mixed

2.5 Riverine Unconsolidated Shore (Beach.

Flat. Bar)

251 Cobble-gravel

2.52 Sand

2.53 Mud/Organic

2.6 Lacustrine Unconsolidated Shore (Beach. Flat. Bar)

2.61 Cobble-gravel

2.62 Sand

2.63 Mud/Organic

27 Palustrine Unconsolidated Shore (Beach, Flat, Bar)

271 Cobble-gravel

2.72 Sand

2.73 Mud/Organic

2.8 Palustrine Emergent Wetland (Persistent)

$2.9 \quad$ Palustrine Woodv Wetland

2.91 Scrub-Shrub

2911 Deciduous

2.912 Evergreen

2913 Mixed

2.92 Forest

2921 Deciduous

2922 Evergreen

2923 Mixed

3.0 Water and Submerged Land (Includes deepwater habitats and those wetlands with surface water but lacking urees. sturubs. and persistent emergents)

3.1 Waler (Bottoms and undetectable reefs. aquatic beds or nonpersistent emergent wetlands) 
APPENDIX B

U.S. FISH AND WILDLIFE SERVICE WETLAND AND DEEP WATER HABITAT CLASSIFICATION KEY 


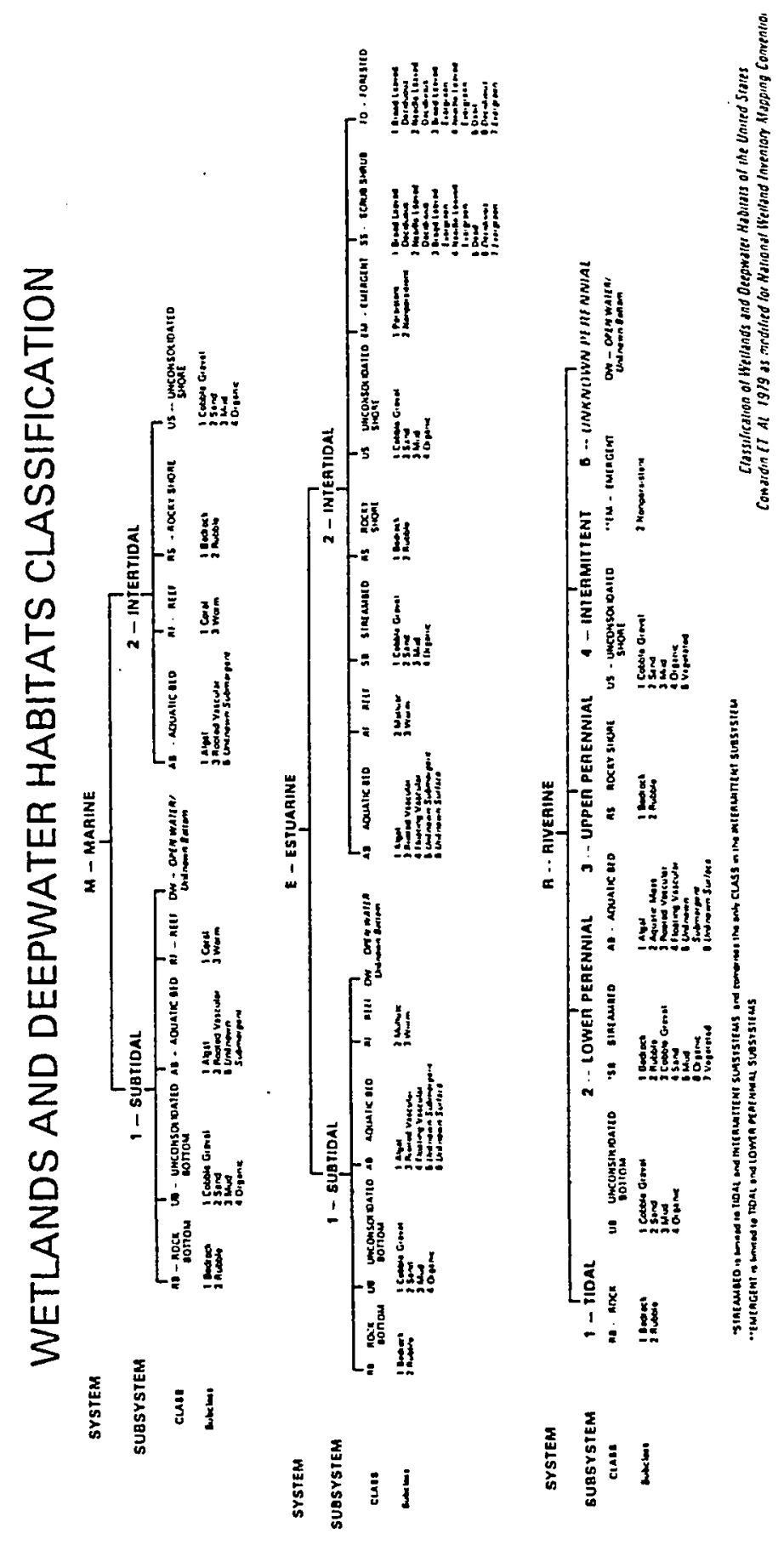




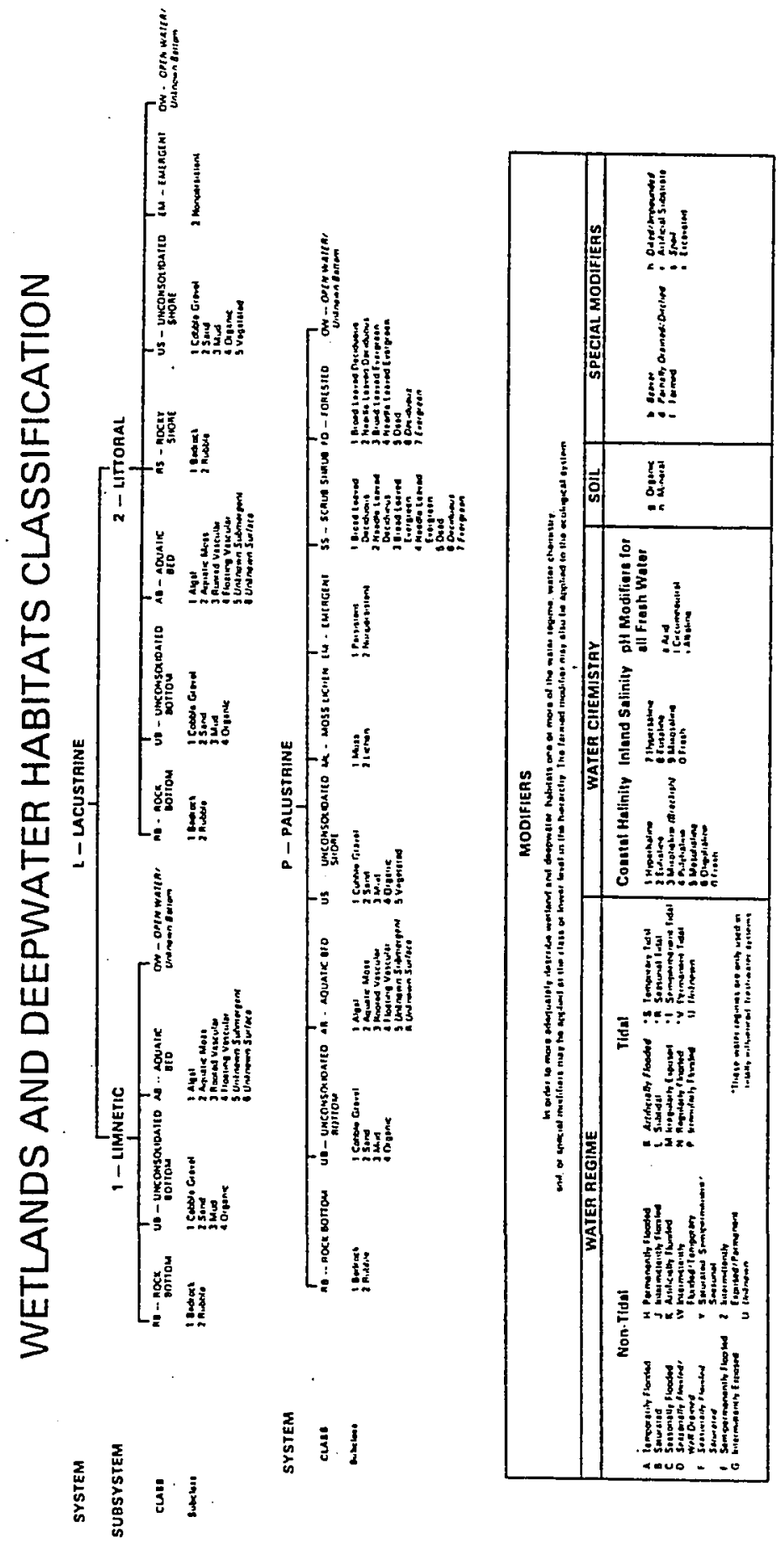

